\title{
Institutional Integration as a Predictor of Success in At-Risk First- Year College Students
}

Jan-Erin Miller

West Virginia University

Follow this and additional works at: https://researchrepository.wvu.edu/etd

\section{Recommended Citation}

Miller, Jan-Erin, "Institutional Integration as a Predictor of Success in At-Risk First-Year College Students" (2013). Graduate Theses, Dissertations, and Problem Reports. 3638.

https://researchrepository.wvu.edu/etd/3638

This Dissertation is protected by copyright and/or related rights. It has been brought to you by the The Research Repository @ WVU with permission from the rights-holder(s). You are free to use this Dissertation in any way that is permitted by the copyright and related rights legislation that applies to your use. For other uses you must obtain permission from the rights-holder(s) directly, unless additional rights are indicated by a Creative Commons license in the record and/ or on the work itself. This Dissertation has been accepted for inclusion in WVU Graduate Theses, Dissertations, and Problem Reports collection by an authorized administrator of The Research Repository @ WVU.

For more information, please contact researchrepository@mail.wvu.edu. 


\title{
Institutional Integration as a Predictor of Success
} in At-Risk First-Year College Students

\author{
Jan-Erin Miller
}

\begin{abstract}
Dissertation submitted to the College of
Human Resources and Education at

West Virginia University

in partial fulfillment of the requirements

for the degree of
\end{abstract}

\author{
Doctor of Philosophy \\ in \\ Counseling Psychology \\ Jeffrey Daniels, Ph.D., chair \\ James Bartee, Ph.D. \\ Anita Mayer, M.P.A. \\ Deborah J. Hendricks, Ed.D. \\ Christine J. Schimmel, Ed.D. \\ Department of Counseling, Rehabilitation Counseling \\ and Counseling Psychology
}

\author{
Morgantown, West Virginia
}

2013

Keywords: Institutional Integration; At-risk College Students; Academic Success

Copyright 2013 Jan-Erin Miller 


\section{ABSTRACT \\ Institutional Integration as a Predictor of Success in At-Risk First-Year College Students}

Jan-Erin Miller

As earning a postsecondary degree becomes more necessary in the preparation for future employment, many of this nation's four-year colleges and universities are admitting underprepared students who are at-risk for poor academic performance and early departure from the institutions. There are a myriad of factors and characteristics that can cause students to be labeled at-risk, including being a first-generation student, coming from a lower socioeconomic environment, and having certain personality traits. At-risk college students have higher incidence of departure from the institutions, which can produce emotional distress and long-lasting financial obligations. Over the past thirty years, research in the area of student retention and departure has consistently found that institutional integration can produce higher levels of retention and commitment to the university. The purpose of this dissertation is to investigate the predictive value of institutional integration with academic success in at-risk first-year college students. Academic success is defined as grade point average, the ability to choose a vocation, and overall college well-being. While the model did not indicate predictive value, it demonstrated relationships between the elements of academic integration with career selfefficacy and mental well-being. 


\section{Acknowledgements}

I would like to thank everyone who have made this dissertation possible. First, I wish to express my gratitude and respect for Jeffrey Daniels, Ph.D., who served as chair for this dissertation. More than being my dissertation chair, Dr. Daniels has been a mentor and advocate to me over the past four years. His wisdom, encouragement, and humor helped guide me during my time at WVU and through this dissertation process. I sincerely bestow my thankfulness to James Bartee, Ph.D., for his tireless work as a member of my dissertation committee and training director of the Counseling Psychology program. Dr. Bartee's ability to balance challenges with reassurances have helped me with my professional and personal growth. I express the highest amount of admiration to Anita Mayer who provided me with the opportunity to work in Undergraduate Advising where I was afforded so many opportunities for professional growth. Ms. Mayer has served as an inspiration over the past three years and shown me how to be a powerful woman without losing values important to me. I offer huge amounts of gratitude to D. J. Hendricks, Ed.D. for assisting me with the statistical analyses and Christine Schimmel, Ed.D. for stepping in at the last minute.

This dissertation would not have been possible without the assistance of Amy RobertsDixon, who was my "Boss Lady" during my time with the TEAM program. I am fortunate to be able to call Ms. Roberts-Dixon a friend. Lastly, I would like to thank my mother Rita Miller and brother Casey Miller for always believing in me and telling me that I can do anything. 
Table of Contents

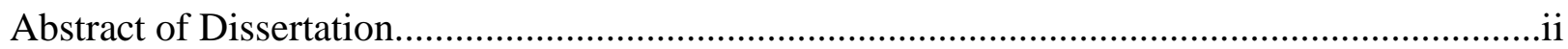

Acknowledgements...............................................................

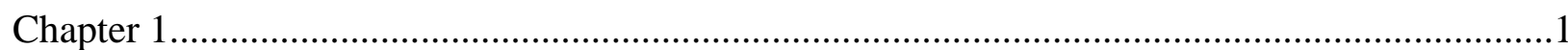

Literature Review and Research Question....................................................................

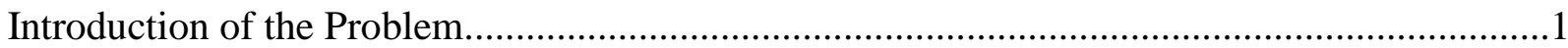

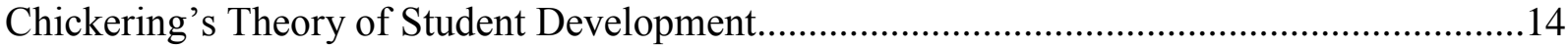

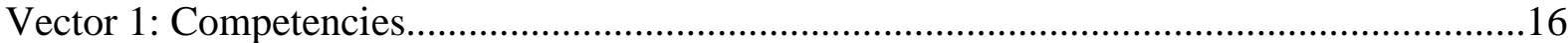

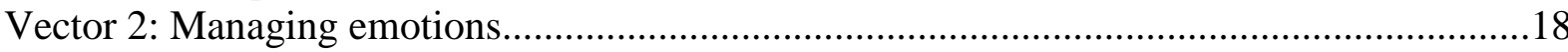

Vector 3: Autonomy toward interdependence............................................................24

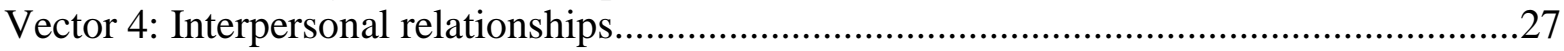

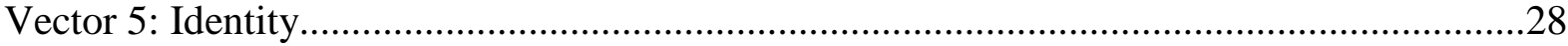

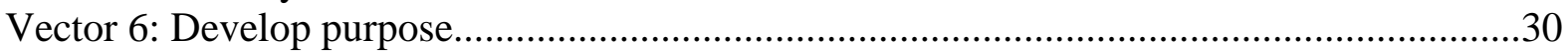

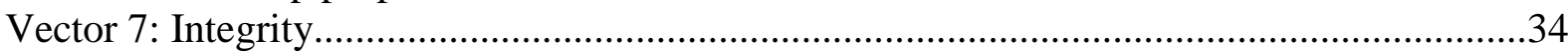

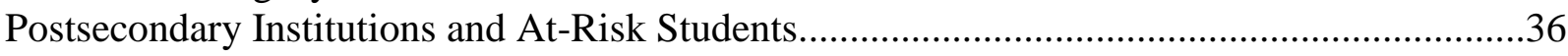

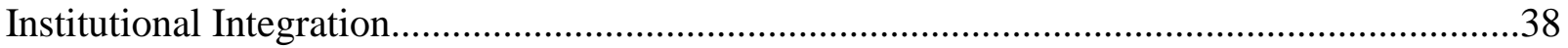

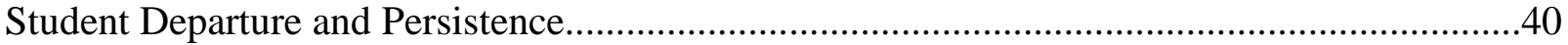

Institutional Integration and Student success...............................................................45

Retention Initiatives in Postsecondary Education.............................................................47

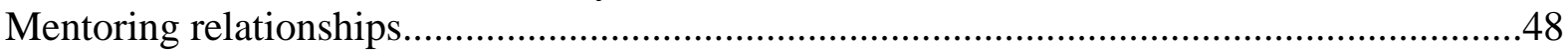

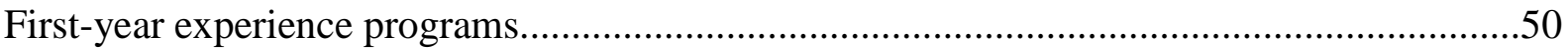

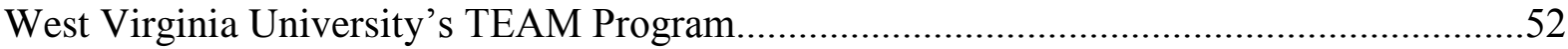

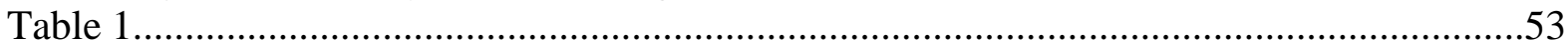

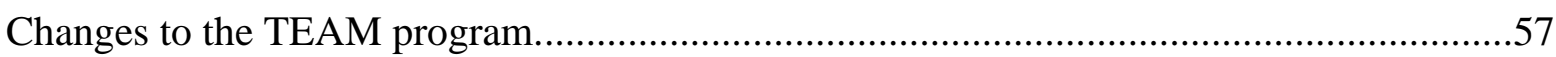

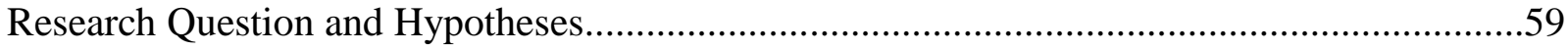

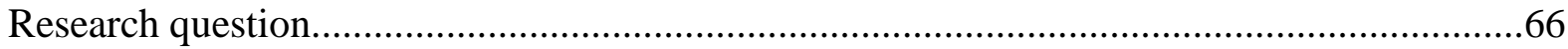

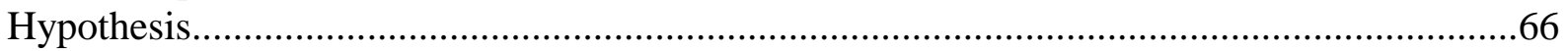

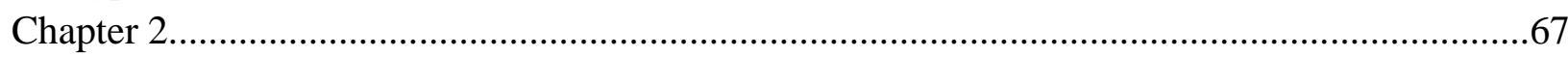

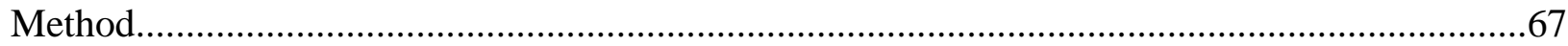

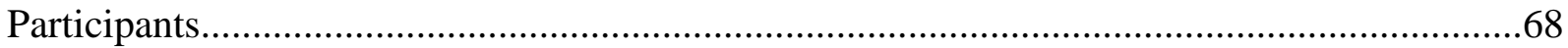

Participant characteristics for spring 2012 data collection.............................................68

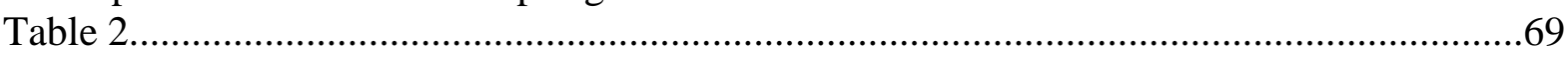

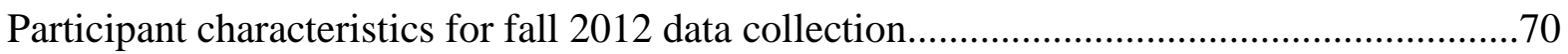

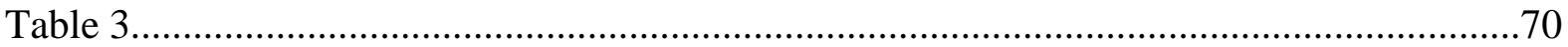

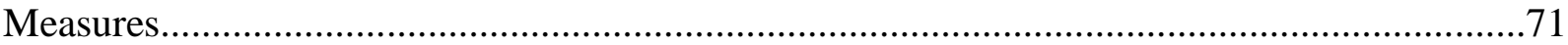

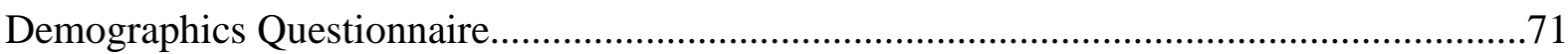

Career Decision Self-Efficacy Scale-Short Form.................................................... 71

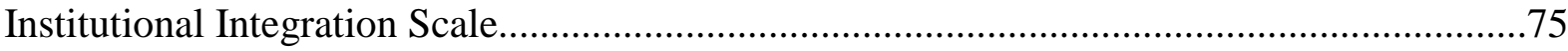

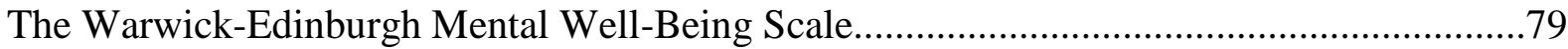

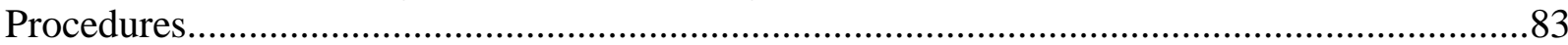

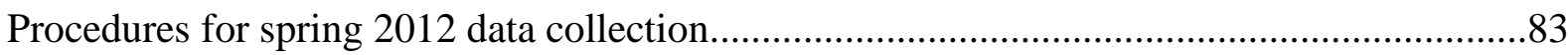

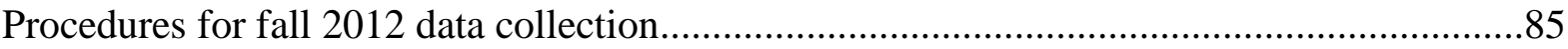

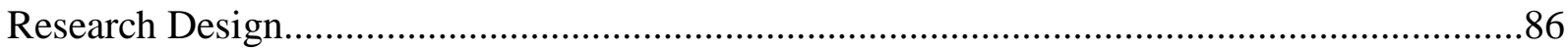

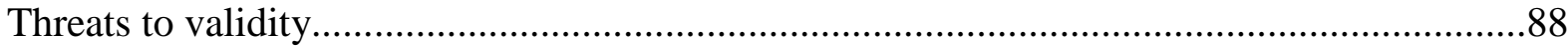




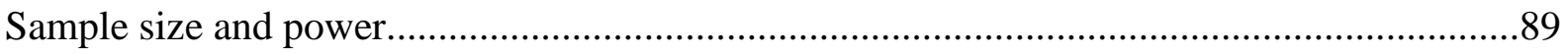

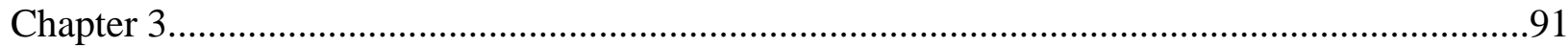

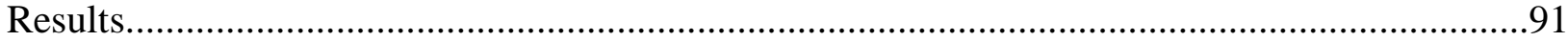

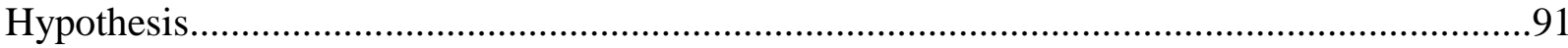

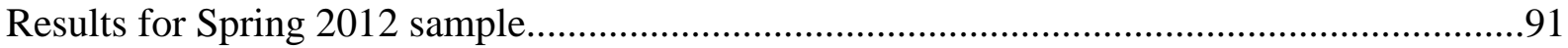

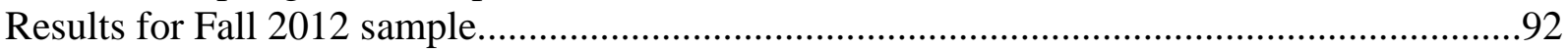

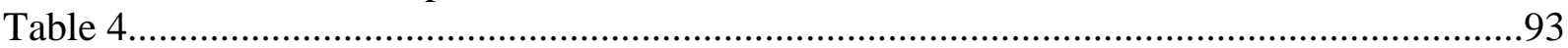

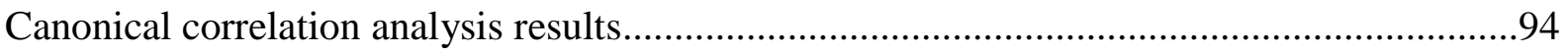

Structural coefficients and squared structural coefficients..........................................95

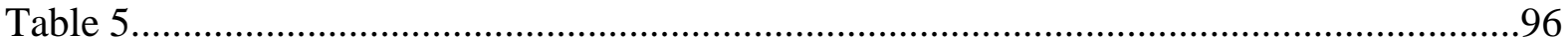

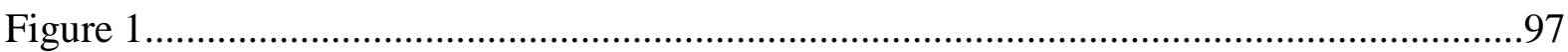

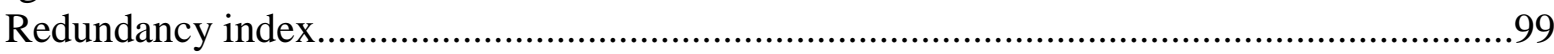

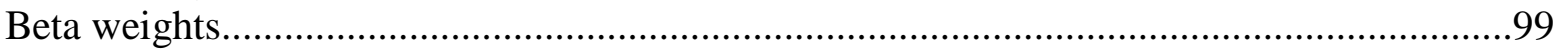

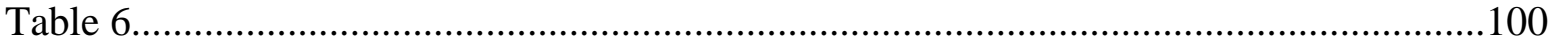

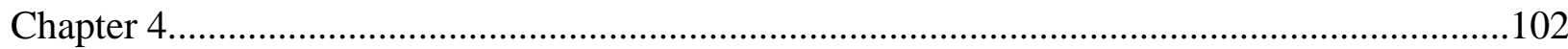

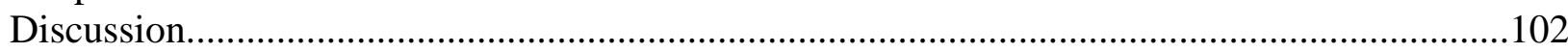

Academic and intellectual development and mental well-being...................................109

Institution and goal commitment and career decision self-efficacy .................................110

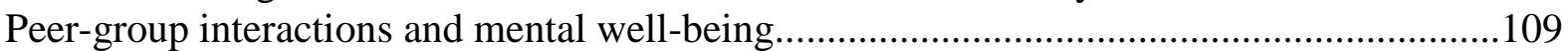

Academic Integration............................................................................................... 111

Institutional Integration Constructs that Did Not Contribute to the Results..........................113

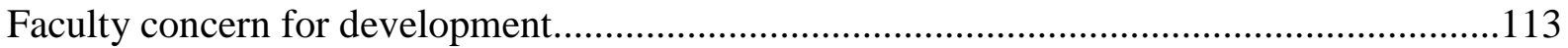

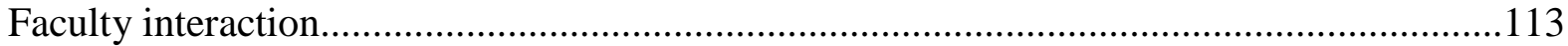

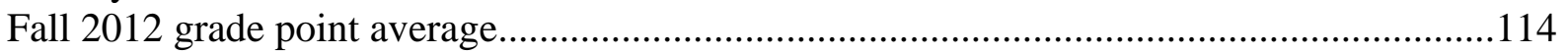

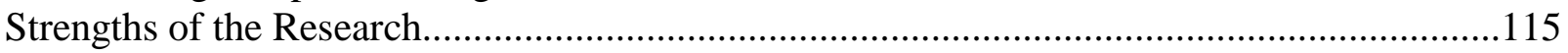

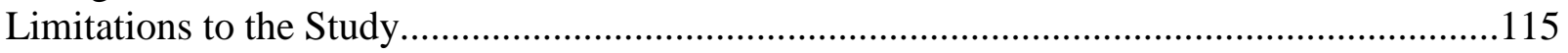

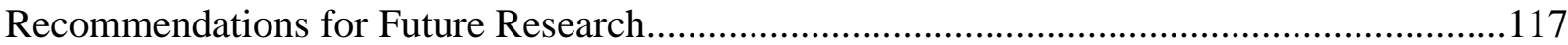

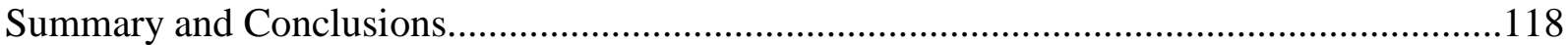

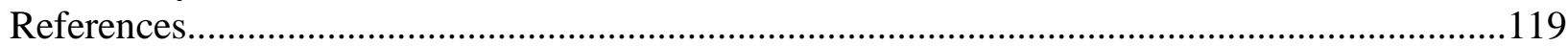

Appendix A

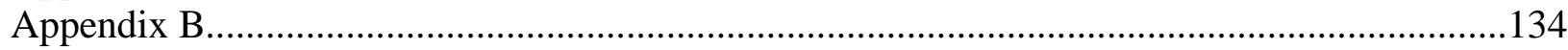

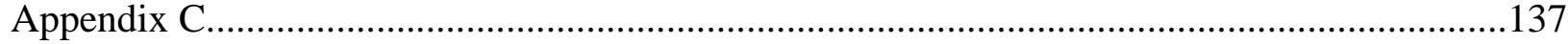

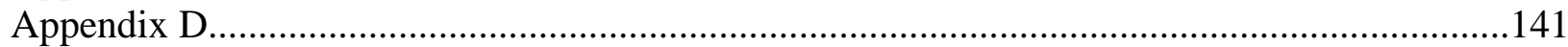

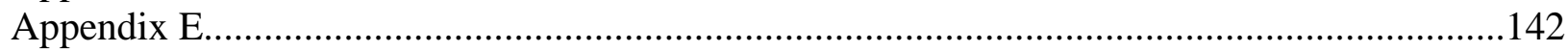

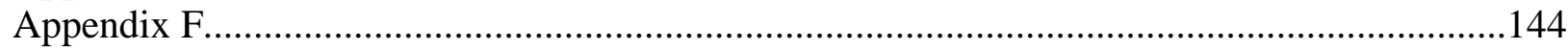

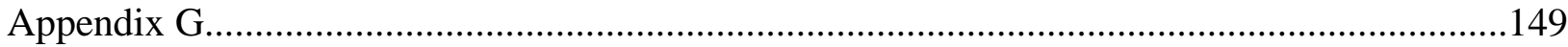




\section{Chapter 1}

\section{Literature Review and Research Question}

\section{Introduction to the Problem}

In the fall of 2010, 19.1 million first-time college students attended this nation's two- and four-year postsecondary institutions, which is a 500\% increase in the rate of enrollment of firsttime college students from a decade ago (Aud et al., 2011). While there are many possible explanations for this massive increase in enrollment, one likely factor is the financial benefits of earning a degree from a postsecondary institution. According to statistics gathered by the U.S. Department of Labor (2010), over a lifetime individuals with a bachelor's degree earn on average 1.8 times more than individuals with only a high school diploma or equivalent and 2.5 times more than individuals with less than a high school diploma or equivalent. Also, trends over the past few decades have shown an inverse relationship between education and unemployment (U. S. Department of Labor, Bureau of Labor Statistics, 2010), which indicates that individuals with postsecondary education tend to be employed more often than those without a postsecondary degree. Merely from an employment standpoint, earning either an associate's or bachelor's degree improves one's employment opportunities and pay. In fact, the impact that educational level has on occupational status is life-long and is not significantly affected by the socioeconomic level of the family of origin or intellectual ability level (Pascarella \& Terenzini, 1991). For the purposes of this dissertation, the terms postsecondary institution, college, and university are used interchangeably as is the status quo for this topic in research (Chait \& Venezia, 2009; Chickering \& Reisser, 1993; Pascarella \& Terenzini, 1991).

The importance of earning a college degree appears to understood by the American public (Pascarella \& Terenzini, 1991) and is reflected in the most common reasons for pursuing a 
postsecondary degree by college students: acquire knowledge and prepare for future employment (Shultz \&Higbee, 2007). With globalization and the technical specificity of many industries, having a postsecondary degree is necessary for many professions including several that did not require advanced degrees even a few decades ago (Chait \& Venezia, 2009; Lotkowski, Robbins, \& Noeth, 2004). This makes earning a postsecondary degree vital for many and has placed postsecondary institutions in a position where they must design and implement structures to help students successfully acquire knowledge and graduate with a degree (Lotkowski et al., 2004).

From an alternate perspective, a postsecondary degree brings with it certain levels of prestige (Pascarella \& Terenzini, 2009). The attainment of a postsecondary education tends to produce individuals who have more intellectual interests, increased tolerance for diversity, greater levels of self-esteem, a greater understanding of one's place in a global community, more savviness as consumers, and more active participation in government (Shultz \& Higbee, 2007). A college education prepares students to live responsibly in society by teaching them how to understand that they are part of the larger culture as well as presents an opportunity for all citizens to be able to function at higher levels of intellectual, emotional, and social complexity required by today's global demands (Chickering, 2010). College, specifically four-year institutions, tends to facilitate the development of soft skills that are important in attaining and maintaining employment. These soft skills include socially acceptable personality styles, attitudes and values, interpersonal skills, ambition, motivation, and self-confidence (Pascarella \& Terenzini, 1991). Overall, earning a degree from a four-year college or university is seen as a necessity for many and as such it is likely that enrollment and the number of first-year students will only increase over time (Shultz \& Higbee, 2007). 
One of the most pertinent issues in postsecondary education, especially with increased enrollment, is that of the preparedness of first-year students. As more individuals have made the decision to attain postsecondary education, more schools have eased their admission policies which has allowed access to postsecondary institutions for many that may not have met the traditional admission criteria and may not be adequately prepared for the rigors of college (Pascarella, Pierson, Wolniak, \& Terenzini, 2004). In addition to increasing enrollment opportunities, many institutions do not receive enough applicants to be particularly choosy or admit only those who meet the admission requirements (Tinto, 1993). Consequently, a significant number of students who are inadequately prepared and therefore at-risk for not performing well academically or earning a college degree are admitted into postsecondary institutions, especially four-year colleges and universities on a regular basis (Markus \& Zeitlin, 1993; Mulvey, 2008; Tinto, 1993).

Preparation, also known as readiness, for four-year colleges can be broken into four broad areas: academic preparation, cognitive strategies, college knowledge soft skills, and academic behaviors (Chait \& Venezia, 2009). While admission criteria into postsecondary institutions differ dependent on the institution, it is unlikely that all four areas of college preparedness are evaluated during the application process. In fact, assessing academic preparation is relatively straightforward and can be done via reviewing high school grades and aptitude test score, while determining the amount of college knowledge soft skills during the application and interview process may be slightly more complicated but not impossible. Many open enrollment institutions do not conduct interviews and, consequently, probably are not in the position to adequately evaluate the area of soft skills while private institutions, which are more 
likely to conduct face-to-face or phone interviews, are often able to assess this area of preparation.

Adequate academic preparation for college typically includes graduation with a traditional high school diploma, completion of the minimum requirements for college that include four years of English, three years of math, two years of a natural science, two years of social science, two years of a foreign language, and the ability to read at the basic level of the National Association of Education Progress reading assessment (Chait \& Venezia, 2009). Completion of these requirements in high school should indicate that first-year college students have acquired the cognitive strategies such as analysis and critical reasoning skills that will help them finish postsecondary level courses with a $\mathrm{C}$ or better and be able to move on to the next course in the sequence without remediation (Chait \& Venezia, 2009). Unfortunately education standards in some high schools may not be stringent enough to teach adequate cognitive strategies for success during the first year of college. This leaves students with deficits that make them underprepared for college. College students can, and often do, engage in remedial coursework to offset these deficits.

However, having academic preparation and knowing how to use cognitive strategies may still not reflect true readiness for college. As previously mentioned, complete college readiness requires attributes that are not always part of postsecondary institutions' admission criteria or even part of high school curricula. In order to be truly prepared for college, students need to have the soft skills and behaviors that provide them with the ability to acquire knowledge on how to successfully navigate in the college environment. This includes knowing when to study, how to manage time, how to communicate with professors, how to successfully resolve roommate issues, how to apply for financial aid, and how to locate various campus resources (Chait \& 
Venezia, 2009; Laskey \& Hetzel, 2011; Pascarella \& Terenzini, 1991). Some of these things, such as effective study skills and time management, may be learned during high school. Others of these skills and behaviors can be gleaned from parents or older siblings who act as guides to first-year students making the transition from high school to college. The reality is that not every student entering college for the first time has learned how to be a good student or has role models who attended and succeeded in college to guide them. Students with deficits in knowledge about college and behaviors of successful students are also underprepared for their first-year experience. Deficits in these areas may be more destructive for first-year students because many postsecondary institutions do not historically supply remedial courses in these areas and students may not know how to improve these deficits (Pascarella \& Terenzini, 1991).

In general, college students who are underprepared are labeled as being at-risk students because they are in danger of not doing well academically and not graduating with a degree (Laskey \& Hetzel, 2011; Lotkowski, Robbins, \& Noeth, 2004). There are many factors aside from being underprepared for college which can indicate that a college student is at-risk for not succeeding. These factors may include background characteristics, internal characteristics, and environmental characteristics (Bulger \& Watson, 2006).

Background characteristics may include low socioeconomic status (SES), single parent family of origin, minority ethnic status, and poor high school performance (Bulger \& Watson, 2006). It is important to note that many families with a single parent head of household, as well as those with families of origin that are part of a minority group status tend to be lower SES households, too (Valverde, 1985). Families that fall within the lower strata of socioeconomic categories often do not have easy access to resources that can help prepare students for higher education and are less likely to have heads of household with a college education, which makes 
these college students first-generation college students (Upcraft, Gardner, \& Barefoot, 2005; Valverde, 1985).These factors often affect students' decision whether to attend college (Anderson, 1985). Without independent financial means, students from lower SES must rely on grants, scholarships, and financial aid to pay for college. It is possible that first-generation students and their families will not know how to navigate this intricate financial system, which could be a barrier to attending college. Finances also dictate which schools these students will apply to and be accepted into. Once in college the SES of students has shown to be a moderate predictor of college retention such that lower SES correlates with lower retention rate (Lotkowski, et al., 2004). Based on this data, when SES is combined with high school grade point average (HSGPA), aptitude test scores, and institutional integration, the combination explains $17 \%$ of the variance of retention in college (Lotkowski et al., 2004). Trends over the past few decades have shown that students with a family of origin from a low SES group have demonstrated a smaller chance of graduating from a four-year postsecondary institution compared to students from higher SES groups when compared on achievement ability (Fox, Connolly, \& Snyder, 2005). The reasons for this are complex and go beyond the scope of this dissertation, but the overall point is important; first-year students with certain background characteristics are more likely not to do well in college.

Individual ability and high school performance are the best predictors for college persistence and academic performance, although this relationship is influenced by many other factors (Crissman, Ishler, \& Upcraft, 2005; Tinto, 1993). Academic performance during high school is a better predictor of college performance than aptitude tests (Laskey \& Hetzel, 2011). Academically at-risk students make up a large portion of this group as they tend to be underprepared for college as evidenced by below average high school performance and aptitude 
test scores (Crissman et al., 2005; Tinto, 1993). At-risk college students tend to have more negative perceptions of relationships with faculty as they view those relationships to be conflictual and themselves as being treated unfairly (Larose, Bernier, \& Soucy, 2005). As a result at-risk students may display more difficulty seeking help from teachers and making connections within the institution.

Students who enter into postsecondary institutions with limited understanding of learning typically adopt ineffective ways of studying (Entwistle, McCune \& Walker, 2001). Students who utilize a deep approach seek to understand ideas and seek meaning whereas those who use a surface approach are trying to cope with the course requirements and do not integrate the material of the course as a whole (Entwistle et al., 2001). Other students may utilize a strategic approach designed to achieve the highest possible grade where they have developed alertness to the assessment process (Entwistle et al., 2001). It is a combination of deep and strategic approaches that most academically successful students use as it allows students to demonstrate an interest in the material while demonstrating the determination to do well (Entwistle et al., 2001).

A deep learning style requires students to relate ideas, use existing evidence to support ideas, and use awareness of understanding. A surface learning style uses routine memorization without any reflection of the material (Entwistle et al., 2001). How do students who have learned to use the surface learning style move to using a deep learning style? This question has yielded much discussion, but few definite answers (Entwistle et al., 2001). Successful interventions appear to center on the teaching of effective techniques through more personal engagements than found in the typical classroom (Entwistle et al., 2001). This suggests that learning style and 
academic performance can be improved and effective methods are affected by the level of institutional integration felt by the student.

While some contend that colleges and universities are institutions of learning, not the care takers for the emotional health of students, the fact remains that many students come to college with emotional issues and many more develop them over the course of their college careers (Kadison \& DiGeronimo, 2004). Emotional well-being affects academic performance so providing an atmosphere where students are cared for emotionally will boost retention and graduation rates. As such, colleges with strong supports for students including mental health and student support services are beneficial to all students (Kadison \& DiGeronimo, 2004).

As postsecondary education has become a necessity and reality for many over the past three decades, the number of first generation college students has increased proportionally (Pascarella, Pierson, Wolniak, \& Terenzini, 2004). Students whose parents' highest level of education is a high school diploma or less are defined as being first-generation (Upcraft, Gardner, \& Barefoot, 2005). On average, students whose parents did not attend college are more likely to enroll in a two-year institution rather than a four-year institution (U.S. Department of Education Institute of Educational Science, National Center for Education Statistics, 2001) and reported feeling less academically prepared than their peers whose parents had attended college (Pascarella et al., 2004).

First-generation students, when compared to their peers, are less likely to access and understand information important to making decisions regarding college including which degree program to choose, persistence to complete the degree program, and social choices (Bills, 2003). Additionally, they report receiving less financial and emotional support from their families, which often exacerbates the stress of the transition to college (Upcraft et al., 2005; Pascarella et 
al., 2004). Since the median household income for families where the heads of the household did not achieve a postsecondary degree are lower than those households where at least one adult has a postsecondary degree (U.S. Department of Labor, Bureau of Labor Statistics, 2010), it is not surprising that many parents of first-generation college students are not able to substantially contribute to their children's educational expenses. Likewise, since those parents did not attend college, they often do not fully understand the experiences of their sons or daughters. The parents are not able to pass along knowledge about college culture and expectations to their children (Meyer, Spencer, \& French, 2009). This lack of support may leave such students feeling isolated or pressured to enter the job force quicker than their peers, which can lead to early departure from college. Combined with feeling a lack of support from their families, first generation students often perceive less support from their institutions which serves to create a feeling of isolation (Pascarella, 2004).

Unfortunately, first-generation college students are more likely to do poor academically, are at higher risk for mental health issues and substance abuse, and are less likely to persist (Carter \& Daraviras, 2010; Pascarella et al., 2004). Results from a longitudinal study comparing the differences between first-generation college students and those whose parents attained a postsecondary degree (Pascarella et al., 2004) suggest that while first-generation students are more likely to drop out than their peers, if they persist they are more likely to attribute their successes to their hard work and seek out cognitively challenging tasks.

Internal characteristics are aspects include such things as weak self-concept and external locus of control (Bulger \& Watson, 2006). Similar to background characteristics, internal characteristics can be negative internal forces that prevent students from accessing postsecondary education as well as decreasing their persistence. A weak self-concept, or poorly formed identity, 
can lead to loneliness and self-doubt, which often results in a failure to effectively cope with the stressors of college (Anderson, 1985). On the other hand, students with well-formed identities tend to do better in their first year of college, especially when being a college student is a significant component of his or her self-concept (Chickering \& Reisser, 1993; Meyer, Spencer, \& French, 2009). Students with an external locus of control tend to not take responsibility for their behaviors and place the blame for poor grades onto everyone but themselves. Not surprisingly, having an internal locus of control is positively correlated with academic success for at-risk college students (Byrd \& MacDonald, 2005).

Personality factors may play a significant role in the discussion regarding factors that may influence the successful integration of at-risk students into college. One of the most prominent personality theories linked with the success of college students is McCrae and Costa's Big Five Personality theory (Laskey \& Hetzel, 2011). Although an extensive review of this theory is beyond the scope of this dissertation, the influence of these traits on academic performance cannot be ignored. Much of the research in this area has been on the Big Five personality traits and intellectual achievement as measured by intelligence tests (e.g., WAIS, the Wonderlic Personnel Test) rather than academic performance, i.e., grade point average (Furnham, Moutafi, \& Chamorro-Premuzic, 2005; Laskey \& Hetzel, 2011). Personality traits may influence learning styles and test taking style, which in turn is reflected in test scores and grade point average (Furnham et al., 2005). Students, regardless of whether they are considered to be at-risk, may benefit best from possessing high levels of the personality traits of Conscientiousness and Agreeableness (Laskey \& Hetzel, 2011). Specific to at-risk students, these traits could moderate characteristics often found in at-risk students such as not seeking assistance from campus resources and not connecting with campus faculty and staff. 
Neuroticism appears to have an inverse relationship with test scores in college students, perhaps due to facets of this trait including anxiety, hostility, and depression (Furnham et al., 2005). However, in at least one study neuroticism was positively correlated with high school grade point average (Laskey \& Hetzel, 2011). One possible explanation for this discrepancy might be that social support received in high school serves as a buffer to the negative traits such as anxiety, which then can be used as a motivator to perform well. Perhaps this adds to support that students who integrate into postsecondary institutions perform better despite the anxiety associated with college. This was not discussed in the article by Laskey and Hetzel (2011).

Those high in the trait of extroversion may have an advantage in performance tasks, but tend to be less accurate in longer tests (Furnham et al., 2005). Openness to experience has consistently produced the highest correlation with psychometric testing, perhaps because this trait produces more motivation to engage in intellectual activities (Furnham et al., 2005). Agreeableness has not demonstrated a significant correlation with intelligence (Furnham et al., 2005), but has shown a positive relationship with seeking academic services such as tutoring (Laskey \& Hetzel, 2011). Conscientiousness has shown a consistent relationship with work and academic performance (Furnham et al., 2005; Laskey \& Hetzel, 2011). It should be noted that the effects of Agreeableness and Neuroticism on academic performance differ dependent on gender, as do self-evaluations of intelligence (Furnham et al., 2005).

Environmental factors include not utilizing institution resources, perceiving a negative campus climate, housing issues, commuting issues, education costs, and not understanding the concept of a learning community (Bulger \& Watson, 2006). Of all the factors that can affect how students do in college, environmental factors seem to have a moderate to strong effect on retention (Lotkowski, Robbins, \& Noeth, 2004). Perhaps this is because environmental factors 
fulfill the basic needs of satisfying biological demands and feeling safe. If these needs are not satisfied, how can students be expected to do well in school? Environmental factors can create obstacles that seem insurmountable, especially combined with background and internal characteristics that already place students at-risk for dropping out (Anderson, 1985). While many postsecondary institutions have little control over the background and internal characteristics of the students they accept, they are able to shape many environmental factors that place and maintain some students at risk for poor performance in an effort to promote academic success and institution retention. I suggest that shaping environmental factors to promote student success can reduce the amount of risk students are in regarding academic success due to background characteristics and internal characteristics so that all students perform well in school and after graduation.

It is important to look at the role of the college faculty, students, and staff in how they shape the environment in which students find themselves (Tinto, 1993). The first view is more suggestive of social support from family and peers prior to college as setting the foundation while the second view seems to focus more on the transformation of the student during college. The latter view has been popular with postsecondary institutions and has helped set policies that stress resources designed to integrate students into the collegiate atmosphere (Tinto, 1993). This supports the theory that institutional integration is essential for academic success and is a major way in which colleges are able to help shape the environmental factors for students. This will be discussed in further detail later in this dissertation.

As previously mentioned, many postsecondary institutions are admitting more and more students who fall into the category of being at-risk. Admittance of at-risk students into postsecondary institutions has left many colleges and universities with a significant percentage of 
their undergraduate population that may not have the skills or persistence to be academically successful (Laskey \& Hetzel, 2011). From the viewpoint of postsecondary institutions, at-risk students often lower institutions' grade point average statistics and retention rates (Anderson, 1985; Laskey \& Hetzel, 2011). These statistics and rates are important as they affect credentialing and financial resources, which affect all students at the institution. Perhaps more importantly is the cost to these at-risk students who are more likely to suffer from maladjustment to college as evidenced by loneliness, self-doubt, career indecision, and poor academic performance (Anderson, 1985).

One may wonder why many postsecondary institutions are not only allowing more admittance of at-risk students but even recruiting them. This is not a new phenomenon as postsecondary institutions have been allowing entrance to students who did not meet admission criteria since the advent of colleges and universities (Stephens, 2001). As mentioned at the beginning of this chapter, there are a multitude of economic reasons for pursuing postsecondary degrees, and postsecondary institutions have responded to this. From a broader perspective, some believe that it is less costly to society to educate as many people who are willing than to have a society with large numbers of minimally educated and moderately skilled individuals (Mulvey, 2008). And perhaps most importantly, not all students who enter college as being at-risk for poor performance and dropping out do poorly. In fact, many at-risk students graduate from postsecondary institutions. Restricting admission to only those who meet criteria that have been shown to predict academic success penalizes late-developing students and those whose abilities are not easily captured by aptitude tests and high school academic performance (Tinto, 1993).

The purpose of this dissertation is to investigate academic success in at-risk first-year college students. Specifically, I will explore the role of institutional integration in the academic 
success of this population. Institutional integration and its role in academia will be delineated below. For the purpose of this dissertation, academic success is defined by grade point average, the ability to choose a vocation, and overall mental health wellness. First-year students are defined as being first time college students who have recently graduated high school or attained a GED. It is presumed that these students are not married and do not have dependents.

I will begin by detailing the psychosocial development of the college student population by using Chickering's Theory of Student Development (Chickering \& Reisser, 1993). While there are many theories of human development and several that are applicable to college students, Chickering's theory was chosen because of its robustness and dedication to this specific population. Chickering developed his theory in 1969 and has been working to refine it since (Chickering \& Reisser, 1993). Upon this foundation of student development, I will illustrate findings from the literature and research regarding the importance of institutional integration in the success and adjustment of college students. I will highlight concerns specific to college students who are classified as being academically at-risk as well as discuss current strategies being used to combat this problem. All of this will lead up to my research question and hypotheses.

\section{Chickering's Theory of Student Development}

The college experience changes students. One preeminent theory that explains this phenomenon and the development of college students is that of Arthur Chickering. Chickering's Seven Vectors of College Student Development reflect the developmental trajectory of modern college students as they are influenced by their environment, social interactions, and internal growth (Chickering \& Reisser, 1993). Chickering's work has mostly surrounded the psychosocial development of college students within the contexts of personal values, modes of 
thinking and learning, and interpersonal and intercultural skills (Chickering \& Reisser, 1993). For the general purposes of this dissertation, and as it is commonly described in the literature, psychosocial development includes growth in the constructs of self, ego, and identity (Chickering \& Reisser, 1993; Erikson, 1959; Pascarella \& Terenzini, 1991). Chickering's theory expands past Erikson's original conceptualization of the development of college age individuals such that it focuses on changes in the self, ego, and identity as a result of being a college student. If the reader will recall, Erikson (1959) theorized that college aged individuals (18-24 years) were typically finishing the stage of identity versus role confusion and entering the stage of intimacy versus isolation.

Chickering's theory is centered on college students of varying ages reaching competencies in the dimensions, or vectors, of intellectual development, interpersonal competency, moral and ethical development, humanitarian concern, capacity for intimacy, and vocational development, which are areas that he has identified as being congruent with the broad mission of higher education (Chickering, 1980; Chickering \& Reisser, 1993). Vectors indicate both magnitude and direction, although Chickering has clarified that student development within each vector is more of a spiral rather than straight line (Chickering \& Reisser, 1993). A spiral conceptualization takes into account minor setbacks which are normal while completing the competencies.

Chickering conceptualizes that individuals demonstrate movement on the vectors at rates distinct to them and that at any given time individuals are showing movement on multiple vectors (Chickering \& Reisser, 1993). Conditions for growth in the competencies require challenges, differentiation and integration, and disequilibrium brought into equilibrium (Chickering, 1980). Growth brings with it awareness, skill, confidence, and stability in that area 
(Chickering \& Reisser, 1993). Chickering (1980) posits that these vectors are conditions for growth into an adult identity. If you will recall, early development of an adult identity may be an important factor for success in first year students (Meyer, Spencer, \& French, 2009).

Chickering's theory may be viewed as a person-in-environment model as well as a developmental model because the role of the college environment in the developmental changes of students is essential to his theory (Chickering, 1980; Chickering \& Reisser, 1993). At the heart of Chickering's theory of student development is the understanding that students do not grow in a vacuum but rather as a result of the interactions between the student and the college environment (Chickering \& Reisser, 1993). His work is based on the proposition that "human development should be the organizing purpose for higher education" (Chickering \& Reisser, 1993, p. 265). To this point, postsecondary institutions have the ability to impact students' development along the seven vectors that will be discussed in detail. Much of the transformation along the vectors begins during adolescence through the influence of family, high school, and friends. College is a unique time where many students are physically separated from the environment they have known for the past 18 years and placed into an environment with unfamiliar and new people, expectations, and opportunities. This is a time for growth and Chickering's theory utilizes the college environment and expectations as a framework for the developmental changes of late adolescence and early adulthood.

Vector 1: Competencies. The first vector is basic competencies. Chickering conceptualizes the development of competencies to fall into the three primary areas of intellect, physical and manual skills, and interpersonal relationships (Chickering \& Reisser, 1993). A sense of confidence that one can successfully cope with adversity and achieve goals is the base of development for these competencies. It is important to note that college students are 
continuously identifying and testing their competencies; cycling between disequilibrium and equilibrium (Chickering \& Reisser, 1993).

It is with the use of one's cognitive functions to comprehend, analyze, interpret, and synthesize, information from the environment that the intellectual competency is mastered (Chickering \& Reisser, 1993). College places students into situations that allow them to achieve this competency on a regular basis since this is the primary priority of education. As students transition into postsecondary education, intellectual competency is often tested and expanded. College students are expected to move beyond previously set benchmarks of intellectual achievement by mastering content, acquiring aesthetic appreciation and cultural interests, developing the ability to reason, solve problems, think originally, weigh evidence, and actively learn material (Chickering \& Reisser, 1993). Recall that students enter into college at varying levels of academic preparation and that there is a negative relationship between this factor and risk level for academic failure (Chait \& Venezia, 2009). For this reason, at-risk students may enter college with lower competency in this vector.

Development of physical and manual competence is often cultivated through athletic and artistic activities (Chickering \& Reisser, 1993). While these skills may not translate into a vocation, they are often a source of satisfaction for adolescents and adults. In fact, there is burgeoning literature supporting the correlation between physical activity and increased cognitive skills (Taras, 2009). Increased levels of self-esteem and management of aggression and anxiety are often byproducts of participation in physical activity, both of which directly impact academic performance (Taras, 2009). Development of skills in arts and crafts often interacts with intellectual competence and the development of an identity (Chickering \& Reisser, 1993). 
Interpersonal competence involves soft skills that are often more subconscious skills that facilitate smooth communication and collaboration with others (Chickering \& Reisser, 1993). The development of interpersonal skills is the prerequisite for successful friendships and intimate relationships (Chickering \& Reisser, 1993). These soft skills are essential for succeeding in and out of the classroom and may not be developed by at-risk students (Chait \& Venezia, 2009). Long-term this competency is especially important for job success as many individuals are either fired or not promoted due to poor interpersonal skills (Chickering, 1980; Chickering \& Reisser, 1993). Improving interpersonal competence is complex and involves a lot of observation and trial-and-error learning. Unfortunately, many postsecondary institutions are not adept at teaching this information to students (Tinto, 1993). Perhaps the assumption is that students should have previously learned this competency prior to entering college but, as has been previously discussed, this is not the reality.

Vector 2: Managing emotions. The second vector of Chickering's theory involves managing emotions. As one can imagine, the college experience naturally provides stressors in the form of academic demands, novel experiences, making new friends, and increased responsibility. Added to these stressors are previous emotional experiences from childhood, selfdoubts, unmet needs, and emotions related to adjusting to a new environment (Chickering \& Reisser, 1993). In order for students to learn how to manage their emotions, they must learn to identify and appropriately express their feelings. Unidentified and miscommunicated emotions can lead to a plethora of issues including depression, anxiety, substance abuse, aggression, and poor academic performance (Chickering \& Braskamp, 2009; Chickering \& Reisser, 1993). Chickering and Reisser (1993) discuss toxic emotions such as anxiety, depression, and 
aggression that have the potential to impede academic success. I will discuss these emotions and mental health prevalence data before examining how students can best grow along this vector.

The fact is that many students enter into college with psychological disorders (Kadison \& DiGeronimo, 2004). In the most recent National Survey of Counseling Center Directors, the majority of counseling center directors reported a general increase of students with severe psychological disorders on campus as well as an increase in students arriving to college already on psychiatric medications (Gallagher, 2010). In general females are more likely to seek out help at college counseling centers due to their emotional maturity (Gallagher, 2010; Kadison \& DiGeronimo, 2004). Also, women tend to feel a greater sense of well-being if they feel a stronger sense of connectedness and support with the college (Kadison \& DiGeronimo, 2004). Men, international students, and African-American students are less likely to seek out help through a college counseling center and are more likely to seek counterproductive coping mechanisms such as drugs and alcohol (Gallagher, 2010; Kadison \& DiGeronimo, 2004). Please recall that the background characteristics of being a minority can be a major factor that places students at-risk for not doing well in postsecondary education.

Every year since 2000, the American College Health Association (ACHA) has collected data from postsecondary institutions in order to assess the health and wellness of college students and compiled it in the National College Health Assessment-II (NCHA-II) (ACHA, 2011). The most recent NCHA-II was collected during the fall 2010 academic semester from 30,093 students at 37 postsecondary institutions across the United States and two postsecondary institutions outside the United States (ACHA, 2011). Twenty-four of these institutions are public schools while 15 are private schools. The majority $(n=36)$ are four-year institutions. Among the data collected for these annual reports is information on mental health issues. 
According to the most recent NCHA-II, $46.4 \%$ of students surveyed expressed having "overwhelming anxiety" over the past 12 months (ACHA, 2011). While some low levels of anxiety can improve performance if the student's ego involvement is moderate, high levels of anxiety or even chronic moderate to high anxiety can be destructive. Students who are high achievers learn early in their academic career that sometimes being good is not good enough, which can produce significant amounts of chronic anxiety (Kadison \& DiGeronimo, 2004). Even the best student can be underprepared for the academic course load in college. This coupled with the reality that his or her undergraduate performance will determine admission into the next phase of his or her vocation, whether it is graduate school or a job, can lead to serious mental health issues including panic attacks, depression, or suicidal thoughts (Kadison \& DiGeronimo, 2004). At-risk students are likely to have increased levels of anxiety when faced with the reality of failing grades and possible suspension (Chickering \& Reisser, 1993; Tinto, 1993).

Managing feelings of frustration is important, because the college environment is ripe for the potential of perceptions of arbitrary authorities, bureaucratic procedures, inflexible rules, and anonymity of the student (Chickering \& Reisser, 1993). If frustrations are not ameliorated they can quickly morph into anger, which if expressed through aggression, is a destructive emotion that can cause interpersonal, academic, and legal problems. Internal aggression involves destruction of the person who is angry, perhaps through depression, anxiety, guilt, disordered eating, disordered sleeping, obsessive and/or compulsive patterns, self-sabotage, overworking, and substance abuse (Chickering \& Reisser, 1993). External aggression typically involves harming other people or objects. This can include provoking physical fights, verbal aggression, sexual coercion or violence, and destruction of property (Chickering \& Reisser, 1993). Women are more likely to present with internal expressions of aggression while men are more likely to 
present with external expressions of aggression. It is common for adolescents, especially females, to be given messages that anger is a bad emotion and it is unacceptable to express anger (Chickering \& Reisser, 1993). This promotes internal aggression, which allows for more covert methods to express angry emotions including depression, eating disorders, and self-injurious behaviors.

The NCHA-II reports that $58.3 \%$ of those surveyed during the fall 2010 semester indicated feeling "very sad" while $28.4 \%$ felt "so depressed that it was difficult to function" over the past 12 months (ACHA, 2011). Depression is a collection of behaviors and feelings that typically combine to create the overall symptomology. In addition to feeling sad, those who are depressed also demonstrate a loss of interest in activities they once found pleasurable, increased or decreased sleep and appetite patterns, fatigue, feeling and thoughts of worthlessness, an inability to concentrate, or even thoughts of dying (American Psychological Association, 2000). It is not uncommon for individuals who are suffering from depression to demonstrate irritability, passivity, gastrointestinal pains and difficulties, and social isolation, (Chickering \& Reisser, 1993; Kadison \& DiGeronimo, 2004). Depressive symptoms require a lot of physical, emotional, and cognitive energy, which typically leaves the individual fatigued and feeling drained (Chickering \& Reisser, 1993). This increases the likelihood of the student not attending class, completing assignments, or interacting with peers, which also aggravates the situation since these behaviors reinforce isolation and academic failure. With students who are at-risk, depression may be a consequence of their circumstances as well as a factor that exacerbates risk factors.

As with those suffering from anxiety, sufferers of depression who are female are more likely to seek treatment. Unfortunately, symptoms of depression may be low grade and ignored by the sufferer. Additionally, those in a position to help the student identify that there is a 
problem and locate resources to help treat the underlying issues may not recognize there is an issue if the symptoms are well concealed, which further lessens the likelihood of the sufferer receiving treatment (Chickering \& Reisser, 1993). To further complicate the picture, depression is often comorbid with anxiety, disordered eating, substance abuse, and suicide, any of which when coupled with depression can exacerbate symptomology and limit the prognosis (Kadison \& DiGeronimo, 2004).

All too often a response to depression is self-medication. Students who feel depressed may attempt to feel better by using drugs and/or alcohol, which may increase mood temporarily but over time exacerbates depressed mood and may cause other problems including legal issues, poor academic performance, and interpersonal problems. The National Institute on Alcohol Abuse and Alcoholism (NIAAA) reports that approximately $60 \%$ of college students between the ages of 18 and 20 consume alcohol and that excessive drinking frequently leads to alcohol related injuries, sexual assaults, unsafe sex, academic problems, and death (Hingson, Heeren, Winter, \& Wechsler, 2005; Johnston, O’Malley, Bachman, \& Schulenberg, 2008). Despite the reputation of college students drinking primarily to "party," research indicates that many drink to numb psychological pain (Kadison \& DiGeronimo, 2004).

Development along this vector requires that one learns to be aware of feelings and then learn how to flexibly control them through appropriate and effective means of expression and integration (Chickering \& Reisser, 1993). Becoming aware of emotions can be a difficult task as it requires knowledge of the full range of various emotions, language to identify emotions, accurate gauging intensity of these emotions, and ability to discriminate the purpose of an emotion during a specific instance (Chickering \& Reisser, 1993). Students who are able to accept that emotions are normal reactions to life experiences find this task easier when they share their 
experiences with others and discover that they are not alone in this struggle to manage emotions (Chickering \& Reisser, 1993). This helps students learn how to affirm the validity of their feelings despite any resistance from others, which is an essential part of identify formation (Chickering \& Reisser, 1993).

Integration into the college environment involves exercising flexible control of emotions via regulating intensity of feelings and expression of feelings without resorting to aggressive or irrational patterns of behavior (Chickering \& Reisser, 1993). College students are regularly presented with stressors that test their ability to manage emotions in order to do well academically including test anxiety, interpersonal cooperation for group projects, and overcoming unpleasant emotions such as boredom. By learning how to channel anxiety, dislike, or boredom into constructive action, students are able to do well on a test, group project, or maintain a consistent study schedule. Experiencing positive emotions helps with integration as the student is able to feel both ends of the emotional continuum and helps to counteract and complement the negative emotions as well as the biological systems that maintain these emotions (Chickering \& Reisser, 1993).

Learning how to identify and integrate emotions in order to effectively manage them is not an easy task. This process requires a certain level of growth and maturity on part of the student as well as an environment that provides support and safety in which the student can learn and practice. One of the most effective ways for this to be accomplished is through a mentorship model (Chickering \& Reisser, 1993). Ideally, students will have had this provided to them during early adolescence through their family of origin and/or a community mentor. The growing reality appears to be that this is not always the case. Does this mean that the responsibility now lies with postsecondary institutions to provide this type of experience? That question cannot be answered 
in this dissertation but I suggest that many postsecondary institutions are in the position to offer mentorship services to students in order to help them succeed both academically and personally. There is a strong link between academic and personal success that suggests that students do better academically when they are cognitively, emotionally, and behaviorally mature (Chickering \& Reisser, 1993).

Vector 3: Autonomy toward interdependence. The third vector involves students moving through autonomy toward interdependence (Chickering \& Reisser, 1993). This requires students learning how to be self-sufficient individuals who are actively part of a community where they help those who need it and ask for help when needed. For many students physical separation is an inevitable result of going to college as they move many miles away from their parents. But physical separation does not necessarily produce the psychological separation required for individuation (Chickering \& Reisser, 1993). Most college students seem to use their family of origin as the secure base from which they begin to explore adulthood. During the first year of college, it is not uncommon for students to have one foot planted at home while the other is planted at college (Kadison \& DiGeronimo, 2004). This is not always bad as it allows parents the opportunity to provide continued support for their children that can help navigate through the fears and anxiety of being first year college students while still helping instill a sense of interdependence. Kadison and DiGeronimo (2004) suggest that parents are often the best judge of their children's mental health and can be the primary force driving students to seek counseling if needed. Given the prevalence of mental health issues on college campuses, it seems advantageous for parents of first-year students to keep a closer watch on their children until it has been established that the student has a support network at school. This seems especially important for at-risk students who by definition need more support. 
First-year college students may find themselves in a precarious situation due to expectations and needs. They are expected to become autonomous beings and responsible adults who are able to navigate through their new environment with independence; however, it is during this time that they most need guidance and support as they are placed into an environment that is unfamiliar (Kadison \& DiGeronimo, 2004). The reality for many first-time college students is that they are high school graduates living in the safety of their parents' home one day and college students with complete freedom literally a day later. This abrupt transition is often welcomed by students who are looking for more freedom but may not realize the extent of responsibility that is fundamentally attached. Not balancing the freedom with responsibility can be a problem for all students.

The first year often involves finding a balance between developing autonomy while developing interconnectedness with the college in order to become self-reliant (Chickering \& Reisser, 1993). Within the area of postsecondary academia, interconnectedness with the college is known as institutional integration, which will be explored in full later in this dissertation. Learning to be autonomous can be difficult as some students may not have learned this (Kadison \& DiGeronimo, 2004). They may have notions that autonomy means not asking for help or speaking up about their needs (Kadison \& DiGeronimo, 2004). If students do not know how to ask for help or feel uncomfortable doing so they can quickly find themselves overwhelmed. Learning responsibility for behaviors and life is at the core of autonomy and one of the most effect ways in which to teach this is through vicarious learning. Postsecondary institutions are best able to do this when students are integrated into the college environment (Kadison \& DiGeronimo, 2004). 
Interdependence is the awareness in place and commitment to the welfare of the larger community and the "capstone of autonomy" (Chickering \& Reisser, 1993, p. 140). This is achieved only after attaining autonomy and understanding one's place in the community. In today's society, students' community has moved beyond the college and university into the global community (Chickering \& Braskamp, 2009). For this reason, integration into the college environment is important. Many students may enter college believing that they must complete their academic journey alone. They may have a good sense of autonomy but a poor sense of interdependence. Common results of this attitude include acting out behaviors and “entitlementarianism” (Chickering \& Reisser, 1993). It is only after students recognize that they are part of the larger environment, the school, and that they cannot receive benefits from the larger environment without contributing positively toward it, that true interdependence is gained.

Moving from autonomy to interdependence involves developing various types of interdependence (Chickering \& Reisser, 1993). Emotional interdependence is the freedom from continuous reassurance, affection, or approval from others (Chickering \& Reisser, 1993). For many college students the physical separation from parents may be the first step in this process. As they leave the safety of home and become more reliant on the support network of the school and their own abilities, self-confidence in this area typically increases (Chickering \& Reisser, 1993). Students learn to discriminate between their wants and needs, how to set and achieve realistic goals, and begin to function as a responsible adult (Chickering \& Reisser, 1993). Students whose parents provided opportunities to increase autonomy during adolescents as well as provided a safe home environment in which to experiment with autonomy typically develop emotional interdependence easier and earlier than those whose who did not (Chickering \& Reisser, 1993). 
Instrumental interdependence is the ability to be self-directed regarding activities and problem solving while having the confidence to pursue opportunities and adventures (Chickering \& Reisser, 1993). This type of interdependence requires generalizability of self-sufficiency among various environments (Chickering \& Reisser, 1993). As one can imagine, emotional and instrumental interdependence are mutually facilitating. Disengaging from parents without having developed a foundation for instrumental interdependence can hamper the student's ability to manage his or her life as a responsible adult (Chickering \& Reisser, 1994). The student may not have learned how to manage his/her finances, cook food, or even maintain a household, which will likely cause problems as he/she transitions through college into adult life. Instrumental interdependence often increases with intellectual competence (Chickering \& Reisser, 1993), which suggests that as students rise in rank they will become more competent in this area.

Vector 4: Interpersonal relationships. Chickering's fourth vector is developing mature interpersonal relationships (Chickering \& Reisser, 1993). Some of the most profound relationships one will ever have are developed during college. These relationships develop during a time when students are transitioning from adolescence to adulthood and forming their adult identity. These relationships often teach students how to express feelings, rethink first impressions, share intimately, resolve problems, and maintain meaningful commitments (Chickering \& Reisser, 1993). It should be noted that one of the most common developmental problems affecting college students is that concerning interpersonal relationship issues (Kadison \& DiGeronimo, 2004). In order to develop mature interpersonal relationships, students must learn how to balance autonomy and attachment needs (Chickering \& Reisser, 1993). As such, this vector requires tolerance and appreciation of differences and the capacity for intimacy so that students develop a sensitivity that allows them to appreciate diversity. Tolerance happens in 
both intercultural and interpersonal contexts and begins by identifying one's own biases

(Chickering \& Reisser, 1993). College environments are often very diverse and present multiple learning experiences from which students can develop cultural sensitivity and understanding. Residence halls, or dorms, are one of the primary environments in which college students are forced to learn how to get along with others, problem-solve issues, and live in an environment they may find to be less-than-perfect. Problems with roommates can disrupt the emotional and mental health of a college student more quickly than almost any other college stressor (Kadison \& DiGeronimo, 2004).

Interpersonal relationships provide social support and intimacy. Within the framework of interpersonal relationships, social support appears to encompass an exchange of supportive acts between individuals (Uchino, 2004) such that the social environment promotes well-being and increases resilience (Haber, Cohen, Lucas, \& Baltes, 2007). Intimacy involves a shift toward interdependence between people, which can be frightening but a life without intimacy is often filled with pain, frustration, and loneliness (Chickering \& Reisser, 1993). Sustaining intimacy requires self-awareness, self-confidence, spontaneity, and continuous communication (Chickering \& Reisser, 1993). Without intimacy, life is often filled with pain, frustration, and loneliness (Chickering \& Reisser, 1993). College environments are ripe with opportunities for students to learn how to cultivate healthy and supportive interpersonal relationships.

Vector 5: Identity. The fifth vector is establishing an identity (Chickering \& Reisser, 1993). Essentially, each of Chickering's vectors is part of identity formation; however, identify formation is an important task and requires a certain level of developmental maturity. Students who develop an adult identity typically do better in their first year of college than those who have a less mature identity (Meyer, Spencer, \& French, 2009). Unfortunately, the percentage of 
first year college students who have developed an adult identity is low. One of the three most common issues facing college students is that of identity development (Kadison \& DiGeronimo, 2004).

An adult identity refers to having a sense of self, coherent self-image that serves as motivation, and an understanding of responsibility to self and society (Chickering \& Braskamp, 2009). Based on work by Erikson (1959), Marcia (1966) posited that identity formation is the result of stimuli or challenge provided by the environment and the individual's commitment to a response to that challenge that affects his or her identity or an aspect of the identity. The individual responds to these stimuli by one of four coping styles: achievement, diffusion, foreclosure, or moratorium (Marcia, 1966). Chickering's model expands beyond this to theorize that identity development involves a more holistic process including having a sense of comfort with appearance, comfort with gender and sexuality, sense of self in the world, clarification of self-concepts through life-style and life-roles, sense of self in response to feedback from others, self-esteem, and personal stability and integration (Chickering \& Reisser, 1993). This is a complex process that builds on the previous vectors of developing competences, managing emotions, developing autonomy and interdependence, and developing mature interpersonal relationships. The student's identity comes from knowing and accepting her beliefs as well as her place in her environment both intimately and globally.

Prior to college, students have developed their identities based on the context of their families and immediate social experiences (Kadison \& DiGeronimo, 2004). College offers opportunities and exposure to many different lifestyles, backgrounds, cultures, and values, all of which can be overwhelming, scary, and exciting to students. College students are able develop and internalize global perspectives into thinking, identity, and interpersonal relationships 
(Chickering \& Braskamp, 2009). While the college experience provides an excellent opportunity for growth, it can also stimulate confusion and anxiety (Kadison \& DiGeronimo, 2004). Students are presented with opportunities to alter their held beliefs and values based on these experiences but some may choose to cling to existing values and beliefs because it is safe and out of loyalty to family, which can cause great internal distress (Kadison \& DiGeronimo, 2004).

Many students may come from cultures that do not value intellectual activity. When students' academic life is devalued by family and friends, the consequences can include isolation and withdraw from the family as well as depression (Kadison \& DiGeronimo, 2004). This issue seems to be prominent with first generation college students, many of which are at-risk first-year students (Laskey \& Hetzel, 2011). Parents may have expectations for their children that are not in line with what their children want, including vocational aspirations. These students may feel that their families are not able to identify with the challenges at college, which can lead to feeling isolated from their families and suffering because they do not have role models to show them how to traverse this area of their lives (Kadison \& DiGeronimo, 2004).

Vector 6: Develop purpose. The previous vectors have allowed students opportunities to create their identities and discover who they are so that they can proceed to develop a purpose, which is the sixth vector (Chickering \& Reisser, 1993). With the expansion of postsecondary education to a wider variety of students has come the emphasis on vocationalization (Altbach, 1998). The purpose of college for many students is to provide training for careers and purpose is most often thought of as the impetus for choosing a specific career trajectory (Chickering \& Reisser, 1993). However, creating purpose is more than choosing a major or career; it requires a sense of attachment to something beyond the self that provides both meaning and significance (Chickering \& Braskamp, 2009). By this definition, purpose can be a foundation for vocation. 
Often having a greater purpose produces more satisfying and productive careers (Chickering, 1980). But developing a purpose is more than solidifying vocational plans; it also involves personal interests and interpersonal and family commitments (Chickering \& Reisser, 1993). At times students may feel that their interactions in college should be purely academic, but avocational and recreational interests provide both satisfaction and stimulation important for holistic growth. Extracurricular activities allow students an arena in which concrete experiences and active experimentation can facilitate academic and personal growth (Chickering, 1980). Also, many graduate programs and employers are interested in individuals who are well-rounded beyond school so developing interests beyond academics may be essential for attaininga desired vocation.

This vector requires students to become more intentional in their endeavors as they assess vocational options and interests, clarify goals, construct plans, and persist despite obstacles (Chickering \& Reisser, 1993). It is not uncommon for students to go through recurrent cycles of challenge and response, differentiation and integration, and disequilibrium and equilibrium while developing this vector (Chickering, 1980). Choosing a vocation can be difficult for many students as it often takes time for students to evaluate their interests and skills while considering the importance of factors such as salary and desire for additional education. Interactions between students and faculty help to foster a sense of purpose (Chickering \& Reisser, 1993; Pascarella, 1980).

It is likely that students have nascent vocational goals when entering college, but many will find that they have to reevaluate these goals based on new interests or insurmountable challenges. College is the perfect time to explore different areas of interests in order to determine which areas best fit with the person. While having a clarified vocational plan is a stabilizing 
force that can help with student persistence, foreclosing on a vocation that is not truly in line with one's purpose is a destabilizing force (Tinto, 1993). It is not uncommon for students to do poorly academically and emotionally because they feel forced to pursue certain careers by their parents (Kadison \& DiGeronimo, 2004). For this reason, it is important that students have the freedom to pursue careers that are congruent with their abilities and interests. Rooting vocational guidance in the development of purpose often increases motivation, effort, and acquisition of knowledge and skills (Chickering, 1980).

Many students enter college without a clear career or vocational plan and many more change career and vocational goals over the course of their time in college, mostly during their first two years of school (Tinto, 1993). This makes sense as first and second year college students are still exploring areas of interest and their own identities (Tinto, 1993). It appears that academic performance and career decision making are not directly related to each other but rather connected through identity formation (Tinto, 1993). As students mature cognitively and emotionally, they typically develop career maturity (Pascarella \& Terenzini, 1991). With career maturity, students accomplish career-oriented developmental tasks, formulate career plans, possess accurate knowledge about their preferred occupation, and have a degree of certainty about their career choice (Pascarella \& Terenzini, 1991).

Super's life-span vocational choice theory (1953), also known as Life-Career Rainbow (Super, 1957), fits well with Chickering's theory of student development. Super (1953) posits that individuals go through five stages regarding career development. According to Super, vocational development is the process of developing and applying self-concept. As the reader may recall, Chickering's theory is built around the concepts of self, identity, and ego where these concepts are at the center of all developmental vectors (Chickering \& Reisser, 1993). Chickering 
theorizes that students actively work to build their self-concepts and identities and Super (1953) posits that it is through these self-concepts and identities that people make stable and realistic vocational choices. People are most satisfied with work when they have implemented their selfconcepts. Chickering supports this by asserting that vocation choices should be made by building purpose, which is part of identity (Chickering \& Reisser, 1993).

According to Super's theory $(1953,1957)$, from birth until the early teenage years, children develop their self-concepts and attitudes about work during the growth stage. Beginning in early adolescence and lasting through college, individuals are in the exploration stage where they investigate various career options and jobs. During this time their self-concepts and vocational choices becomes more realistic. By the time students have graduated from postsecondary institutions, they are typically in the establishment stage. The establishment stage involves beginning one's career and working to make their occupation secure. By middle adulthood, most people enter into the maintenance stage. During this time individuals adjust their skill set to remain competitive in their careers. Limitations are accepted and new skills may be learned. By the age of 65 years, many people are either beginning retirement or are only a few years away. There is a general decline in the number of hours worked and a renewed interest in non-occupational activities. Many people choose to remain employed part-time after retirement. Typically they choose to work in an area that they enjoy.

As individuals pass through each stage they must complete specific tasks related to that stage. As they complete each task, their career maturity grows, which indicates that they are better able to make vocational choices (Super, 1953). During the growth stage, children must complete the task of beginning to develop their self-concept, understand the meaning of work, and begin exploring areas in which they might want to work. In the exploration stage, individuals 
are often enrolled in secondary and postsecondary schools where they must complete the task of choosing a vocational preference, learning more about that vocation, and continuing to develop a realistic self concept. It is during the establishment phase that individuals must complete the tasks of becoming more stable with their chosen vocation and work toward advancement in that area. The tasks of the maintenance phase revolve around keeping one's position in the chosen vocation and continuing to achieve status. All of this culminates with the final phase, decline, where the tasks are to plan for and engage in retirement (Super, 1953).

Super (1980) discussed the various roles that individuals inhabit throughout their lifetime. These are child, student, leisurite, citizen, worker, spouse, homemaker, parent, and pensioner. At any given time people may be fulfilling multiple roles (e.g., student, parent, and spouse) and some people may never occupy some of these roles as they may choose to not marry or have children (Super, 1980). These roles are primarily conducted in four areas: home, school, community, and workplace (Super, 1980). At any given time, individuals inhabit multiple roles in various areas, which can lead to role conflict. One needs to look no further than the college population to see examples of this. Many college students occupy the roles of student, leisurite, citizen, and worker, if not more nontraditional roles of spouse, homemaker, and parent. These roles are evident at home, school, in the community, and at work. Roles often interact with each other so success at one may lead to success in another (Super, 1980). However, role obligations of students may conflict with those of leisurite and worker in school, whereas the role of parent and leisurite many conflict both at home and at work. Students, as well as all individuals, are able to minimize role conflicts by balancing roles and prioritizing needs (Super, 1980).

Vector 7: Integrity. The last vector is developing integrity (Chickering \& Reisser, 1993). This vector is an extension of the previous vectors and closely related to developing an 
identity and clarifying purposes (Chickering \& Reisser, 1993). Students bring with them core values and beliefs to school and during their time as an undergraduate, they will be exposed to ideas, people, and situations that are novel. They will likely have opportunities to experiment with new identities and cultures all with the end goal of finding who they are. As they journey through this time, it is hoped that their behavior becomes congruent with a valid and consistent set of values while showing responsibility for themselves and others by applying ethical principles (Chickering \& Reisser, 1993). In developing integrity, students must move away from automatic application of uncompromising beliefs and move toward balancing their own selfinterest with that of society, consciously affirm core values and beliefs while respecting those of others, and displaying congruence of personal values and responsible behavior (Chickering \& Reisser, 1993).

Up to this point, I have discussed reasons that necessitate a postsecondary education, risk factors that influence academic success and graduation, and a model of development for college students with special attention paid to at-risk students. This model of development addresses areas including emotional, identity, and vocational development. In the next part of this dissertation, I will turn my focus toward postsecondary institutions' attempt to foster good academic performance and retention for at-risk students. As we have learned, national trends indicate that enrollment in four-year postsecondary institutions will continue to rise as the current economic climate necessitates education beyond high school. This, along with lowered admission criteria, has increased the number of students who are at risk for poor academic performance and dropping out. I will continue by outlining a brief history of postsecondary institutions, detailing a model of student persistence and departure developed by Vincent Tinto, 
discussing the concept of institutional integration, and reviewing retention programs commonly used by colleges and universities, concluding with my research question and hypotheses.

\section{Postsecondary Institutions and At-Risk Students}

The University model, which is the foundation for the modern university system, was developed in France during the $13^{\text {th }}$ century as a means to pass on knowledge and training for a select few (Altbach, 1998). These institutions excluded more than they included and reserved education for the male elite and clergy. This model, which has continued to some degree as the foundation for four-year colleges and universities, places professors at the center of the university environment and student autonomy part of the academic ethos (Altbach, 1998). This foundation has the ability to perpetuate elitism within postsecondary education as it creates a system that is more easily navigated by those who have had the educational background and structure which supports autonomy within learning; those students with the college knowledge and behaviors discussed at the beginning of this paper. Within America, the University model was greatly impacted by the growing egalitarianism of society which placed colleges in areas meant to serve rural students (Altbach, 1998). American universities have been heavily influenced by both the English liberal arts tradition and the German research concept (Altbach, 1998). Within the American postsecondary school system, there is a hierarchy with the most prestigious and well-funded institutions being research-oriented universities, followed by fouryear arts and sciences colleges and then community colleges (Altbach, 1998). While this system is intended for mobility among the levels, students rarely transfer to levels outside of where they started (Altbach, 1998).

By the 1970s, the federal government began to provide financial support to students seeking postsecondary education so that they could one day become a force for change 
(Chickering, 2010). More government-provided financial support and an increasing middle class have meant an expansion of students seeking a postsecondary education (Altbach, 1998). As America's middle class has increased, the demand for access to high prestige occupations has increased and postsecondary educations are often the only access to these occupations (Altbach, 1998). All of this has led to open enrollment admission standards and an influx of students who may not be adequately prepared for the rigors of college (Chickering, 2010). One consequence of this was the attrition of many students after only a year or two of college (Chickering, 2010).

Although there has been a dramatic increase in the enrollment in postsecondary institutions, there are a large number of high school seniors applying for a finite number of college slots (Kadison \& DiGeronimo, 2004). This has produced the necessity for high school students to go beyond only getting good grades. In order to be competitive for top ranked colleges, students must excel on aptitude tests, have participated in leadership roles, joined extracurricular clubs and sports, and volunteered in humanitarian projects (Kadison \& DiGeronimo, 2004), which are less likely to be done by students who are at-risk for not doing well in college to begin with (Pascarella, Pierson, Wolniak, \& Terenzini, 2004). These pressures do not end once students enter college, in fact they increase as there is now pressure to get into a graduate program or attain a job after graduation (Kadison \& DiGeronimo, 2004). Once in college, pedagogical practices move students from merely memorizing information to the level where they regularly use critical-thinking and problem-solving skills (Chickering \& Stamm, 2002). This practice is easier for students and institutions if students have been adequately prepared for the demands of college.

Chickering and Stamm (2002) suggested that all postsecondary institutions emphasize that students acquire knowledge, intellectual competence, interpersonal competence, emotional 
intelligence, integrity, and motivation during their time at the institution. They provide several suggestions on how institutions can best help their students achieve these benchmarks including adjusting the content and structure of curriculum, modifying the delivery of material, incorporating more experiential learning experiences, and by increasing peer and studentrelationships. The first three suggestions are beyond the scope of this discussion, but their final suggestion to make faculty members more accessible to students adds further support to the importance of institutional support in the overall success of college students. Creating this culture where faculty can regularly link academic work to global needs and concerns and students can connect their role as student to their role as a member of the larger society is essential for success in college as well as in employment settings (Chickering \& Stamm, 2002). This requires that students become an integral part of the college environment and feel connected to faculty, other students, and resources (Chickering \& Reisser, 1991; Chickering \& Stamm, 2002; Pascarella \& Terenzini, 1991). This concept is known as institutional integration.

\section{Institutional Integration}

Within education, institutional integration is the term used to describe a student's academic and social integration into the post-secondary institution's environment (Pascarella \& Terenzini, 1980; Pascarella \& Terenzini 1991; Tinto, 1993). The concept of institutional integration was originally developed from Tinto's (1975) model of student departure and persistence. Pascarella and Terenzini $(1980 ; 1991)$ then created a scale based on Tinto's work, the Institutional Integration Scale (IIS), as a measure of this concept while adding to the literature in the area of student departure and persistence in postsecondary education.

The psychometric properties of the IIS are discussed in the Methods section of this dissertation. This scale measures the two broad constructs of social and academic integration via 
the five subscales: peer-group interaction, interaction with faculty, faculty concern for student development, academic and intellectual development, and institution and goal commitment. The subscale of peer-group interactions measures the level of satisfaction of peer interactions, amount of positive relationships that foster intellectual and personal growth, and the ability to easily form friendships. The faculty interaction subscale measures non-classroom interactions with faculty members. Specifically, these questions tap into the amount of positive interactions students have had with at least one faculty member regarding the development of personal, intellectual, and career growth. The next subscale looks at the student's perception of his interactions with all faculty regarding the level of concern he feels from faculty. This subscale taps into the amount of interest, good contact, willingness to spend time outside of the classroom with the student, and genuine interest in teaching. The fourth subscale, academic and intellectual development measures the student's satisfaction with their own intellectual growth and academic experiences at their institution. Students are asked to consider if the institution has fostered their interest in intellectual and cultural events. Also, they are asked to assess their own academic performance. Lastly, the subscale of institution and goal commitment measures the student's own commitment to graduating from the institution, choosing a major, and achieving academically.

The greater the student's involvement in academic life via faculty contact, the greater his acquisition of knowledge and development of skills, all of which lead to academic success (Pascarella, 1980; Tinto, 1975; Tinto, 1993). As mentioned previously, frequent interactions between students and faculty help to foster purpose, which is a driving force for doing well academically and selecting a vocation (Chickering \& Reisser, 1993; Pascarella, 1980; Tinto, 1993).This may be explained by the role faculty play in increasing student involvement and 
persistence (Tinto, 1993). Faculty members are able to act as mentors, teachers, role-models, and overall sources of institutional integration support for students. Even one relationship with a faculty member may offset any negative effects of social isolation (Tinto, 1993). In short, student engagement and involvement in the campus community is essential for academic persistence (Tinto, 1993).

When entering into a discussion of institutional integration, it is important to look at student persistence and departure as it is at the root of the concept of institutional integration. Tinto's model of student persistence and departure asserts that students enter college with a range of background characteristics such as gender, ethnicity, academic ability, and family social status (Pascarella \& Terenzini, 1980; Tinto, 1975; Tinto, 1993). These characteristics combine with students' college-specific goal commitments such as highest degree expected and importance of graduating. This combination influences how well students perform academically in college as well as how well they are able to integrate into the social life of the postsecondary institution (Pascarella \& Terenzini, 1980; Tinto 1993).

\section{Student Departure and Persistence}

Tinto’s original model integrates the importance of intellectual and social communities in the academic success of students (Crissman et al., 2005; Tinto, 1975). Additionally, the model places the responsibility for first-year student academic success and social integration with both the institution and student (Crissman et al., 2005; Tinto 1975). In general, the more integrated students are in the social and intellectual life of college, the more likely they are to persist until achievement of a degree (Tinto, 1993). This integration happens both inside and outside of the classroom and with a variety of interactions, including with faculty, staff, peers, and the community (Pascarella \& Terenzini, 2009). 
On an institutional level, the themes for departure are adjustment, difficulty with expectations, incongruence with the institution or departments, and isolation (Tinto, 1993). Lack of integration into the institution arises specifically from incongruence and isolation (Tinto, 1993). Adjustment to college can be very difficult for some students and problems in this area are typically due to an inability to separate from the previous social environment, which includes both high school peer groups and family of origin and the inability to meet new social and intellectual demands (Tinto, 1993). Proper adjustment to college requires developing autonomy and, over time, interdependence (Chickering \& Reisser, 1993). As previously noted, it is common for first-year students to rely on a significant amount of social support from high school peer groups and family while they are becoming assimilated into their new social environment at college. Over time this reliance will lessen as students develop relationships with college peers and grow in the area of autonomy (Chickering \& Reisser, 1993). Poor adjustment can undermine even the strongest commitment to academic goals and be a reason for departure from the institution (Tinto, 1993). While some students may enter postsecondary institutions with mental health issues, many students encounter their first episodes of depression or anxiety during their time in college as a result of problems adjusting to their new environment.

Another area of difficulty for first-year college students that may lead to institutional departure is that of understanding and meeting the expectations of the university (Tinto, 1993). University expectations include the social and intellectual criteria that students are expected to reach (Tinto, 1993). These university expectations are set by a variety of variables including the norms of the university, the institution's mission statement, and individual expectations set by faculty members (Tinto, 1993). Expectations influence a student's willingness to encounter, engage in, and persist in academic challenges (Schilling \& Schilling, 2005). If students do not 
understand the expectations or find it too difficult to meet expectations, they are likely to not do well (Tinto, 1993). This can also leave students feeling incongruence with the institution and prevent integration.

Incongruence with the university or specific departments within the university can be a significant reason for poor performance and student departure. Incongruence is a mismatch between the needs, interests, and preferences of the student and the institution (Tinto, 1993). This can be observed in several areas including expectations, academics, campus climate and culture, and interpersonal interactions. Students who do not feel that their needs are being met by the institution are more likely to feel unsupported, which is correlated to student departure (Pascarella et al., 2004).

Incongruence can arise from a mismatch between the student's abilities, skills, or interests and the demands placed on the student from the institution. Universities often set high standards for their students but sometimes fail at informing their students how to meet these standards, thus setting the stage for failure (Schilling \& Schilling, 2005). Some faculty members are more clear than others about what actions will produce a good grade in the course but few will provide extensive details on how to study as it is assumed that students entering college know how to study (Schilling \& Schilling, 2005).

Sometimes these incongruences can be assuaged by students' uses of college resources (Tinto, 1993). These resources may include tutoring, advising, counseling, meeting with professors outside of class, and extracurricular organizations. Failure to utilize campus resources can be due to not knowing that these resources exist, not understanding how to initiate contact with the various resources, or finding these resources irrelevant (Tinto, 1993). While true incongruence may exist for some students, it seems likely that for a percentage of students who 
feel that their postsecondary institution is not a good match for them, they may not have found common ground and the support they seek.

Faculty involvement is important both inside and outside of the classroom, as well as interactions with faculty that may set the ethos for commitment to student intellectual growth and opportunities for student involvement in learning (Tinto, 1993). Students who have nonclassroom contact with faculty tend to perceive more intellectual growth, have more intellectual curiosity, demonstrate more autonomy and interdependence toward scholarly careers, have more sensitive interpersonal skills, and persist in college (Pascarella \& Terenzini, 2009). Faculty and student involvement in the institution and academic environment help to guide students toward being global citizens and assist in students' development of an identity (Chickering \& Braskamp, 2009; Chickering \& Reisser, 1993).

Also, students can feel incongruence if they do not find a fit in the social aspects of college, including a peer group, and this can lead to isolation (Tinto, 1993). These students do not form a close bond with either faculty or peers. While incongruence inevitably happens for some students, isolation does not have to occur (Tinto, 1993). Isolation can also be viewed as the absence of institutional integration and is a better predictor of student departure than academic performance (Tinto, 1993). Students who have formed at least one relationship or connection with someone in the institutional environment are more likely to persist at the institution (Schroder, 2010; Tinto, 1993). The likelihood of persistence is increased when the relationship or connection is made with a faculty or staff member of the university (Schroder, 2010).

Students leaving postsecondary institutions prior to degree completion are problematic for both the student and institution (Tinto, 1993). Students seem to be at the highest rate of 
attrition at the end of their first year (Pascarella \& Terenzini, 1980). There is a difference between institutional departure and system departure (Tinto, 1993). Leaving an institution may mean that the student is transferring to another institution or postponing his education briefly, while departing from the system typically indicates that he will discontinue seeking a college degree. Retention rates for institutions do not differentiate between institutional and system departures and as such do not provide an accurate view of student departures. Postsecondary institutions are primarily concerned with retaining students from first enrollment until graduation for a myriad of financial reasons. Retention rates are used as an indicator of an institution's effectiveness in educating students. So, whether or not it is in a student's best interest to remain at a particular postsecondary institution is not factored into retention rates. When a student makes the decision to end his postsecondary education, he may be left with a sense of failure, poor job prospects, and student loan payments.

While the exact reasons for a given student's departure are personal and idiosyncratic, most reasons can be delineated between the themes of intention to attain a degree or vocation and commitment to persevere (Tinto, 1993). Having the intention to attain a degree is not sufficient by itself; students must have goal and institutional commitment (Crissman et al., 2005; Tinto, 1993). Goal commitment is the student's dedication to educational and occupational goals, while institutional commitment refers to the degree to which he is willing to work in order to achieve goals within a particular institution (Tinto, 1993). In general, the greater the commitment to an educational goal, the more likely the student is to persevere at the institution (Tinto, 1993). These commitments help students to buffer the difficult moments during college.

There is also a relationship between commitment and academic competence. As one might expect, students who have high levels of academic competence and high levels of 
commitment tend to persist in college and earn a degree while students with low levels of academic competence and low levels of commitment tend to perform poorly and exit the postsecondary system (Tinto, 1993). Students who have high levels of academic competence but low levels of commitment tend to depart the institution by either transferring to another institution or taking a break in their education and re-enrolling at a later time (Tinto, 1993). The last group is that of students with low levels of academic competence but high levels of commitment. These students tend to persist in college until suspended due to poor grades (Tinto, 1993). Lotkowski, Robbins, and Noeth (2004) found that non-academic factors like selfconfidence, goal setting, institutional commitment, social support, financial support and social involvement lead to higher rates of retention.

\section{Institutional Integration and Student Success}

There are multiple definitions of student success. One of the narrowest defines student success as completion of academic courses and continued enrollment for the following academic

year (Upcraft, Gardener, \& Barefoot, 2005). This is measured via grade point average (GPA) and retention. Upcraft et al. (2005) suggested that student success cannot be limited to passing classes and remaining in the institution. Rather, they advocate that student success be measured by intellectual and academic competence, establishing and maintaining interpersonal relationships, exploring identity development, deciding on a vocation, maintaining health and wellness, considering spiritual dimensions, and developing multicultural awareness and civic responsibility. These echo Chickering's seven vectors of student development. As with Chickering's seven vectors, these measures of student success occur at different rates based on individual differences as well as developmental differences (Upcraft et al., 2005). 
Students and parents often have a limited understanding of what is needed for a successful career and life; it extends past cognitive development and into moral, character, and social development (Chickering, 2010). The belief that preparation, ability, and motivation are sufficient for student success is deficient (Crissman, Ishler, \&Upcraft, 2005). In addition to having these qualities, students' persistence is influenced by a variety of environmental variables that can make the difference between academically achieving and remaining in school and failing classes and leaving school. These environmental variables may include first-year grade point average, chosen academic major field, enrollment status, quality of effort, interactions with faculty, interpersonal interactions, participation in extracurricular activities, employment, student satisfaction, substance use, financial aid, institutional interventions including first-year seminars and orientations, academic advising, supplemental and developmental education, and campus climate (Crissman et al., 2005).

Schilling and Schilling (2005) provided several suggestions to postsecondary institutions that have established high expectations for first year students. These suggestions include shaping student expectations from the first encounter, understanding and responding to the expectations students bring with them, intentionally socializing first-year students to rigorous and demanding academic work, integrating students' expectations with educational goals, designing first-year curricula to mold the type of senior students the university wants, encouraging faculty to share realistic information on how to be academically successful with students, using first-year experience classes to orient students to the college culture, regularly collecting data on expectations from all members of the university, and sharing these data with all involved parties in order to evaluate the system and make changes as needed. An exploration of the use of these suggestions is beyond the scope of this dissertation. 


\section{Retention Initiatives in Postsecondary Education}

Reasons why students depart from institutions are often psychological in nature, which is not always in line with the policy needs of many institutions (Tinto, 1993). Many institutions attempt to address retention by affecting environmental concerns which are more sociological, economic, and organizational in nature (Tinto, 1993), perhaps areas that are easier for institutions to make changes in. Tinto (as cited in Crissman et al., 2005) stated that effective retention designed to reduce the rate of student departures must be committed to the students they serve, committed to the education of all of their students, and committed to the development of supportive social and educational communities in which students are integrated as members. Added to this is the responsibility of institutions to provide additional layers of support and opportunities for students that they admit that are at-risk for not performing well (Mulvey, 2008). Many colleges and universities have instituted programs designed to help retention of at-risk students. These programs may offer remediation via college readiness seminars, freshmanexperience programs, academic bridge programs, and counseling (Michael, Dickson, Ryan, \& Koefer, 2010).

Mentoring relationships. One way in which to help first-year students learn how to balance is through a scaffolding method (Michael, Dickson, Ryan \& Koefer, 2010; Mulvey, 2008). Through this method a mentor, sometimes in the form of an instructor, assists students in learning how to navigate through their first year of college. Most specifically, scaffolding helps students learn how to achieve their goals while learning to control frustration (Michael et al., 2010). The application of mentoring programs in postsecondary institutions has demonstrated that mentoring relationships in an academic setting can be a retention and enrichment strategy (Jacobi, 1991). Although there is not a widely accepted definition of mentoring, there are some 
accepted commonalities concerning this relationship found in the relevant literature (Crisp \& Cruz, 2009; Jacobi, 1991).

Mentoring relationships are helping relationships focused on the achievement of the protégé (Jacobi, 1991). These relationships typically include emotional support, professional and career development, and role modeling (Blickle, Schneider, Meurs, \& Perrewe, 2010; Crisp \& Cruz, 2009; Jacobi, 1991). Mentors help mentees transition through learning experiences while providing consistent support so the protégé does not feel alone or abandoned (Hodges, 2009; Roberts, 2000). Essentially, mentors act as role models and advocates in the professional arena in which they have experience (Hodges, 2009). As advocates, mentors should be passionate, flexible, risk-takers, patient, and persistent (Chaskes \& Anttonen, 2005). Mentorships are personal and reciprocal relationships as mentors derive a sense of satisfaction from their role (Crisp \& Cruz, 2009; Jacobi, 1991).

Mentoring relationships can come about naturally or through a more planned formal process (Crisp \& Cruz, 2009; Roberts, 2000). The primary difference between these two types of mentoring relationships is that planned mentoring tends to have a more formal relationship where there is another component in the relationship, the organization (Roberts, 2000). Unlike natural mentoring relationships, planned mentoring may lack a goodness-of-fit between the mentor and protégé, which can result in a less than successful relationship (Roberts, 2000). However, natural mentoring requires more effort on the part of the potential protégé in identifying and connecting with a mentor, which can be difficult for some individuals and lead to no mentoring (Blickle et al., 2010; Jacobi, 1991; Roberts, 2000). Both natural and planned mentoring relationships are common in several areas of higher education including business, engineering, and nursing (Crisp \& Cruz, 2009). 
For nearly two decades, one of the most pertinent questions about the role of mentoring in academic settings is whether mentoring relationships can improve academic success (Jacobi, 1991). Unfortunately, there has been little research done to answer this question and many of the research studies that have been conducted have methodological issues that undermine their results (Brittian, Sy, Stokes, 2009; Crisp \& Cruz, 2009; Jacobi, 1991). There appears to be some indirect support that contact with faculty and staff contributes to academic success (Jacobi, 1991; Mulvey, 2008; Pascarella \& Terenzini, 1991; Pascarella \& Terenzini, 1995), while there are other studies that find mentoring relationships to be an inefficient strategy for producing academic success (Jacobi, 1991). Research has shown that mentoring in academia has a positive impact on adjustment for college students (Jacobi, 1991; Larose, Bernier, \& Soucy, 2005). Specifically, informal contacts between students and faculty outside of the classroom may improve academic performance, life satisfaction, retention, and career goals (Larose et al., 2005). It appears that these relationships between students and faculty help to increase students' integration into the university environment, which in turn affects their performance in the academic environment (Jacobi, 1991; Tinto, 1991).

While there is a lack of consensus on the definition of mentoring, there tends to be more agreement on the characteristics of an effective mentor. Jacobi (1991) compiled definitions of mentors from various scholarly publications from higher education journals and found that many authors agreed that mentors provide guidance, professional socialization, support, nurturance, and advising information with the overarching goals of development and refinement of professional skills, success, and insight. These characteristics were echoed in an updated review of mentoring relationship literature (Crisp \& Cruz, 2009). Mentors do not necessarily have to be faculty members but can also include staff and peers as long as the integrity of the relationship 
maintains that the protégé is guided by the knowledge and experience of the mentor (Crisp \& Cruz, 2009). In postsecondary institutions, these relationships typically last nine months, or one academic year (Jacobi, 1991). There is no direct evidence that longer mentor relationships produce better results than shorter ones (Jacobi, 1991).

The literature regarding mentorships in postsecondary education has shown that matching for gender may help in establishing and maintaining the relationship especially with women (Blickle et al., 2010; Jacobi, 1991). Women may feel that they are unable to find appropriate mentors, fear rejection when initiating contact with potential mentors, and fear sexual misinterpretation from men when initiating contact with potential mentors (Blickle et al., 2010). Regarding matching of mentor and protégé for ethnic minorities, research has demonstrated that some ethnic minority students, specifically African American students, demonstrate higher rates of retention when matched with African American mentors (Brittian et al., 2009). The larger picture has shown that cross-ethnic and cross-gender mentoring relationships are effective, but many programs continue to match mentees with mentors from their own ethnicity and gender (Jacobi, 1991). In some cases, matching may not be feasible or possible. Regardless, mentoring relationships can help students succeed academically and personally.

First-year experience programs. Over the past 25 years, there has been a lot of attention given to the first year of college, specifically in the area of strategies to help first-year students (Meyer, Spencer, \& French, 2009; Upcraft, Gardner, \& Barefoot, 2005). Several postsecondary institutions have programs specifically designed to help at-risk students do well their first year (Carter \&Davarias, 2010; Stephens, 2001). Currently, the first-year experience is firmly entrenched in most postsecondary institutions as evidenced by initiatives to help these students succeed, closer collaboration between academic affairs and student affairs, valid assessment 
studies that demonstrate the efficacy of first-year experience initiatives, and substantial funding for first-year experiences (Upcraft, Gardener, \& Barefoot, 2005). However, there are a multitude of problems and challenges within this area including no clear sense of purpose in many firstyear programs, poor academic success rates among first-year students, lack of responsiveness of first-year programs to today's diversity, lack of priority given to the first year on some campuses, disintegrated institutional efforts and competing institutional priorities, and the emphasis on retention rather than student learning (Upcraft, Gardener, \& Barefoot, 2005).

Many institutions utilize first-year experience programs to assist with integrating students into the university environment and atmosphere (Upcraft, Gardner, \& Barefoot, 2005). These programs may assist with teaching students how to use college resources as well as improve their cognitive skills and academic behaviors. Some first-year experience programs are catered toward special populations such as particular majors or demographic groups. One first-year experience program used by the Brooklyn College, City University of New York, called Search for Elevation Education and Knowledge (SEEK), has found success by providing remedial and supplemental services along with academic support to students from poor academic and economic backgrounds (Carter \& Daraviras, 2010). The SEEK program familiarizes students with campus resources, provides clear goals for assignments, opportunities for peer review and revisions, and opportunities to participate in the intellectual life of the college (Carter \& Daraviras, 2010). The faculty is encouraged to be role-models for these students and in many cases mentor relationships form. In addition to helping students do well academically, this program appears to foster self-efficacy in students who might not have felt competent as college students when entering Brooklyn College (Carter \& Daraviras, 2010). First-year experience programs like SEEK create an environment where student persistence is bolstered by integrating 
students into the campus environment and providing students with mentors who help them navigate through their first year. Next, I will explore the literature surrounding the mentoring relationship and its affect on college students.

West Virginia University's TEAM program. West Virginia University (WVU) has a program similar to the SEEK program called TEAM, which is an acronym for Teach, Empower, Advise, and Mentor. This program is the only one at WVU that is designed specifically for atrisk first-year students. TEAM is a year-long program designed to provide additional support to first-year students who did not meet at least one of the admission criteria regarding aptitude test scores and high school grade point average (HSGPA) for the university. This university's admission criteria for in-state resident students is a minimum HSGPA of 2.0 and either a composite ACT score of 19 or combined Math and Critical Reading SAT score of 910 (West Virginia University, 2011). Incoming nonresident students are held to the criteria of at least a 2.5 high school GPA and either a composite ACT score of 21 or a combined Math and Critical Reading SAT score of 990 (West Virginia University, 2011).

Like other institutions of higher learning, West Virginia University utilizes a system known as the IR level to identify incoming first-year at-risk students. The IR system classifies students according to high school grade point average (HSGPA) and aptitude test scores (SAT and ACT) (Schroeder, 2010). Table 1 provides a review of the IR classification system levels. It should be noted that all TEAM students for both the 2011-2012 and 2012-2013 academic years are IR level 5. 


\section{Table 1}

IR Classification of Students

$\begin{array}{llll}\text { IR Level } & \text { HSGPA } & \text { ACT } & \text { SAT } \\ 1 & \geq 3.6 & \geq 26 & \geq 1180 \\ 2 & 3.5 & 22-25 & 1030-1179 \\ 3 & 3.0-3.49 & 22-25 & 1030-1179 \\ 4 & 2.75-2.99 & 21 & 990-1029 \\ 5 & \leq 2.74 & \leq 20 & \leq 989\end{array}$

Note. (Schroder, 2010); HSGPA=High School Grade Point Average; ACT=ACT aptitude test; $\mathrm{SAT}=$ Scholastic Aptitude Test

Aside from HSGPA and aptitude test scores, this university considers other factors to identify at-risk students. It is unknown by the author how these additional factors may affect the IR level assigned to students since this information could not be attained. Like many other postsecondary institutions, this university considers low SES, first-generation, English as a second language, being a non-traditional student, and physical or learning disability to be factors that can indicate potential risk (Schroeder, 2010). Additionally, weak study skills, being uncertain of reasons for attending college, being a late applicant, being from a rural area, lacking a support system, being an athlete, and not attending the first choice college are considered to be indicators that students may not perform well academically and graduate from the institution (Schroeder, 2010). Any of these characteristics alone could be enough to cause challenges for first-year students but when combined with a history of mediocre to poor academic performance as indicated by HSGPA and below average aptitude test scores students may feel overwhelmed and find themselves not succeeding during their first year. 
As a condition for acceptance into the university, TEAM students must actively participate in the program for an academic year unless they have met the requirements to be accepted into their major of choice, which would mean that the students have done well academically during their first semester. Aside from the requirements that are part of the TEAM program, students who are part of the TEAM program are equivalent to other first-year students; they live in residence halls, must take at least 12 credit hours per semester, and are encouraged to take classes toward fulfilling requirements for their desired majors. There are several conditions placed upon students in the TEAM program that are designed to promote a support network and connection with the university.

During their first semester, TEAM students must be enrolled in Orientation 110, which is a one credit hour first-year experience class equivalent to the university's general first-year experience class, WVUe 191. The instructor for the Orientation 110 class is also the advisor for all students in his or her Orientation 110 class for the academic year except for students that are able to transfer to the department of their desired major in the spring term. All Orientation 110 instructors are either full-time advisors employed by the Undergraduate Advising Services Center (UASC) or graduate students working at the UASC as part of a graduate assistantship. This arrangement provides TEAM students with a unique relationship in which they have an assigned advisor for their first year of college with whom they have weekly contact. As a general rule, no other first-year students at this institution have this arrangement where they are in constant contact with an academic advisor.

As mentioned, TEAM advisors/Orientation 110 instructors are employed through the UASC. For the 2011-2012 academic year, the TEAM staff consists of the program coordinator who is a full-time developmental advisor and does not teach a section of Orientation 110, another 
full-time developmental advisor who teaches one athletes-only section of Orientation 110, and four graduate assistants who each teach three sections of Orientation 110. Regarding the four graduate assistants, one (author of this dissertation) has been a TEAM advisor/Orientation 110 instructor for two years, two have been TEAM advisors/Orientation 110 instructors for a year, and one is new to both TEAM and advising but has experience working in academic services at this university. For the 2012-2013 academic year, the program staff consisted of the same program coordinator and the same full-time advisor who teaches the athletes-only section of Orientation 110, and four graduate assistants. Of the graduate assistances, one has been a TEAM advisor/Orientation 110 instructor for 3 years, one for 2 years, and two are new to the TEAM program. The author of this dissertation was not part of the TEAM program for the 2012-2013 academic year. Graduate assistants volunteer to participate in the TEAM program and understand that in addition to advising they are required to teach and mentor at-risk students.

Additionally, TEAM students are required to declare their major as General Studies in order to ensure that their advising center is the UASC and not another college or department within the university. Keeping all TEAM students advised in the UASC makes sense, as the program itself is part of this center and it prevents confusion and potential conflicts with other colleges and departments. While all TEAM students must be classified as General Studies, they are encouraged to work toward the requirements for their desired majors and all efforts are made by TEAM staff to enroll students into classes specific to their major in the fall and spring semesters of the first year.

As mentioned earlier, TEAM students are required to take Orientation 110 their first semester at the university. For the vast majority of students this occurs during the fall semester; however every year a small number of students are admitted as first-year students into the 
TEAM program during the spring semester. For the 2011-2012 TEAM students, there was strong encouragement for them to enroll in a section of Orientation 293M taught by their TEAM advisor/Orientation 110 instructor in the spring semester if they were on academic probation, which occurs for any student with a cumulative GPA below a 2.0. If students are not able to enroll in this class, they are mandated to enroll in one of several other academic probation classes. Orientation 293M and the other academic probation classes are designed to help increase study skills and motivation so that these students can increase their GPA. This was not an option for 2012-2013 TEAM students due to changes in the program that will be detailed below.

Another requirement of the TEAM program is that students are not allowed to join fraternities or sororities during their first semester, but may join their second semester provided they earn a cumulative GPA of 3.0 or higher. This stipulation is designed to protect TEAM students from overloading their first semester with too many extracurricular obligations, as well as to serve as an incentive to do well their first semester. TEAM students are required to meet with their TEAM advisor/Orientation 110 instructor for a 15-minute meeting outside of class time during the first month of the semester. This provides both the TEAM advisor/Orientation 110 instructor and students with an opportunity to make contact outside of the classroom and begin to form the advising and mentoring aspect of their relationship. During this meeting students are encouraged to disclose any potential threats to academic success, adjustment issues, or general problems and schedule their Fall Advising Workshop, which is required of all firstyear undergraduate students advised by the UASC. This meeting provides one of the first out-ofclassroom points of contact for the student and his or her advisor, which can help facilitate institutional integration. 
Another component of the program is that TEAM students are required to schedule midterm meetings with their TEAM advisor/Orientation 110 instructor if they have two or more midterm reports (cumulative grades of $\mathrm{D}$ or $\mathrm{F}$ ) in their classes. At this institution, instructors for all classes must submit mid-term grades and students receive a mid-term report for any class in which they have a D or F. TEAM advisors/Orientation 110 instructors receive notification of mid-term grades for all of their students and know which students are not doing well in which classes. If a student neglects to schedule a mid-term meeting, points are deducted from his or her Orientation 110 grade. During this meeting TEAM advisor/Orientation 110 instructors and students work together to create a plan of action to help the student bring up failing grades. This is another mandatory point-of-contact built into the TEAM program that is not necessarily provided to other first-year students.

Changes to TEAM program. During the summer prior to the 2012-2013 academic year, two significant changes were made to the TEAM program with the intention of increasing the students' academic performance during their first semester and retention rate at WVU. The first change was that all TEAM students were to be enrolled in a specially designed section of EDP 101, which is a three credit hour study skills class. Each section of Orientation 110 was assigned a specific section of EDP 101. This ensured that the Orientation 110 instructors could have open communication with the EDP 101 instructor regarding the performance of his or her students. As previously mentioned, TEAM students who earned below a 2.0 GPA after their first semester were strongly encouraged to enroll in a study skills class during their spring semester. Unfortunately, TEAM students could not be required to enroll in a study skills course for the spring semester and often many would not. In worst case, the second semester resulted in continued lackluster academic performance and, in some cases, academic suspension and loss of 
financial aid. Another serious concern was that taking a study skills course after academic failure did nothing to prevent academic problems. Allowing students a semester to use the study skills they employed during high school may continue to reinforce poor and ineffective study habits. This change was made in an attempt to be proactive rather than reactive and place the students, who are at-risk to begin with, in the best position to begin their college careers utilizing good study skills and habits.

The second change was that students who fell below the suspension GPA after the fall semester were suspended rather than waiting until the end of the spring semester. The suspension GPA guideline is based on credit hours and the majority of TEAM students are enrolled in 13-16 credit hours for the first semester. This places the suspension cut-off at 0.90 . While this was always part of the TEAM program guidelines, this rule had not been enforced. Perhaps many believed that the TEAM students would benefit from a second chance at improving their GPA during the spring semester. However, it was determined by the program coordinator and the head of the UASC that enforcing this rule might be beneficial. One could argue that given the first change to the TEAM program, mandatory enrollment into EDP 101, along with the other requirements of the program provide an environment meant to nurture and ensure academic success. Students who fail to earn above a 0.90 GPA after being giving the various advantages afforded to them via the TEAM program may not be ready for college at this time. Perhaps allowing them to continue for another semester may do more harm than good as they are accruing additional financial debt, potentially lowering their GPAs, which could take many semesters of good academic performance to undo, and negatively affecting well-being and selfesteem. 
I have addressed common reasons students do not persist with their education and leave institutions and institutional integration in general and specifically in first year-experience programs and mentoring relationships in the second half of this dissertation. The question for this dissertation arises from the foundation that this literature review has explored. At many four-year institutions' underprepared students are regularly admitted despite being at high risk for doing poorly, which is typically measured by grade point average and retention rates. For the past few decades the literature in the area of student persistence and departure has shown that the construct of institutional integration can be vital in the success of all college students such that those who are more integrated into the college environment have higher grade point averages and graduate from that university. Is this true for at-risk students? The answer is assumed to be that this is true for at-risk students but there has been little research specifically with this population, although there is evidence supporting this for first-generation college students and minority college students.

\section{Research Question and Hypothesis}

This leads to my research question: is the level of institutional integration predictive of success for at-risk first-semester college students? Specific to this research, at-risk college students are those who are part of the TEAM program at a large four-year institution in the midAtlantic region. All students who are part of the TEAM program are classified as high-risk students. The infrastructure of the TEAM program provides a basic level of institutional integration that other first-year students at this university do not regularly receive, which includes consistent interaction with a faculty member (i.e., TEAM advisor), consistent interaction with peers that serve as a cohort (i.e., students with each other in their Orin 110 and EDP 101 classes), and faculty concern as TEAM advisors regularly spend time with their 
students outside of the classroom. Many TEAM students take advantage of the program's infrastructure and become more integrated into the university environment while other TEAM students do not, which provides a natural comparison group design regarding institutional integration. Until now, this has not been investigated and I am interested if the level of integration is predictive of success for these students after their first semester.

As previously defined, institutional integration is the combination of students' academic and social integration into the institution's environment (Pascarella \& Terenzini, 1980; Tinto, 1975). Pascarella and Terenzini designed their Institutional Integration Scale (IIS) as a multidimensional instrument to assess the components of Tinto's model of student persistence and departure (Pascarella \& Terenzini, 1980; Tinto, 1975; Tinto, 1993). Tinto hypothesized that academic integration is measured by academic performance and level of intellectual development and social integration is reflected by the quality of peer and faculty interactions (Tinto, 1975). The IIS yields five subscales: peer-group interactions, interactions with faculty, faculty concern for students, academic and intellectual development, and institutional and goal commitments (Pascarella \& Terenzini, 1980). The subscales of peer-group interactions and interactions with faculty are believed to represent Tinto's social integration while the subscales of faculty concern for students, academic and intellectual development, and institutional and goal commitments are believed to represent Tinto's academic integration (Pascarella \& Terenzini, 1980); however, there has been some evidence that interactions with faculty play a role in academic and intellectual development so this subscale may also tap into academic integration (French \& Oakes, 2004). Overall, the IIS does a good job at discriminating between students who will persist with their education and those that will depart (French \& Oakes, 2004; Pascarella \& Terenzini, 1980). The literature has found that goal commitment and faculty 
interactions are essential components of institutional integration for successful retention in college (Chickering \& Reisser, 1993; Schroder, 2010, Tinto, 1993). This is not meant to suggest that the three other components measured by the IIS are not important elements of institutional integration but that students report that they are most likely to persist in college when they are committed to their goal and have relationships with faculty members. However, only the interaction with faculty members subscale has demonstrated relationships with increased ability to choose a vocation or major and increased mental well-being.

Once again, successful completion of college often requires more than academic knowledge and skills; students need non-cognitive constructs to persist (French \& Oakes, 2004). Involvement in academic life via faculty contact often leads to the greater acquisition of knowledge and development of skills, which benefit academic pursuits (Pascarella, 1980; Tinto, 1975; Tinto, 1993). Frequent and meaningful interactions between students and faculty help to foster purpose, which also aids in selecting a major or career (Chickering \& Reisser, 1993; Pascarella, 1980; Tinto, 1993). This relationship is so powerful that even one relationship with a faculty member may offset any negative effects of social isolation, which can lead to poor academic performance as well as poor mental well-being (Tinto, 1993). In short, students' perception that they are engaged and involved in the campus community is essential for academic success and persistence (Tinto, 1993). One of the primary benefits of the TEAM program is that students are placed in the position to develop a relationship with a faculty or staff member because their FYE teacher is also their academic advisor. These students must maintain contact with this faculty or staff member outside of the classroom at least once a semester per their contract and many students have multiple interactions outside the classroom with teachers/advisors. 
For the purpose of this dissertation, and based on a review of the literature involving success in college from the perspective of students, I define success as cumulative grade point average (CGPA), overall mental well-being, and ability to choose a career or vocation. This definition of student success moves beyond the traditional view of college success held by institutions, which narrowly focuses on retention and CGPA. A CGPA of 2.0 is consistent with most university policies for students to be in good academic standing and is interpreted as a level of academic success. Consistent with Chickering's theory of student development positive mental well-being, which involves the ability to use coping mechanisms and the absence of chronic mental health issues like depression and anxiety, and ability to choose a vocation are areas in which first semester college students can demonstrate a level of success. Also, high levels of mental well-being and the ability to choose a vocation are correlated with persistence in college (Tinto, 1993).

Positive mental health is the foundation by which individuals are able to function in their community, realize their abilities, cope with stressors, and work productively (Tennant et al., 2007). In the literature the terms "positive mental health" and "mental well-being" are used interchangeably (Tennant et al., 2007). For the purpose of this dissertation, I will use the term mental well-being as it is the term used by the creators of the instrument I used to measure this construct. Mental well-being is now largely accepted as covering the perspectives of the subjective experience of happiness and life satisfaction (hedonic perspective) and good interpersonal relationships (eudemonic perspective) (Ryan \& Deci, 2001). The eudemonic perspective includes the capacity for self-development, positive relations with others, autonomy, self-acceptance and competence (Ryan \& Deci, 2001), which are consistent with Chickering's theory. 
It should be noted that well-being is not the absence of mental illness, but rather its own construct (Ryan \& Deci, 2001; Seligman \& Csikszentmihalyi, 2000). Evidence has indicated that well-being is probably best conceived as a multidimensional phenomenon that includes aspects of both the hedonic and eudemonic concepts (Ryan \& Deci, 2001). Ultimately, the two concepts of hedonic and eudemonic well-being work together to help protect individuals from the stressors of daily life as well as more dramatic life events (Ryan \& Deci, 2001). Well-being is seen as "an array of positive aspects of functioning that are promoted by attainment of strong attachment relationships, acquisition of age appropriate cognitive, interpersonal, and coping skills, and exposure to environments that empower the person" (Ryan \& Deci, 2001, p. 161).

Research on emotions and well-being has found that in general people experience emotions regularly and consistently, affect is typically easily judged by the person experiencing the emotion as positive or negative, and most people report having positive affect most of the time (Diener \& Lucas, 2000). There is also research linking the Big Five Personality Traits with well-being (Costa \& McCrae, 1992; Deiner \& Lucas, 2000). The traits of high extroversion, high conscientiousness, and low neuroticism have been linked to the eudemonic dimensions of selfacceptance, mastery, and life purpose while high openness to experiences was shown to correspond with personal growth (Schmutte \& Ryff, 1997). Higher levels of agreeableness and extroversion have been correlated with positive interpersonal relationships and low levels of neuroticism have been correlated with autonomy (Schmutte \& Ryff, 1997).

Specific to college students, Chickering considered well-being to be evident when students worked toward achieving competencies in the seven vectors (Chickering, 1980; Chickering \& Reisser, 1993). Recall that conditions for growth in the competencies require overcoming challenges and growth brings with it awareness, skill, confidence, and stability in 
that area (Chickering \& Reisser, 1993). The hedonic concept that includes happiness and life satisfaction, which can be achieved by managing emotions, developing competencies, and developing a purpose while the eudemonic concept can be achieved by moving into interdependence, developing mature interpersonal relationships, developing competencies, and developing an adult identity (Chickering \& Reisser, 1993; Ryan \& Deci, 2001; Tennant et al., 2007). Thus, the Warwick-Edinburgh Mental Well-being Scale (WEMWBS) may also provide some indication of how well students are traversing through Chickering's vectors. Chickering and Reisser (1993) hypothesized that growth in the vectors would result in better awareness, skills, and stability, which may be influenced by and influence mental well-being.

I have chosen to utilize the Warwick-Edinburgh Mental Well-Being Scale, as it was designed to measure both the hedonic and eudemonic concepts of well-being (Tennant et al., 2007). The psychometric properties of this instrument will be described in Chapter 2 but it is important to be aware that this instrument was normed on a college population (Tennant et al., 2007). Research on the area of well-being suggests that it is a fairly stable construct that is influenced by life circumstance (Ryan \& Deci, 2001; Seligman \& Csikszentmihalyi, 2000). Measuring well-being will give an overall picture of how well the students are coping with the stressors of college.

I am interested in these students' ability to choose a career or vocation and how this is affected by their level of institutional integration. As previously discussed, there is a positive relationship between commitment to attaining a degree for a specific vocation and persistence in college (Tinto, 1993). Furthermore, persistence in college is strongly affected by the amount of integration into the school environment by the student (Tinto, 1993). Adding to this is the relationship between institutional integration and choosing a vocation such that students who are 
more connected with faculty and staff at a university often note it is easier to choose a major (Chickering \& Reisser, 1993; Pascarella, 1980). As noted in theories by Chickering (Chickering \& Reisser, 1993) and Super (1983) first-year students, especially first-semester students, are not expected to have a strong career commitment since it is developmentally appropriate for them to use this time to explore various areas that interest them. While students will probably have budding vocational goals when entering college new interests and unanticipated challenges may make original vocational goals obsolete. It is, however, important that these students have the skills and ability to explore various vocational areas in order to move closer to choosing a career or vocation. Also, vocational aptitude is strengthened by intellectual competence, which often increases with age and progression through academia (Chickering, 1980). For these reasons, I have chosen to measure the career decision self-efficacy by using Taylor and Betz's Career Decision Self-Efficacy Scale. For construction of the original scale, the authors applied the theoretical framework of Bandura's self-efficacy theory to Crites' (1978 as cited in Taylor \& Betz, 1983) model of career maturity. Self-efficacy theory suggests that one is able to perform a task better if one believes that she or he has the capability to perform that task (Bandura, 1977). Self-efficacy affects both performance and persistence such that even difficult tasks are more likely to be mastered if the individual believes that she can complete the task well (Bandura, 1977). Bandura (1977) discussed four sources through which self-efficacy expectations are learned. These include performance accomplishments, vicarious learning or modeling, verbal persuasion, and emotional arousal. Many of these sources can be provided through institutional integration, specifically a first-year experience class. In fact, several first-year experience classes are structured so that the students are taught how to explore various careers and majors, how to construct a resume, and how to interview for jobs, all of which can provide opportunities for 
performance accomplishments, vicarious learning, and verbal persuasion while decreasing anxiety. Taylor and Betz have extended Bandura's concepts to career-related behaviors and career development issues.

Crites' model provided the framework in which to operationalize the skills required in career decision-making. Crites' theory postulated that effective career decision-making requires competence in the career choice areas of accurate self-appraisal, gathering occupational information, goal selection, making plans for the future, and problem solving. Taylor and Betz used self-efficacy as the competence to navigate through Crites' five career choice areas (Betz \& Taylor, 2006). As such, the Career Decision Self-Efficacy Scale (Taylor \& Betz, 1983) measures "an individual's degree of belief that he/she can successfully complete tasks necessary to making career decisions" (Betz \& Taylor, 2006, pp. 6-7).

Research question. Is institutional integration predictive of success for at-risk firstsemester college students regarding fall grade point average, mental well-being, and career decision self-efficacy?

Hypothesis. Based on the literature in this area, I hypothesize that institutional integration will be predictive of the success of TEAM students during their first year. This is an exploratory study so I am attempting to see which specific sublevels of institutional integration are more predictive of some or all of the criterion variables. 


\section{Chapter 2}

\section{Method}

The purpose of this research was to investigate to what degree, if any, the five elements of institutional integration (i.e., peer-group interactions, interactions with faculty, faculty concern for student development, academic and institutional development, and institutional and goal commitment) were predictive of success (i.e., grade point average, career decision-making selfefficacy, and mental well-being) in a population of at-risk first-year students. Originally, this research was designed so that data collection would occur at the end of the fall 2011 semester from the 2011-2012 TEAM cohort. However, there was an unexpected delay in attaining IRB approval that semester as well as a poor response rate. As such, the first data collection did not achieve the minimum number of completed survey sets required for adequate statistical power for the canonical correlation. As will be detailed in the Results section, this data were analyzed and did not yield statistically significant results.

The researcher and her dissertation committee decided to collect data in fall 2012 from the 2012-2013 TEAM cohort with the hope of collecting at least 100 completed survey sets, which would yield good statistical power. Data from the two collection phases was not aggregated for analysis because of the previously detailed changes in the TEAM program for the 2012-2013 academic year. The 2012-2013 TEAM program required participation in a study skills class during the fall semester in order to increase the students' study skills and academic performance. Additionally, these TEAM students are now eligible to be suspended after the fall semester if they do not earn a GPA above the suspension criterion based on earned credit hours. These two changes were made to the TEAM program in order to improve academic skill and 
motivation to perform, which creates a different environment for the 2012-2013 TEAM cohort. As a result, it would be inappropriate to aggregate the data.

\section{Participants}

For both data collection phases of this research, participation was offered to all TEAM students. In both the spring and fall data collections, all TEAM students, 296 and 225 respectively, were emailed invitations to participate in this research. These students were firstyear students who were part of the TEAM program at a large public land grant, four-year institution located in the Mid-Atlantic region of the United States. The characteristics of the TEAM program were described in detail in Chapter 1.

This university typically enrolls approximately 29,000 students with $76 \%$ of enrolled students being undergraduates and 14\% being graduate students (West Virginia University, 2011). Approximately 52\% of undergraduate students are West Virginia residents and $48 \%$ are non-residents. Additionally, within the undergraduate population, $52 \%$ are male and $48 \%$ are female (West Virginia University, 2011). The incoming first-year cohort for the 2011-2012 academic year was 5,022 students ("WVU enrollment rises," 2011) and for the 2012-2013 academic year was 5,200 students ("WVU's largest freshman class,” 2012).

Participant characteristics for spring 2012 data collection. Sixty students participated in the first data collection. Data were incomplete for five participants, which meant that only data from 55 survey sets could be analyzed. The complete demographic information is presented in Table 2. For this data collection, the respondents' ages ranged from 18 to 20 with the majority of students identifying as being 18 years old. With regards to ethnicity, $70 \%$ of the participants identified as being Caucasian. There were slightly fewer male respondents. Most students 
reported not being employed and living in a WVU residence hall. Only $34 \%$ indicated that they were first-generation college students but 90\% reported being non-West Virginians.

\section{Table 2}

Frequency and Percent Statistics for Demographics of Spring 2012 Participants

Demographic

Age
18
19
20

Ethnicity

Caucasian

Hispanic

African American

Indian

Asian

Gender

Male

Female

Employment

Employed

Unemployed

Residence

Dormitory

Off Campus

$1^{\text {st }}$ Generation

Yes

No

Residence

West Virginia

Out-of-State

Frequency Percent

100.0

58.2

38.2

03.6

$2 \quad 03.6$

$55 \quad 100.0$

$39 \quad 70.9$

$2 \quad 03.6$

$12 \quad 21.8$

$1 \quad 01.8$

101.8

$55 \quad 100.0$

$26 \quad 47.2$

$29 \quad 52.7$

$55 \quad 100.0$

$12 \quad 21.8$

$43 \quad 78.1$

$55 \quad 100.0$

$52 \quad 94.5$

$3 \quad 05.5$

$55 \quad 100.0$

$19 \quad 34.5$

$36 \quad 65.4$

$55 \quad 100.0$

$5 \quad 10.0$

$50 \quad 90.0$ 
Participant characteristics for the fall 2012 data collection. For the fall 2012 data collection, 179 students completed at least a portion of the survey set. Twenty-one survey sets were discarded for various reasons: completed by a non-TEAM student $(n=1)$, incomplete survey sets $(n=6)$, and two survey sets completed by the same participant $(n=14)$. In all of the cases where participants completed multiple survey sets, the survey set that was completed and submitted first was kept for analysis and the second survey set was discarded. One hundred and fifty-eight survey sets were used in the statistical analyses and their demographic information is presented in Table 3. For these participants, three did not disclose their age $(n=155)$, and the age distribution was 18 to 22 years old with the majority of students reporting that they were 18 years of age. Similarly to the spring 2012 sample, most respondents endorsed being Caucasian.

More males participated in this research. Sixteen participants reported employment and 25 reported living off-campus. Forty-one percent of the respondents identified as being firstgeneration students and only 19\% indicated that they were West Virginia residents.

\section{Table 3}

Frequency and Percent Statistics for Demographics of Fall 2012 Participants

\begin{tabular}{lrr} 
Demographic & Frequency & Percent \\
\hline Age & & \\
18 & 155 & 100.0 \\
19 & 107 & 69.0 \\
20 & 47 & 30.3 \\
21 & 0 & 00.0 \\
22 & 0 & 00.0 \\
& 1 & 0.65 \\
Ethnicity & 158 & 100.0 \\
Caucasian & 108 & 68.4 \\
Hispanic & 10 & 6.3 \\
African American & 28 & 17.7 \\
Asian & 6 & 3.8 \\
Other & 6 & 3.8
\end{tabular}




$\begin{array}{lrc}\text { Gender } & 158 & 100.0 \\ \text { Male } & 92 & 58.2 \\ \text { Female } & 66 & 41.8 \\ & & \\ \text { Employment } & 155 & 100.0 \\ \quad \text { Employed } & 16 & 10.3 \\ \text { Unemployed } & 139 & 89.7 \\ & & \\ \text { Residence } & 158 & 100.0 \\ \quad \text { Dormitory } & 133 & 84.2 \\ \text { Off with friends } & 19 & 12.0 \\ \text { Off with family } & 6 & 3.8 \\ & & \\ 1^{\text {st }} \text { Generation } & 158 & 100.0 \\ \text { Yes } & 66 & 41.8 \\ \text { No } & 92 & 58.2 \\ \quad & 155 & 100.0 \\ \text { Residence } & 31 & 20.0 \\ \quad \text { West Virginia } & 124 & 80.0 \\ \text { Out-of-State } & \end{array}$

\section{Measures}

Demographics questionnaire. The demographics questionnaire was created for this project by the author and checked for face validity by the author's dissertation committee. It asked each participant to provide information regarding his or her age, gender, ethnicity, living location, location of origin, first year student status (i.e., they have earned less than 29 college credit hours), to confirm his or her TEAM status, employment status, and name. The participants were asked to provide their names so that the researcher could later attain the first semester GPAs to include in the analysis. It is estimated that it will take participants approximately 5 minutes to complete. Please see Appendix A for a copy of the demographics questionnaire.

Career Decision Self-Efficacy Scale-Short Form. The Career Decision Self-Efficacy Scale (CDSE; Taylor \& Betz, 1983) was administered to participants in order to quantify their belief in competency or self-efficacy to choose a career or vocation. The CDSE was originally 
created by Taylor and Betz in 1983. At this time the measurement was called the Career Decision-Making Self-Efficacy Scale but the name was change in 2006 to remove the term "career decision making" as it violated trademark of another scale (Betz \& Taylor, 2006). This assessment was designed to indicate an individual's pattern of confidence regarding career decision making competencies (Taylor \& Betz, 1983). It can be useful in identifying students who might benefit from career or academic interventions. The assessment yields five subscales: self-appraisal, occupational information, goal selection, planning, and problem solving. The selfappraisal subscale measures a student's ability to accurately appraise his or her educational and career abilities, interests, and values (Taylor \& Betz, 1983). The occupational information subscale assesses the student's ability to locate information and resources about college majors and occupations. The goal selection subscale measures the student's ability to match his or her characteristics to careers so that he or she can identify college majors. The planning subscale gauges the ability to implement education and career choices such as enrolling in educational programs, conducting job searches, and writing a resume. The last subscale, problem solving, assesses the student's ability to formulate alternative plans or coping strategies when original plans go awry (Taylor \& Betz, 1983).

The original CDSE consisted of 50-items with a 10-point Likert-type continuum response (Taylor \& Betz, 1983). In 1996, this tool was shortened to 25 items with the same 10-point Likert-type continuum response, the Career Decision Self-Efficacy Scale-Short Form (CDSESF) (Betz \& Klein, 1996; Betz \& Taylor, 2006). In 2006, Betz and Taylor adjusted the CDSE-SF in two ways: they shortened the continuum response to a 5-point Likert-type scale and replaced two questions in an effort to update the questionnaire to reflect advances in computer technology 
(Betz \& Taylor, 2006). It is this latest version of the CDSE-SF that will be used for data collection in this research project.

According to the CDSE manual, the original version was initially validated on a sample of 346 college students (156 students, 68 males and 88 females, attending a private liberal arts college and 193 students, 60 males and 130 females, attending a large state university) with both schools located in the Midwestern United States. Psychometric properties established during this time indicated that the CDSE has high internal consistency reliability with a coefficient alpha of .97 within the total group (Taylor \& Betz, 1983). Coefficient alpha reliabilities of the five subscales were as follows: Self-Appraisal $=.88$, Occupational Information $=.89$, Goal Selection $=.87$, Planning $=.89$, and Problem Solving $=.86$ (Taylor $\&$ Betz, 1983). Taylor and Betz did not find statistically significant differences in mean scores of the subscales between the two groups of students (private liberal arts college versus large state university) or between gender.

Taylor and Betz used the Career Decision Scale (CDS), developed by Osipow, Carney, Winer, Yanico, and Koschier (1980; as cited in Taylor \& Betz, 1983), to demonstrate concurrent and construct validities such that participants who were more undecided on a career or vocational choice reported less confidence in their ability to complete the tasks required to make career decisions. A stepwise multiple regression analysis was performed using the scores from the CDS as the dependent variable and scores from the CDSE and verbal and math ability as measured by ACT or SAT scores as independent variables. This analysis revealed that the total CDSE score was the strongest predictor of career indecision and accounted for $20 \%$ of the variance (Taylor $\&$ Betz, 1983). The authors then conducted an iterated principal components analysis in which the five variables (i.e., accurate self-appraisal, gathering occupational information, goal selection, making plans for the future, and problem solving) accounted for $52 \%$ of the overall variance. 
Based on these results, Betz and Taylor (2006) suggest that the CDSE measures a broad range of career decision-making skills.

Regarding the short-form version, psychometric testing was conducted on 180 college students. The Cronbach's alpha for the CDSE-SF total score was shown to be .93 (Betz \& Klein, 1996; Betz \& Taylor, 2006). The integrity of this instrument thus has not been altered by the change from a 10-point to a 5-point item response (Betz \& Taylor, 2006). The short form was developed by eliminating five of the ten items from each of the five CDSE scales such that the retained generality, having an item correlation equal to or exceeding .50 , loading on appropriate factor only, and were recommended by a split-scale analysis of the subscale structure (Betz \& Taylor, 2006).

The authors collected reported mean scores and standard deviations of scores for the CDSE-SF from a study conducted in 2001 on 603 college students by Paulsen (as cited in Betz \& Taylor, 2006). The means and standard deviations for each scale are: self-appraisal $(M=4.0, S D$ $=.64)$, occupational information $(M=4.1, S D=.64)$, goal setting $(M=3.9, S D=.73)$, planning $(M=3.9, S D=.70)$, problem solving $(M=3.8, S D=.67)$, and total score $(M=3.9, S D=.61)$. A study conducted by Smith (2001, as cited in Betz \& Taylor, 2006) found no statistical difference in means and standard deviations when conducted on 423 college students. No gender differences were observed during either the study validating the original version or the study validating the short-form version (Betz \& Taylor, 2006).

The CDSE-SF takes approximately 10 minutes to complete. The researcher converted the scale into the web-based survey so that participants completed it exactly as they would if the scale was on paper so that the integrity of the instrument was not disturbed. Participants were asked to read each statement and then choose from a 5-point, Likert-type scale the response that 
best fits. The scale runs from $1=$ "no confidence at all" to 5= "complete confidence." Please see Appendix B for this questionnaire. Scores are then tabulated to yield a total score and a score for each of the five domains (Betz \& Taylor, 2006). The sum of all the responses divided by 25 yielded the overall score (Betz \& Taylor, 2006). For the purpose of this research, only the overall score was calculated and used in the analysis.

Betz and Taylor (2006) recommended that score interpretations be based on Bandura's self-efficacy theory so that the interpretations are relative to a prediction of approach versus avoidance behavior. This means that high self-efficacy predicts approach behaviors, while low self-efficacy predicts avoidance behaviors. The authors recommended that scores of 3.5 or higher be predictive of "a willingness to approach or try the behavior in question" (p. 33), while scores below 3.0 be interpreted as "suggesting confidence inadequate for approach behavior" (p. 33).

Institutional Integration Scale. The Institutional Integration Scale (IIS) was developed by Pascarella and Terenzini (1980) in order to measure the levels of social and academic integration of college students into universities based on Tinto's model of college students' persistence. The IIS has proven to be a multidimensional measure of social and academic integration that is able to discriminate between first-year students who persist in college from those that voluntarily drop out after their first year (Pascarella \& Terenzini, 1980). Please see Appendix C for copy of this scale.

Psychometric properties of this measure were established from a longitudinal study conducted at Syracuse University for the 1976-1977 academic years (Pascarella \& Terenzini, 1980). At the beginning of the school year, 1,457 first year students completed a questionnaire designed to assess college expectations and these students were asked to complete a second questionnaire in which they were asked about the reality of their college experience in the spring 
semester. Responses for these questions were placed onto a five-point Likert-type scale (5=strongly agree to $1=$ strongly disagree). By pulling questions from these two questionnaires, Pascarella and Terenzini (1980) developed a 55-item questionnaire designed to tap the constructs of peer-group interactions, interactions with faculty, faculty concern for student development and teaching, academic and intellectual development, and institutional and goal commitments. The authors reduced the number of items to 35 by eliminating items deemed to not adequately tap into the five dimensions of Tinto's model (Pascarella \& Terenzini, 1980).

A total of 773 students provided complete data for both sets of questionnaires and were included in the study. Pascarella and Terenzini reviewed records for each of the 773 students the following fall semester in 1977 in order to determine the drop-out rate. It was discovered that 10 had been dismissed or advised to leave, and 90 voluntarily left the university. Data collected for the students who had been dismissed or advised to leave was excluded from this study. A Chisquare goodness-of-fit test was used to determine that the 763 students were representative of the first-year population regarding gender, ethnicity, college of enrollment, aptitude test scores, and cumulative GPA (Pascarella \& Terenzini, 1980).

Pascarella and Terenzini (1980) controlled for pre-college characteristics (i.e., gender, ethnicity, program of enrollment, academic aptitude scores, high school achievement ranking, number of high school extracurricular activities, expected number of informal contacts with faculty, parents' combined annual income, parents' formal education, student's highest expected degree, importance of graduating, choice in attending this university, and confidence that choosing to attend this university was the right decision), freshman cumulative grade point average, and involvement in extracurricular activities during the freshman year. The authors justified removal of the last two variables by noting that these behaviors are significant aspects 
of social and academic integration and the authors wanted to determine if their measurement has independent predictive contributions to institutional integration (Pascarella \& Terenzini, 1980). Also, the sample of 763 was divided such that two-thirds $(n=497)$ were used as a calibration sample for the following statistical analyses. The discriminant function derived from this sample was added to the raw data from the remaining $(n=266)$ in order to judge the efficiency of the function in correctly classifying students who persist and those who drop out.

The authors conducted a principal components factor analysis of the 34 items in order to determine if the items showed consistency with Tinto's model (Pascarella \& Terenzini, 1980). Thirty of the 34 items loaded into the five factors from Tinto's model and accounted for $44.45 \%$ of the overall variance. The authors later excluded the four items that did not load onto any of the factors from the measurement. The Cronboch alpha reliability for each scale is as follows: peergroup interactions $=.84$, interactions with faculty $=.83$, faculty concern for student development and teaching $=.82$, academic and intellectual development $=.74$, and institutional and goal commitment $=.71$ (Pascarella \& Terenzini, 1980). Intercorrelations among the five scales ranged from .01 to .33 with a median correlation of .23 , which suggests that the scales are assessing dimensions of institutional integration that are independent of each other (Pascarella \& Terenzini, 1980).

The authors then conducted a multivariate analysis of covariance and a stepwise discriminant analysis in order to establish predictive validity of the measurement. The multivariate analysis of covariance revealed that there was a difference between the first-year students who persisted and those who voluntarily dropped out (Pascarella \& Terenzini, 1980). The stepwise discriminant analysis was used to estimate the scales' contributions toward group discrimination and the predictive utility of each scale. The discriminant analysis correctly 
predicted persisters $81.4 \%$ of the time and dropouts $75.8 \%$ of the time in a cross-validation sample (Pascarella \& Terenzini, 1980).

French and Oakes (2004) conducted a confirmatory factor analysis on the IIS using a sample of 2,507 first semester college students in order to add to the literature about the validity of this measure. Their results suggest that this instrument is a useful tool for measuring academic and social integration in college students. Peterson (1993) used the IIS on a group 418 underprepared college students who were not only first year students and found the overall Cronbach's alpha coefficient to be .91 , social integration to be .83 , and academic integration to be .88 .

The IIS takes approximately 10 minutes to complete (French \& Oakes, 2004). Please see Appendix $\mathrm{C}$ for the questionnaire. The researcher converted the scale into the web-based survey so that participants completed it exactly as they would if the scale was on paper so that the integrity of the instrument was not disturbed. The IIS contains 30 items that make up the subscales of peer-group interactions ( 7 items), interactions with faculty (5 items), faculty concern for student development and teaching (5 items), academic and intellectual development (7 items), and institutional and goal commitment (6 items) (Pascarella \& Terenzini, 1980). Participants were asked to read each statement and then choose from a 5-point, Likert-type scale the response that best fits. The scale runs from $5=$ "strongly agree to" to $1=$ "strongly disagree to." Ten of the items are reverse scored $(5,6,7,13,14,15,21,28,29$, and 30). This scale was not constructed to yield an overall score but rather five subscale scores (Pascarella \& Terenzini, 1980). Each subscale score represents a distinct element of institutional integration and is a criterion variable. Halpin (1990) demonstrated means and standard deviations on subscale scores in 291 college freshmen as follows: peer-group interactions $(M=21.69, S D=5.00)$, interactions 
with faculty $(M=16.72, S D=4.36)$, faculty concern for student development and teaching $(M=16.29, S D=4.99)$, academic and intellectual development $(M=33.62, S D=6.65)$, and institution and goal commitment $(M=12.72, S D=2.49)$.

The Warwick-Edinburgh Mental Well-Being Scale. The Warwick-Edinburgh Mental Well-being Scale (WEMWBS) was developed by faculty from various disciplines including psychiatry, psychology, public health, and social sciences from the University of Warwick in England and the University of Edinburgh in Scotland (Tennant et al., 2007). Through the methods of reviewing the current academic literature, qualitative research with focus groups, and psychometric testing of the Affectometer 2, the WEMWBS was constructed. During the process of testing the Affectometer 2, the researchers developed a new scale by identifying items for retention from Affectometer 2 so that the new scale composed only of positively-worded items relating to aspects of positive mental health (Tennant et al., 2007). While the Affectometer 2, which was developed in 1980 in New Zealand, demonstrated good face and construct validity as well as good test-retest reliability, its high internal consistency reliability suggested redundancy, the scale appeared to be very susceptible to social desirability bias, and it was potentially too lengthy (Tennant et al., 2007).

The research panel conducted nine focus groups (three in England and six in Scotland) where a total of 56 participants were recruited from the community and deemed to be representative of that community based on gender, age, and socioeconomic status (Tennant et al., 2007). Participants were asked to complete the Affectometer 2 and then the focus group was asked to discuss concepts of positive mental health. The focus groups were taped and transcribed. The researchers then used content analysis to identify items which participants found consistently confusing or difficult to understand as well as concepts relating to mental well-being 
which participants thought should be included in the scale (Tennant et al., 2007). Then the research panel analyzed the content from the focus groups and referred to the current academic literature regarding psychological and subjective well-being to determine which questions would be included in the new scale (Tennant et al., 2007).

The final version of the WEMWBS consisted of 14 items covering both hedonic and eudemonic aspects of mental health including positive effect, satisfying interpersonal relationships, and positive functioning (Tennant et al., 2007). Individuals completing the scale are asked to tick the box that best describes their experience of each statement over the past two weeks using a 5 -point scale $(1=$ none of the time, $2=$ rarely, $3=$ some of the time, $4=$ often, $5=$ all of the time). Please see Appendix D for a copy of the scale. All items are scored positively and the overall score for the WEMWBS is calculated by totaling the scores for each item, with equal weights (Tennant et al., 2007). A higher score on the WEMWBS indicates high levels of mental well-being and the maximum score is 70 . For an adult population (18 years and older), the mean is 48.8 with a standard deviation of 6.8 (Tennant et al., 2007).

Scale testing data used to determine psychometric properties of the WEMWBS was collected from a total of 1749 participants (Tennant et al., 2007). First, 348 undergraduate and graduate student from the University of Warwick and the University of Edinburgh were asked to provide information on age, sex, and subject being studied and to complete WEMWBS and between two and four other scale each from a pool of eight different scales, which were randomly assigned to students, with WEWMBS either appearing at the beginning or end of the sequence of scales (Tennant et al., 2007). The authors used these scales to demonstrate criterion validity. The additional scales included the Positive and Negative Affect Scale (PANAS), the Short Depression-Happiness Scale (SDHS), the Short Psychological Well-being scale (SPWB), 
the WHO-5 well-being index, the Satisfaction With Life Scale (SWLS), the Global Life Satisfaction scale (GLS), the Emotional Intelligence Scale (EIS), and the EuroQol Health Status Visual Analogue Scale (EQ-5D VAS) (Tennant et al., 2007). The authors did not report how many participants completed each of these scales.

Later, data were collected from 1401 participants from the combined data from two representative Scottish population datasets, the Scottish Health Education Population Survey (HEPS) and the Well? What do you think? Survey (Tennant et al., 2007). These data were used to test the results obtained from the student sample as well as to assess whether the new scale discriminated between population groups (Tennant et al., 2007). These groups were asked to complete the WEMWBS only (Tennant et al., 2007).

The WEMWBS's test-retest reliability was demonstrated using a random sub-sample of 124 students who had completed the original scale pack. They were given the WEWMBS scale to complete one week later. The reliability at one week was $0.83(p<0.01)$ (Tennant et al., 2007). Cronbach's alpha was used to determine internal consistency. For the student sample the Cronbach's alpha was 0.89 and for the population sample it was 0.92 (Tennant et al., 2007).

Construct validity was established via confirmatory factor analysis using weighted least squares estimation from both the student and population samples to test the appropriateness of the structural equation models that specified the pre-hypothesized one-factor structure of WEMWBS using SAS statistical software (Tennant et al., 2007). The goodness-of-fit index (GFI) and adjusted goodness of fit index (AGFI), based on a correction for degrees of freedom, were assessed with their desired levels (>0.9 and > 0.8 respectively) and the Root Mean Square Error of Approximation (RMSEA) was below the desired 0.06 level, which led the authors to conclude that there was only a minimal amount of unexplained variance (Tennant, 2007). 
Criterion validity was established by using both total and item scores that were examined for floor and ceiling effects and by investigating the normality assumption using the ShapiroWilk test on both samples (Tennant et al., 2007). Correlations between scores on the WEMWBS and eight other scales were calculated using Spearman's rank correlation coefficients, using data from the student sample (Tennant et al., 2007). The authors found significant high correlations with WEMWBS: (PANAS-PA $r=0.71, \mathrm{p}<0.01$, SPWB $\mathrm{r}=0.74, \mathrm{p}<0.01$, SDHS $\mathrm{r}=0.73, \mathrm{p}<$ 0.01, WHO-5 0.77, $\mathrm{p}<0.01)$ and moderate negative correlations with the PANAS-NA $(\mathrm{r}=$ 0.54, $\mathrm{p}<0.01$ ). There were high correlations with WEWMBS (SWLS r $=0.73, \mathrm{p}<0.01$, GLS $0.53, \mathrm{p}<0.01)$ and a low to moderate correlation with the EIS and the WEMWBS $(\mathrm{r}=0.48, \mathrm{p}<$ 0.01) (Tennant et al., 2007).

Confirmatory factor analysis of the 1749 respondent population sample confirmed that the estimated factor matrix matched with the hypothesized factor matrix (Tennant et al., 2007). The GFI and AGFI were both above their desired levels (GFI = 0.91 and AGFI $=0.87$ ) and the RMSEA $=0.050$ fell below the desired upper limit (Tennant et al., 2007). A confirmatory factor analysis from the 348 respondent student sample showed adequate GFI, AGFI and RMSEA value $(\mathrm{GFI}=0.93, \mathrm{AGFI}=0.89, \mathrm{RMSEA}=0.055)$. A significant chi-squared statistic was again obtained (chi squared $=141.6, \mathrm{df}=69, \mathrm{p}<0.000$ ). From these results, both samples showed verification of the pre-hypothesized one-factor scale structure and all items loaded $>0.5$ onto the single factor (Tennant et al., 2007). Overall, the authors determined that this scale is "short, acceptable, and meaningful to the general population" in determining a measure of overall wellbeing (Tennant et al., 2007, p. 73). It is estimated that this scale takes less than five minutes to complete. While the initial norming of this instrument included college students, it has not been normed on American college students. 
Participants spent approximately 5 minutes completing this measure. The researcher converted the scale into the web-based survey so that participants completed it exactly as they would if the scale was on paper so that the integrity of the instrument was not disturbed. A total score was obtained with the expectation that the higher the score, the better mental well-being reported by the participant. The maximum score is 70 .

\section{Procedures}

As previously stated, there were two data collection phases. The first data collection phase lasted from March to May 2012 and sampled from the 2011-2012 TEAM cohort. The second data collection phase lasted from November to December 2012 and sampled the 20122013 TEAM cohort.

Procedure for spring 2012 collection. Approval from the West Virginia University's Institutional Review Board (WVU IRB) was received in January 2012. The demographics questionnaire and three surveys were created in a web-based survey system. Prior to inviting TEAM students to participate in the research, the researcher assigned each TEAM student to receive one of four survey sets in order to provide balance and counter against order effects. Each survey set contained: demographics questionnaire, Institutional Integration Scale (IIS), Warwick-Edinburgh Mental Well-Being Scale (WEMWBS), and Career Decision Self-Efficacy scale (CDSE). In each survey set the demographics questionnaire was always presented first. The order of each survey set was as follows: survey set 1=demographics, CDSE, IIS, WEMWBS; survey set 2=demographics, IIS, WEMWBS, CDSE; survey set 3= demographics, WEMWBS, CDSE, IIS; survey set 4=demographics, WEMWBS, IIS, CDSE.

The researcher then separated all TEAM students into four sections in order to determine which students would be assigned which survey set. This was done by the following procedure. 
A list was created with each TEAM student's name arranged alphabetically according to his or her last name. Beginning with the first name on the list, the researcher assigned a number of one through four repeatedly until each TEAM student's name had a number assigned to it. Then the list of TEAM students was reordered by grouping the students according to their number assignment (i.e., all those assigned number 1 were grouped together, etc.). This assigned each TEAM student to a specific survey set so those students assigned with the number 1 received survey set 1 and so forth. There were 74 students assigned to each of the four data sets.

Two-hundred and ninety-six TEAM students from the 2011-2012 cohort were sent an email (see Appendix E) on March 9, 2012 inviting them to participate in this research and informing them that completion of this research made them eligible to win one of four $\$ 25$ VISA gift cards that would be awarded after the data collection ended. Within the email was an embedded web-link to the web-based survey that connected them with their assigned survey set. The informed consent was attached to the email (see Appendix F). Once participants clicked on the web-link within the email they were directed to the survey site and able to complete the survey set in approximately 15-20 minutes. All TEAM students were sent two follow-up emails (see Appendix E). The first was sent at the end of March 2012 and the second was sent at the end of April 2012. Both follow-up emails included an attachment with the informed consent and their assigned web-link to the survey sets. The survey sets were closed and data collection ended on May 9, 2012, which was the end of the spring semester.

As previously stated, sixty TEAM students completed at least some of the survey sets and remained part of the pool eligible for winning one of the VISA gift cards. A random drawing of names produced four winners who were contacted via email and subsequently mailed a VISA gift card. Five participants did not fully complete all the surveys and their data could not be used 
for the statistical analyses. The researcher had access to TEAM students' GPAs as part of her graduate assistantship and was able to access the fall 2011 GPAs for the 55 participants who submitted complete data.

Procedure for fall 2012 collection. The approval to collect data from the 2012-2013 TEAM cohort was received by the WVU IRB in September 2012. During this IRB review, it was determined that the recruitment email sent to the participants would serve as the informed consent and that attaching one, as done in the first data collection, was redundant. Similarly to the first data collection, the demographics questionnaire and three surveys were created in a webbased survey system. As with the previous sample, four survey sets were created and are as follows: survey set 1=demographics, CDSE, IIS, WEMWBS; survey set 2=demographics, IIS, WEMWBS, CDSE; survey set 3=demographics, WEMWBS, CDSE, IIS; survey set 4=demographics, WEMWBS, IIS, CDSE. Also, as previously detailed, each TEAM student was assigned to receive one of the four survey sets. Fifty-seven students were assigned to receive survey set 1 and 56 students each were assigned to receive survey sets 2,3 , or 4 .

Two hundred and twenty-five students were contacted on November 5, 2012 via email (see Appendix G) with embedded web-links to their assigned survey sets. No monetary incentive was offered for participation during this data collection. Reminder emails (see Appendix G) were sent out on mid-November 2012 and early December 2012. The survey sets were closed and data collection ended on December 15, 2012.

Since the researcher was no longer a graduate assistant with the TEAM program, she did not have access to the participants' GPAs. After data collection ended, survey sets were reviewed and it was determined that of the 179 survey sets that were initiated by participants, only 158 could be used for analysis, one was completed by a non-TEAM student, six had incomplete data, 
and 14 were duplicate surveys. A list of the names of the 158 participants was sent to the TEAM coordinator Amy Roberts-Dixon who provided the researcher with the students' fall 2012 GPAs.

\section{Research Design}

In order to answer the research question, a correlational design was used and it was determined that a canonical correlation analysis (CCA) was the most appropriate analysis for examining the data (Kerlinger \& Pedhazur, 1973). Canonical correlation analyses are not often widely used but they are valuable in social science research that tends to ask complex questions (Sherry \& Henson, 2005; Thompson, 1984). A CCA is the most suitable statistical analysis for two reasons. First, CCAs can be employed to investigate several types of research questions including those that seek to determine the extent to which a single or set of variables can be used to explain another single or set of variables (Sherry \& Henson, 2005; Thompson, 1984), which is consistent with the research question posed in this dissertation. It is often cited as a good exploratory tool to see if sets of data are related (Sherry \& Henson, 2005; Thompson, 1984).

The second reason involves the issue that there are three criterion variables being investigated in the research question. The reader may be familiar with statistical analyses, most notably regression analyses, used to demonstrate the predictive value in one variable set with regard to a single dependent variable. A researcher could employ the use of a multiple linear regression, but this type of analysis is designed to investigate data sets with only one criterion or dependent variable. In cases such as the one found in this dissertation where there are multiple continuous predictor variables and multiple continuous criterion variables, one could conduct several multiple regression analyses; one for each criterion variable but this would increase the likelihood of Type II error (Kerlinger \& Pedhazur, 1973). As such, it was determined based on 
the research question and type of variables that a canonical correlation was the most appropriate analysis to help answer the research question.

There are five basic statistical assumptions underlying canonical correlation analyses: the relationship between any two variables is based on a linear relationship, multivariate normality, homoscedasticity, large number of cases to achieve good reliability, and an absence of mutlicollinearity (Sherry \& Henson, 2005; Tabachnick \& Fidell, 2007; Thompson, 1984). While multivariate normality it always desired since it standardizes a distribution in order to allow for the highest possible correlation between variables, CCAs are robust and can accommodate nonnormal distributions (Hair, Anderson, Tatham, \& Black, 1998). However, it is suggested to test each variable for univariate normality prior to interpreting significance (Hair et al., 1998).

Several of the basic statistical assumptions underlying canonical correlation analyses were not met for the spring 2012 data collection. While the relationship among the variables is based on a linear relationship and the predictor variables do not demonstrate multicollinariety (Pascarella \& Terenzini, 1980), the sample size was half of the minimum requirement, which damaged reliability. Also, there was an absence of multivariate normality and homoscedasticity, probably due to the low sample size.

Regarding the fall 2012 data collection, the basic statistical assumptions underlying canonical correlation analyses were mostly met (Sherry \& Henson, 2005). The sample size exceeded the minimum requirement of 100 participants. Per suggestion by Hair and colleagues (1998), univariate normality was assessed. Only the IIS subscale of institution and goal commitment demonstrated non-normal distribution, as it was bimodal. CCAs are robust and this violation of univariate normality does not eliminate the subscale from being used in the analysis (Hair et al., 1998). It should be noted that GPA demonstrated some outliers that were not seen in 
the other variables. The relevance of this will be discussed later but outliers can have an impact on canonical analysis (Tabachnick \& Fidell, 2007). Homoscedasticity was tested using linear regressions for each criterion variable and was found to be true. The predictor variables have been shown to have acceptable levels of multicollinearity (Pascarella \& Terenzini, 1980). Given that the CCA is a robust analysis and the underlying assumptions have not been grossly violated, it was determined that the data were appropriate for analysis.

The basic mechanism of the canonical correlation analysis is that by using least squares analysis two linear composites are formed, one for the predictor variables (X), and one for the criterion variables $(\mathrm{Y})$, and that the correlation between these two composites is the canonical correlation (Kerlinger \& Pedhazur, 1973). This analysis produces the maximum correlation possible between the X and Y sets of correlations (Kerlinger \& Pedhazur, 1973). The estimate of variance shared by the two composites is the square of the canonical correlation $\left(R^{2}\right)$ (Kerlinger \& Pedhazur, 1973).

In this research, the predictor variables are the five subscales of institutional integration: academic and intellectual development, peer-group interactions, interactions with faculty, faculty concern for student development and teaching, and institutional and goal commitments (Pascarella \& Terenzini, 1980). Within the analysis, these variables are combined to yield the synthetic predictor variable also known as the canonical variate from the weighed sum (Hair et al., 1998; Sherry \& Henson, 2005). There are three criterion variables: GPA, total score from the CDSE-SF, which measures career decision-making self-efficacy and a total score for the WEMWBS, which measures mental well-being. These also combine to yield a canonical variate.

Threats to validity. In any research there are several potential threats to internal and external validity. Internal validity is the extent to which the data collected is what is intended to 
be measured by the instruments and can include history (previous and concurrent), maturation of the subjects, testing order, instrumentation, statistical regression, attrition, and selection. Within this study, the threats to internal validity were determined to be history, testing order, selection, and attrition. Having a large sample size minimized history as a threat to internal validity. While it is possible that the subjects may have had experiences in their past or even during the time of testing that could skew the data, with a large sample size the effects of these outliers is minimized. Rotating the order in which participants completed the three surveys minimized testing order effects. Offering the entire population the opportunity to complete the research minimized selection. While it is possible that students with specific characteristics were more likely to participate, it is unlikely that this will greatly affect the results because of the large sample size. Lastly, having a large sample size minimized any potential effects from attrition. Additionally, the use of validated and standardized measures along with standardized collection of the data contributed to minimize internal validity threats.

External validity is the extent to which the current research can be generalized to a larger group. Threats to external validity include the extent to which the sample is representative of the population from which it was selected, extent to which the context of the study is representative of the larger context, experimenter bias, and specificity of variables. It was determined that these threats would best be minimized by having a large sample size, using standardized instruments that were normed on a college population, having an in depth understanding of the variables being researched, and by using the appropriate research design. It is the opinion of the researcher that this study has demonstrated acceptable levels of both internal and external validity.

Sample size and power. Power is dependent on the type of statistical test being used, the alpha level, the directionality of the statistical test, the size of the effect, and the number of 
participants (Heppner et al., 2008). Using an a priori analysis of power helps determine the minimum number of participants needed to achieve a specific level of power, which is important because the higher the level of power the higher the probability of finding a true relationship among the variables (Heppner et al., 2008).

As previously explained, based on the research question and the number of predictor variables and criterion variables used, it was determined that a canonical correlation analysis is the most appropriate statistical analysis (Sherry \& Henson, 2005; Thompson, 1984). Based on a standard alpha level of .05 , the standard of .80 power, which is considered to be of moderate strength, an a priori G-Power Analysis revealed that a minimum of 92 participants would be necessary (Heppner et al., 2008). This is consistent with the general rule of 20 participants for each predictor variable when conducting a canonical correlation, which would place the minimum number of participants needed for this research at 100 participants (Stevens, 1986). As described above in the Participants section, data were fully gathered from 55 participants from the spring 2012 collection, and from 158 participants during the fall 2012 collection. 


\section{Chapter 3}

\section{Results}

\section{Hypothesis}

As previously stated and based on the literature in the area of institutional integration, I hypothesized that the level of institutional integration would be predictive of success for TEAM students during their first year. This is an exploratory study so I was attempting to determine which specific domains of institutional integration are more predictive of some or all of the criterion variables for GPA, career decision-making self-efficacy, and mental well-being.

\section{Results for Spring 2012 Sample}

As discussed in the Research Design chapter, there were violations of the basic assumptions of canonical correlation analyses with this data, most significantly regarding the sample size. Although the minimum number for participants was not met, the researcher analyzed the data in order to determine if there were statistically significant results. A canonical correlation analysis was conducted using the five Institutional Integration Scale (IIS) subscale variables as predictors of the three student success outcome measures including first semester grade point average (GPA), ability to make a decision regarding career via the Career Decision Self-Efficacy Scale-Short Form (CDSE), and overall mental well-being through the WarwickEdinburgh Mental Well-Being Scale (WEMWBS) to evaluate the multivariate shared relationship between the two sets (i.e., IIS variables and student success outcome measures). The Wilks's $\lambda=.727$ criterion, $\mathrm{F}(15,130.15)=1.06, p=.399$ was not statistically significant with alpha $=.05$, which means that the null hypothesis, there is no correlation between the sets of variables, cannot be rejected. It is suspected that this may be the result of the low sample size $(n=55)$. This statistical analysis requires a fairly large sample size that was projected to be a 
minimum of 100 participants. The researcher and her dissertation committee determined that a second phase of data collection would be initiated with the 2012-2013 TEAM cohort in fall 2012. The data from the two collection phases was not combined and analyzed together. There were significant changes to the 2012-2013 TEAM program, which changed the experiences for the students between these two years. Also, the first data collection occurred during the spring semester after the TEAM students had completed a semester of school and were not as entrenched in the TEAM program (i.e., no longer receiving weekly contact with TEAM advisor/instructor). The second data collection took place at the end of the first semester while the TEAM students were still in Orientation 110 and receiving consistent contact with their TEAM advisor/instructor.

\section{Results for Fall 2012 Sample}

As previously discussed in the Research Design section, there were no gross violations of the assumptions of the canonical correlation analyses. Table 4 shows the means and standard deviations for the three measures used in this research for the fall 2012 sample. A comparison of the sample's means and standard deviations for each measure was compared to the means and standard deviations established in the literature for each measure in order to determine if this sample is comparable to the college samples reported in the literature reviews of the measures. It was determined that the results from the data collected during fall 2012 are mostly consistent with the literature and appropriate for use in this research. 


\section{Table 4}

Means and Standard Deviations of Measures for Fall 2012 sample.

Measure/Subscale

IIS/Peer-Group

IIS/Faculty Interaction

IIS/Faculty Concern

IIS/Development

IIS/Commitment

CDSE

WEMWBS

GPA
Mean

24.38

18.06

15.30

24.29

23.15

3.66

49.81

2.31
Standard Deviation

4.74

3.33

1.94

4.05

4.42

0.57

8.24

0.80

Halpin (1990) set forth the means and standard deviations for the Institutional Integration Scale for a college population. The subscales of peer-group interaction, interaction with faculty, and faculty concern means for the current sample are comparable to those set by Halpin and are not more than one standard deviation different from those provided by Halpin (1990). However, the subscales of academic and intellectual development and institution and goal commitment means for the current sample are not consistent with the means set forth by Halpin (1990). For the academic and intellectual development subscale, the mean from the current sample was two standard deviations lower. The mean from the current sample for the institution and goal commitment subscale was six standard deviations higher than that set by the Halpin sample.

There may be several explanations for these differences with the most obvious being that the Halpin study was conducted 22 years prior to the current research. The difference of two 
decades may affect how current students perceive their own academic and intellectual development as well as commitment to their goals and the institution. Also, Halpin collected data from a general sample of first year college students and the current participant pool is from a specific group of first-year students. The current participants are at-risk and may differ from the general population in these two areas of institutional integration. It should also be noted that the institution and goal commitment subscale did not demonstrate a normal distribution. Lastly, these two subscales have demonstrated the lowest reliability for the five subscales via coefficient alpha at .74 and .71, respectively (Pascarella \& Terenzini, 1980). These reliability coefficients are acceptable but not desirable (Nunnally \& Bernstein, 1994). It should be noted that the current sample has less variability on all subscales of the IIS than in the Halpin study indicating reduced spread of responses.

Regarding the WEMWBS, the mean of the current sample is comparable and within one standard deviation of the mean set by Tennant and colleagues in 2007. Similarly, the mean of the current sample for the CDSE is comparable and within one standard deviation of the mean set forth by Betz and Taylor (2006). Unlike the research that demonstrated the means in a college population for the IIS, these research studies are more recent. Overall, the three scales were found to be consistent with the literature and appropriate for use.

Canonical correlation analysis results. A canonical correlation analysis (CCA) was used to test the hypothesis that institutional integration is predictive of student success in at-risk first year college students and evaluate the multivariate shared relationship between the two sets (i.e., IIS variables and student success outcome measures). The Institutional Integration Scale subscale variables constructed the predictor variables and the three student success outcome measures, GPA, career decision-making self-efficacy via the CDSE, and mental well-being via 
the WEMWBS, constituted the criterion variables. The analysis yielded three functions with canonical correlations of $.467, .284$, and .043 , respectively, and squared canonical correlations $\left(R_{C}^{2}\right)$ of .217, .080, and .002 for each successive function. Collectively, the full model across all functions was statistically significant using the Wilks's $\lambda=.718$ criterion, $F(15,414.49)=3.53$, $p<.001$. This allowed a rejection of the null hypothesis that there is no correlation between the predictor and criterion variables. Therefore, I assert that there is a relationship between institutional integration and student success outcome measures.

The dimension reduction analysis allows for the testing of the hierarchal arrangement of functions for statistical significance. The full model (Functions 1 to 3) was statistically significant and accounts for $21.8 \%$ of the observed variance. The first function was created to maximize the canonical correlation, or Pearson $r$, between the two synthetic variables (Sherry \& Henson, 2005). Function 2 to 3 was not statistically significant, $\mathrm{F}(8,302.00)=1.66, p=.109$ and Function 3, which was the only function tested in isolation, also was not statistically significant, $\mathrm{F}(3,152.00)=.092, p=.964$. Thus, only the full model was statistically significant and will be interpreted beyond this point (Hair et al., 1998; Sherry \& Henson, 2005; Thompson, 1984).

Structure coefficients and squared structure coefficients. Table 5 presents the standardized canonical function coefficients, structure coefficients and squared structure coefficients for Function 1. The structure coefficient is the bivariate correlation between an observed variable and the synthetic variable, also known as a canonical variate, and are deemed to be of significance with a correlation of .30 or higher (Sherry \& Henson, 2005; Thompson, 1984). The squared structure coefficient is the percent of variance linearly shared by an original variable with its synthetic variable and are of interest when $30 \%$ or higher. The interpretation of the structure coefficients and squared structure coefficients will allow for a more complete 
understanding of which elements of institutional integration created the predictor and criterion variates. This is visually represented in Figure 1. It is important to remember that each canonical variate only captures a portion of the variance from its own set and the overall canonical correlation measures the relationship between the created variates.

\section{Table 5}

Canonical Solution for Institutional Integration Prediction Success Outcomes for Function 1.

$\begin{array}{llll}\text { Variable } & \text { Coef } & \mathrm{r}_{\mathrm{s}} & r_{s}^{2}(\%) \\ \text { IIS-Peer } & .414 & \underline{.77} & \underline{.59} \\ \text { IIS-FInt } & .157 & \underline{.59} & \underline{.35} \\ \text { IIS-FCon } & -.154 & .01 & .00 \\ \text { IIS-Dev } & .593 & \underline{.88} & \underline{.77} \\ \text { IIS-Comm } & .132 & \underline{.52} & .27 \\ \text { GPA } & .015 & .14 & .02 \\ \text { CDSE } & .319 & \underline{.56} & \underline{.31} \\ \text { WEMWBS } & .862 & \underline{.95} & \underline{.90}\end{array}$

Note. Structural coefficients $\left(\mathrm{r}_{\mathrm{s}}\right)$ greater than .30 are underlined. Squared structural coefficients $\left(r_{s}^{2}\right)$ greater than $30 \%$ are underlined. Coef=standardized canonical function coefficient; $\mathrm{r}_{\mathrm{s}}=$ structure coefficient; $r_{S}^{2}=$ squared structural coefficient. GPA=fall 2012 grade point average; CDSE=Career Development Self-Efficacy Scale; WEMWBS=Warwick-Edinburgh Mental WellBeing Scale; IIS-Peer=peer-group interactions; IIS-FInt=faculty interactions; IIS-FCon=faculty concern for student development and teaching; IIS-Dev=academic and intellectual development; IIS-Comm=institution and goal commitment. 
Figure 1. Model of the Canonical Correlation Analysis

Structural coefficients and the canonical coefficient.

\section{Predictor Variables}

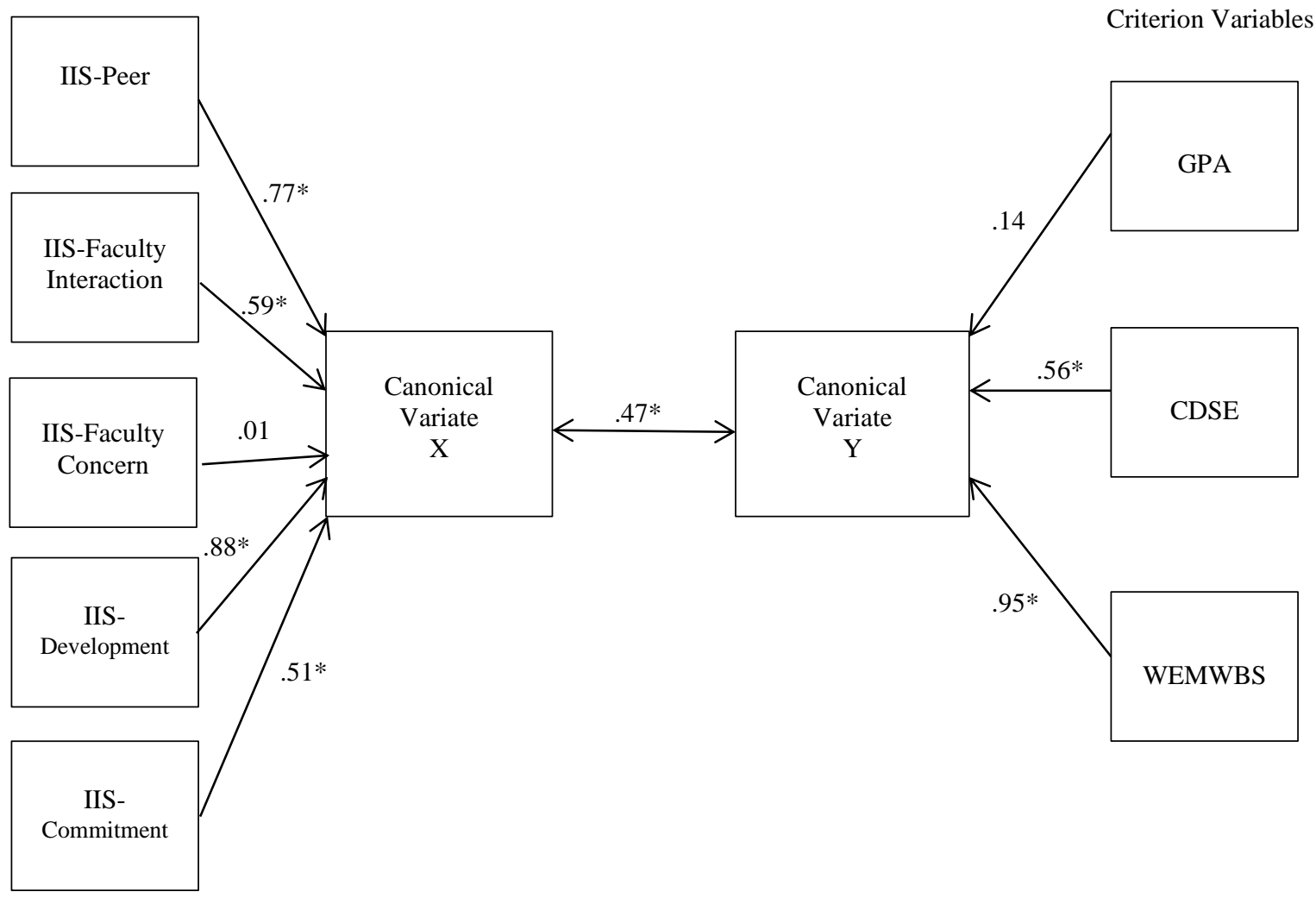

Figure 1. A visual representation of the model created by the canonical correlation analysis. Displayed are the structural coefficients that measure the correlation between the variables and their respective canonical variate. In the center of the figure is the canonical correlation, which measures the strength of the overall relationship between the canonical variates. These are Pearson's $\mathrm{r}$ correlations. Correlation above a $+/-0.30$ are indicated with an asterisk and are considered to show at least a moderate relationship. GPA=fall 2012 grade point average; CDSE=Career Development Self-Efficacy Scale; WEMWBS=Warwick-Edinburgh Mental WellBeing Scale; IIS-Peer=peer-group interactions; IIS-Faculty Interactions=nonclassroom interactions with faculty; IIS-Faculty Concern=perception of overall faculty concern for student development and teaching; IIS-Development=academic and intellectual development of student; IIS-Commitment=institution and goal commitment of student. 
Regarding the observed predictor variable set in Function 1, the institutional integration categories of peer-group interactions, interactions with faculty, academic and intellectual development, and institution and goal commitment significantly contributed to the creation of the synthetic predictor variable in Function 1 with the structure coefficients of $.77, .59, .88$, and .52 , respectively. Recall that structure coefficients demonstrate the relationship between the observed predictor variables and the synthetic predictor variable. Thus, we can see that the strongest relationships between the subscales and the created variate in order: academic and intellectual development, peer-group interactions, interactions with faculty, and institution and goal commitment. The structure coefficient of the faculty concern subscale was below the criterion of .30 at .01 with a squared structure coefficient of essentially $0 \%$, indicating that it does not contribute to the synthetic predictor variable or the model as a whole.

Regarding the squared structure coefficients for the other four IIS subscales, the academic and intellectual development subscale has the most proportion of linearly shared variance with the synthetic variable at $77 \%$. This is followed by the peer-group interaction subscale that has $59 \%$, followed by the subscale of interactions with faculty with $35 \%$. The subscale of institution and goal commitment demonstrated that only $27 \%$ of its variance is shared with the synthetic variable and this is not above the generally accepted criterion of $30 \%$ (Thompson, 1984). By averaging the squared structure coefficients of all five subscales we learn that the predictor canonical variate extracted $39.6 \%$ of the variance from the observed variables (Hair et al., 1998).

Concerning the criterion variables of CDSE, WEMWBS, and GPA, only the CDSE and WEMWBS had structure coefficients that exceeded the generally accepted criterion of .30. The structure coefficient for the CDSE was .56 and the structure coefficient for the WEMWBS was 
.95. Their squared structure coefficients are $31 \%$ and $90 \%$, respectively. This indicates that the WEMWBS shares a large portion of linear variance with the synthetic criterion variable for Function 1 while the CDSE shares a moderate portion of linear variance. The structure coefficient for GPA was .14 and the squared structure coefficient was $2 \%$, indicating that this observed variable did little to contribute to the synthetic canonical criterion variate. The shared variance among all three observed criterion variables found in the synthetic criterion variate was $41 \%$.

Redundancy index. Several statisticians (Hair et al., 1998; Tabachnick \& Fidell, 2007; Thorndike, 1978) suggest calculating the redundancy index $\left(R_{\mathrm{d}}\right)$ as an additional step when interpreting CCAs. The Stewart-Love method is most commonly used for finding the redundancy index (Hair et al., 1998; Tabachnick \& Fidell, 2007; Thorndike, 1978). This index is derived from multiplying the average of squared structure coefficients for each variable set (i.e., predictor or criterion) by the squared canonical coefficient. The redundancy index for the predictor variate is .086 and for the criterion variate, .088. This means that institutional integration explains $8.8 \%$ of variance in the outcome measures. Likewise, GPA, career decisionmaking, and mental well-being explain $8.6 \%$ of the variance in institutional integration. These are not high percentages of explained variance and indicate that there is little predictive value between these variable sets.

Beta weights. Another way to unpack the data presented in a CCA is to examine the beta weights. Similarly to regression analyses, beta weights in CCAs are calculated to weight the predictor variables so that they are maximally correlated with the criterion variables while demonstrating order of importance of the IIS variables to the contribution of the outcome 
variables (Pedhazur, 1997). Table 6 illustrates the standardized beta weights produced in the CCA.

Table 6

Standardized Beta Weights.
GPA
WEMWBS
CDSE

\begin{tabular}{lllllll}
\hline Variable & $\beta$ & $\mathrm{p}$ & $\beta$ & $\mathrm{p}$ & $\beta$ & $\mathrm{p}$ \\
\hline Peer-Group Interactions & .015 & .878 & $.178^{*}$ & .040 & .125 & .168 \\
Faculty Concern & -.024 & .792 & .056 & .495 & .080 & .357 \\
Interaction with Faculty & -.032 & .694 & -.074 & .320 & -.025 & .743 \\
Academic Development & .064 & .523 & $.329 *$ & .000 & -.023 & .803 \\
Institutional Commitment & .026 & .774 & -.027 & .745 & $.264 *$ & .002
\end{tabular}

Note. An asterisk (*) indicates $\beta$ weights where $p<0.05$.

As would be expected, none of the beta weights were statistically significant for the contribution to GPA. In examining the beta weights for the IIS variables to the WEMWBS, the subscales of peer-group interaction $(\beta=1.77)$ and academic and intellectual development $(\beta=.329)$ were statistically significant $(p<.05)$. The beta weight on academic and intellectual development indicated a moderate impact upon mental well-being while peer-group interaction had a weaker impact on the construct. Thus, students who reported being satisfied with their academic experiences and satisfied with their peer-group interactions also indicated a positive mental wellness. For career decision-making self-efficacy, only institution and goal commitment ( $\beta=.264, p<.05)$ was relevant. This indicates that having a commitment to the institution, in this case West Virginia University, graduating from the university, choosing a major, and earning 
good grades is found in students who report having the self-efficacy and ability to choose a vocation. 


\section{Chapter 4}

\section{Discussion}

This dissertation investigated the the level to which institutional integration, as measured by the Institutional Integration Scale would be predivice of success for TEAM students during their first year of college. Success was defined as academic, measured by the first semester grade point average, career-decision making, measured by the Career-Decision Self-Efficacy Scale, and mental well-being measured by the Warwick-Edinburgh Mental Well-being Scale. A canonical correlation analysis found that the Institutional Integration subscales of Academic and Intellectual Development and Peer-Group Interactions correlated with mental well-being. The Institutional Integration subscale of Institutional and Goal Commitment correlated with career decision-making. There was no significant relationship between grade point average and any of the Institutional Integration subscales.

Earning a degree from a four-year college or university is seen as a necessity for many. The benefits include higher earning potential (U.S. Department of Labor, 2010), increased job security, ability to work in technical industries (Chait \& Venezia, 2009), and prestige. Likewise, there are numerous non-work related benefits that can be gained from a college education such as having more intellectual interests, increased tolerance and appreciation for diversity, greater self-esteem, more shrewdness as a consumer, and ability to function at higher levels of intellectual, emotional, and social complexity (Chickering, 2010; Pascarella \& Terenzini, 2009). In short, many college students report that it is not an option not to attend or depart prematurely from college (Chait et al., 2009; Shultz \& Higbee, 2007).

As attending a four-year postsecondary institution has become an increased possibility and probability for many young adults, the issue of academic preparedness must be addressed, 
particularly with first-year students (Shultz \& Higbee, 2007). Unfortunately, a trend of postsecondary schools easing their admission policies has allowed access for many first-year students that may not be adequately prepared for the rigors of college (Pascarella et al., 2004). Additionally, education standards in some high schools may not be stringent enough to teach adequate cognitive strategies for success during the first year of college, leaving students with deficits that make them academically underprepared for college. These students are at-risk for not doing well academically and not graduating from the institution (Laskey \& Hetzel, 2011; Lotkowski, Robbins, \& Noeth, 2004).

Aside from not being prepared academically, there are other factors that can increase the risk of failure for college students including internal and background characteristics of the students and environmental characteristics of the institution (Bulger \& Watson, 2006). Internal characteristics such as a weak self-concept or external locus of control can engender feelings such as loneliness and self-doubt resulting in a failure to cope effectively with the stressors of college (Anderson, 1985; Bulger \& Watson, 2006). Background characteristics such as being from a low socioeconomic status (SES), coming from a single parent family of origin, being a minority ethnic status, and being a first-generation college student greatly increases the likelihood of poor academic performance, mental health issues, and institutional departure (Bulger \& Watson, 2006). Environmental factors include not utilizing institution resources, perceiving a negative campus climate, housing issues, commute issues, education costs, and not understanding the concept of a learning community (Bulger \& Watson, 2006; Lotkowski, Robbins, \& Noeth, 2004). These precollege characteristics may contribute to underpreparedness and appear to have a moderate to strong effect on retention as they can create obstacles that seem insurmountable (Anderson, 1985). 
There are many serious consequences for underprepared and at-risk students including early departure, financial debt, depression, anxiety, substance use, and stunted development as a student and adult (ACHA, 2011; Chickering \& Reisser, 1993). The consequences affect both the institution and student. Decreased retention rates affect the amount of money institutions may receive from funding sources, which in turn affect all aspects of the university community. From a student's point of view, being suspended from an institution can engender or exacerbate feelings of worthlessness, sadness, anxiety, and substance usage. In general, students who are identified as being at-risk are more likely to suffer from negative feelings of self and have mental health issues to begin with, which then increases the likelihood that they may not perform well (Barbatis, 2010; Tinto, 1993). Perhaps the most long-lasting of these consequences may be the financial burden students are left with if they depart without earning a degree. It has been shown that many jobs with good pay typically require at least some postsecondary education, which may be out of reach for those who departed college (Shultz \& Higbee, 2007). This may leave the individual with a low salary and the burden of repaying student loans.

Given the powerful consequences for both the institution and students, most postsecondary institutions have instituted initiatives to protect against these risk factors. Within the literature, this incorporation of students into the university community is known as institutional integration (Pascarella \& Terenzini, 1980; Tinto, 1975). Institutional integration can be achieved between the students and institution in five broad areas: interacting with peers, perceiving that faculty care about teaching and students, having non-classroom interactions with faculty, feeling that their intellectual growth is being fostered, believing in their choice to attend the University, and feeling committed to graduating from the University (Pascarella \& Terenzini, 1980; Tinto, 1975). 
Research in the area of student persistence and departure has found that students who feel connected to the university community and adopt the role of student tend to do better academically and graduate (Tinto, 1975, 1993). Pascarella and Terenzini (1980) suggest that the greater students' involvement in academic life, the greater the acquisition of knowledge and development of skills, all of which can lead to academic success. Frequent interactions between students and faculty help to foster purpose, which is a driving force for doing well academically and selecting a vocation (Chickering \& Reisser, 1993; Pascarella, 1980; Tinto, 1993). This has been echoed in research demonstrating that non-classroom involvement positively contributes to student success (Astin, 1993).

As postsecondary institutions seek to increase institutional integration in their students and buffer against the negative consequences of risk factors, initiatives such as first-year experience classes and mentorship programs have been utilized (Carter \& Daraviras, 2010; Meyer, et al., 2009; Upcraft et al., 2005). Over the past four decades, first-year experience classes have been utilized by many colleges and universities (Upcraft, et al., 2005). They appear to help students succeed by facilitating the academic and social integration of students into the university community (Meyer, et al., 2009; Upcraft, et al., 2005). Research has shown that mentoring in academia has a positive impact on adjustment for college students (Jacobi, 1991; Larose, Bernier, \& Soucy, 2005). It appears that these relationships between students and faculty help to increase students' integration into the university environment, which in turn affects their performance in the academic environment (Jacobi, 1991; Mulvey, 2008; Pascarella \& Terenzini, 1991; Pascarella \& Terenzini, 1995).

At West Virginia University, the TEAM (Teach, Empower, Achieve, Mentor) program is a mentorship-type first-year experience program created to assist at-risk first-year college 
students succeed academically and retain at the school. This program accepts approximately 300 students every academic year who did not meet the admission requirements for West Virginia University as evidenced by low high school grade point averages (i.e., below a 2.0) and a low aptitude score (i.e., ACT $\leq 20, \mathrm{SAT} \leq 989$ ). These criteria strongly imply that these students are underprepared for college and at-risk for low GPA and institutional departure. As with other atrisk students, TEAM students may be at a high risk for depression, anxiety, substance usage, and interpersonal concerns.

Inclusion in the TEAM program provides the students with individualized attention from a person who is both their academic advisor and first-year experience instructor. The advisor/instructor works with the same students, approximately 90, for the academic year and is able to form a more personal relationship. During the course of the first semester, students meet weekly for the first-year experience class where they learn now to identify and utilize university resources, navigate the university community, and grow into an adult identity. The TEAM program provides a higher level of institutional integration via faculty interactions. The purpose of this dissertation was to investigate the predictive value of institutional integration in the success outcome measures of GPA, career decision self-efficacy, and mental well-being in the TEAM students.

Data were gathered via web-based survey sets from the 2011-2012 TEAM cohort. Unfortunately, only 55 survey sets could be used in the data analysis, which yielded nonstatistically significant results. Thus, the null hypothesis could not be rejected. Data were collected on the 2012-2013 TEAM cohort. The data from the two collections was not aggregated for analyses because of changes to the 2012-2013 TEAM cohort that significantly changed the program. It was judged that these changes separate the two cohorts' TEAM experiences and that 
combining the results would be inappropriate. Only the data gathered from the 2012-2013 cohort of TEAM students yielded statistically significant results and is the focus for this discussion.

All 225 TEAM students were invited to participate in the web-based data collection and 179 students submitted surveys, which represents a $79.6 \%$ response rate. Attrition due to redundant surveys, non-TEAM status, and incomplete data left 158 completed survey sets to be analyzed. A canonical correlation analysis (CCA) was used to test the hypothesis that institutional integration is predictive of student success in at-risk first year college students. The analysis revealed a full model that is statistically significant with a canonical correlation of .467 and squared canonical correlation of .217. This indicates that there is a moderate relationship between the variable sets and that the canonical variates share $21.7 \%$ of the variance. These results support a conclusion that there is a relationship between institutional integration and student success outcome measures. However, there is a significant proportion of variance between the predictor and criterion variables that is not accounted for in the current model.

A review of the standardized canonical function coefficients, structure coefficients, and squared structure coefficients yielded the following conclusions. In the predictor variable set, the observed variables of academic and intellectual development, peer-group interactions, interactions with faculty, and institution and goal commitment contributed in order of most to least to the creation of the synthetic predictor variate. It was revealed that faculty concern did not significantly contribute to the synthetic predictor variable or the model as a whole. The synthetic canonical predictor variate was created using $39.6 \%$ of the variance extracted from the institutional integration subscales.

Regarding the criterion variables of career decision self-efficacy as measured by the Career Decision Self-Efficacy Scale (CDSE), mental well-being as measured by the Warwick- 
Edinburgh Mental Well-Being Scale (WEMWBS), and first semester grade point average (GPA), it was revealed that GPA did not significantly contribute to the creation of the synthetic criterion variable or the model as a whole. In reviewing the standardized canonical function coefficients, structure coefficients, and squared structure coefficients of the CDSE and WEMWBS, it was evident that the WEMWBS contributed most to the creation of the synthetic criterion variable. The shared variance among all three observed criterion variables found in the synthetic criterion variable was $41 \%$.

The redundancy index was calculated to determine the amount of variance each variable set was able to explain in the other variable set. It was determined that the institutional integration variable set explains $8.8 \%$ of variance in the outcome measures of career decisionmaking self-efficacy and mental well-being. Also, the outcome measures of career decisionmaking and wellness explain $8.6 \%$ of the variance in institutional integration. These redundancy indices are low and suggest a lack of predictive value in the model. Overall, it appears from these indices that there are other constructs that might provide better predictive value. From this information it was determined that the level of institutional integration is not predictive of GPA, career decision self-efficacy, or mental well-being in at-risk, first-year college students. However, there are relationships between elements of the predictor and criterion constructs that are noteworthy. There were significant relationships among career decision self-efficacy and mental well-being with some of the institutional integration subscales. These results may indicate that these students are moving through some of the early vectors in Chickering's (1980) theory of student development, particularly the vectors of competencies, managing emotions, and autonomy toward interdependence. 
Academic and intellectual development and mental well-being. Not surprisingly, the IIS variable of academic and intellectual development was found to have a moderate relationship with mental well-being (Chickering \& Reisser, 1993). This subscale was the top contributor to the predictor variate. This result indicates that TEAM students who report being satisfied with their academic experiences and intellectual growth during their first semester of college also reported elements of mental well-being such as optimism for the future, feeling useful, interest in others, ability to cope with problems, and feeling good about themselves.

Chickering and Reisser's (1993) research has shown that students who feel competent in intellectual areas tend to have less mental health concerns. While mental well-being is not the absence of mental health issues, higher levels of mental well-being does suggest an increased ability to deal with daily stressors and find contentment in life (Seligman \& Csikszentmihalyi, 2000). This may help students navigate Chickering's vector of managing emotions. The connection between academic and intellectual development and mental well-being likely speaks to students' transition to the role of student and acclimation to the university community.

As students integrate into universities, they are likely to do better if they understand the expectations and find ways to meet these expectations (Tinto, 1993). At WVU, the TEAM program was initiated as a means to foster academic development in at-risk students with an infrastructure to help students identify and utilize university resources. This subscale's questions tap into satisfaction with intellectual development since enrolling in WVU, positive influence on intellectual growth, satisfaction with academic experience at WVU, intellectual stimulation, increase in intellectual ideas, increased attendance of cultural events, and academic performance (Pascarella \& Terenzini, 1980). It cannot be concluded that the TEAM students have expanded their academic and intellectual development because they are part of the program. However, the 
TEAM program promotes experiences via the Orientation 110 class (first-year experience) and study skills class to influence intellectual growth, attend cultural events, and increase the likelihood of good academic performance. This may suggest that inclusion in the TEAM program can boost academic and intellectual development in students who may be less likely to succeed in this area of institutional integration.

\section{Institution and goal commitment and career decision self-efficacy. For career}

decision self-efficacy, only institution and goal commitment demonstrated a statistically significant relationship. This indicates that for at-risk students, having a commitment to West Virginia University, graduating from the University, choosing a major, and earning good grades is related to students having the self-efficacy to choose a major or career. It makes sense that there is a moderate relationship between being committed to one's education and the university and believing that one can choose a major and eventual career at some point in time.

First-year students are typically in the exploratory stage of career development and should not be expected to have commitment to a specific major or career (Super, 1957; 1980). It is more important at this stage of vocational identity for students to feel competent and efficacious that they can complete this task within a timely manner. Career choice is a major task for college student development. The ability to effectively do this can help students navigate through Chickering's vectors of identity and developing a purpose. The current results may be suggestive that these at-risk students are moving toward interdependence. The TEAM program incorporates a significant element of career exploration into the First-Year Experience class and each TEAM instructor is also an undergraduate advisor. Perhaps, as TEAM students are exposed to various ways to identify their career values and skills, their career decision self-efficacy increases. This is good since previous research has demonstrated that institution and goal 
commitment is an essential component of institutional integration for successful retention in college (Chickering \& Reisser, 1993; Schroder, 2010, Tinto, 1993).

Peer-group interactions and mental well-being. The relationship between peer-group interactions and mental well-being is supported by the literature (Chickering \& Reisser, 1993; Ryan \& Deci, 2001; Tinto, 1975). As students report satisfaction in their relationships with peers, they are more likely to report feeling good about themselves and others. This relationship was not as strong as the one between mental well-being and academic development, suggesting that for these first-year students who are academically at-risk, academic integration may be more important to mental well-being than relationships with peers. The TEAM program does allow for students to develop a cohort bond since they are with the same students in both the FYE and study skills class, but this was not evaluated in this research.

As seen with the institutional integration area of academic and intellectual development, students' movement through Chickering's vectors, especially developing interpersonal competencies, managing emotions, and moving toward interdependence, may be aided by having good peer relationships. The IIS measures peer relationships with regard to fostering personal and intellectual growth (Pascarella \& Terenzini, 1980). This suggests that the satisfaction that the participants are reporting is positive for the development of their student identity and academic growth and may act as a protective factor against the stressors associated with college. Also, effective integration into college requires mature control of emotions, which can be improved by positive peer relationships (Chickering \& Reisser, 1993).

\section{Academic Integration}

The constructs of academic and intellectual development and institution and goal commitment fall under the broader construct of academic integration. The fact that two of the 
three areas of institutional integration that were found to be significant in this research make up the construct of academic integration suggests that the TEAM program builds more academic integration than social integration. Barbatis (2010) explored factors that could lead to academic success and persistence in underprepared ethnic and racial minorities attending college. His research indicated that involvement in a specialized first-year experience class helped to increase the participants' awareness, understanding, and development of the skills essential for academic success. Given that the participants in this dissertation are identified as being at-risk because of underpreparedness, increasing academic integration may be more useful to them than social integration, especially in the first semester.

Academic integration may serve as protection from several of the consequences of being an at-risk student. Academic integration may help prepare at-risk students to adopt the role of college student and embrace the needed attitudes and behaviors to succeed in college. The more TEAM students are able to identify as college students with motivation to do well in school and graduate with a degree, the more likely they will have a good GPA, be able to choose a major and career that is realistic, and persist until graduation. This type of integration may aid at-risk first-year students in developing intellectual and interpersonal competencies, learn to better manage emotions, and move toward interdependence, which are the initial vectors of student development (Chickering \& Reisser, 1993). As students reach competencies along these vectors, they are more likely to do well academically and persist until graduation. At-risk students are more likely to not do well and to depart early and benefit from programs such as WVU's TEAM that provide an infrastructure that aids in academic integration. Also, it is possible that these students will have lower incidents of depression, anxiety, substance abuse, low self-esteem, and isolation. However, mental health and substance abuse were not measured in these students. 


\section{Institutional Integration Constructs That Did Not Contribute to the Results}

Faculty concern for development. The overall results did yield surprises that certain observed variables were not significant in their contribution to the creation of their canonical variates. The first surprise was regarding the IIS subscale of faculty concern. This subscale asks participants to view the faculty as a whole regarding the level of perceived concern for student development. In retrospect, the specification that the perception is of the faculty as a whole rather than identifying at least one faculty member may provide some insight as to its lack of significance. Most first year students are in introductory level classes with hundreds of other students and may not feel a connection with the instructors.

Also, the sampled population is at-risk students. As seen in the literature about at-risk students, they are more likely to have external loci of control and weaker self-concepts, which can influence students' ability to connect with faculty in meaningful ways (Crissman, Ishler, \& Upcraft, 2005; Entwhistle et al., 2001; Tinto, 1993). It is also possible that the sampled students may not have the appropriate awareness or insight to determine if the faculty has concern for students' development. Specific to at-risk students, lower levels of conscientiousness and agreeableness are often predictive of not seeking assistance from campus resources and not connecting with campus faculty and staff (Laskey \& Hetzel, 2011). Perhaps this is an area that is not important to the sampled students. As these students move through WVU and become more integrated into their major departments and are in classes with fewer students, they may report having more non-classroom or beneficial relationships with faculty.

Faculty interaction. A second curiosity was that the subscale of faculty interaction was not relevant in this model. The questions in this subscale ask participants to evaluate nonclassroom interactions and relationships with at least one faculty member. The TEAM program 
has several built-in non-classroom interactions between the advisor/instructor and students. It was hoped by the researcher that this would be reflected in the collected data since research shows a strong predictive relationship between this element of institutional integration and the ability to choose a vocation and mental well-being (Pascarella \& Reisser, 1993).

It is possible that the sampled students did not identify their advisor/instructor as faculty. It is also equally possible that the sampled students simply did not perceive that the nonclassroom interactions with TEAM advisors/instructors demonstrated genuine interest, willingness to spend time outside of the classroom, or positive interactions. Previous research has shown the subscale of faculty interaction to be essential in predicting retention (Chickering \& Reisser, 1993; Pascarella \& Terenzini, 1980; Schroder, 2010, Tinto, 1993). This creates the question of whether a lack of statistical significance for this subscale in this model suggests low retention rates for these TEAM students? However, institution and goal commitment has demonstrated a relationship with institutional persistence (Chickering \& Reisser, 1993; Pascarella \& Terenzini, 1980; Schroder, 2010, Tinto, 1993).

Fall 2012 grade point average. A third wonder was that GPA did not contribute to the overall model or criterion variate. As GPA is one of the two indicators of academic success used by universities, it was assumed that it would be a significant element of the statistical model. It was intuited that at least academic integration would have a relationship with GPA. As mentioned in the Research Design section of this dissertation, GPA for the sampled group had several outliers, which does affect the inclusion of this variable in the canonical correlation model. Several of the participants earned low fall GPAs that fell two or more standard deviations below the mean $(M=2.31, S D=0.80)$. Also, many elements factor into a student's grade point average including foundation of knowledge, difficulty of classes, and amount of studying. The 
results of this research strongly indicate that there is little to no relationship between the academic and social integrations and grades for these at-risk first-year students.

\section{Strengths of this research}

As previously noted, the fall 2012 sample had nearly an $80 \%$ response rate and $70 \%$ of 2012-2013 TEAM students' data were used in the final analysis. This suggests that the data has captured a significant portion of the population and supports the generalizability of these results to at-risk first-year students at West Virginia University and, perhaps, to the larger population of academically underprepared first-year students enrolled at public postsecondary institutions.

In a time that postsecondary institutions are working to increase student persistence, West Virginia University's TEAM program supports the academic integration of at-risk first-year students. The current research has demonstrated that students in this program reported a link between feeling academically integrated into WVU and increased self-efficacy regarding career decision making, which increases the likelihood of persistence. Also, these students reported a connection between their academic integration and feeling mentally well. Mental well-being can serve as a protective factor against the challenges of being a first-year college student. Overall, it seems that the results of this research can help other postsecondary institutions in retaining students, including those that are underprepared and at-risk for institutional departure.

\section{Limitations of this research}

There were some limitations of this research. Due to circumstances beyond the researcher's control, data could not be collected via paper surveys and had to be collected using web-based surveys. While data collected via web-based surveys are as reliable and valid as that collected through traditional paper and pencil methods (Russell, Goldberg, \& O’Connor (2003), it is strongly believed that this collection method contributed to the low response rate for the 
spring 2012 collection sample. TEAM students were not receiving weekly contact with the TEAM program during the spring 2012 semester. Perhaps the 2012-2013 TEAM students participated at a higher rate because they were actively part of the TEAM program and reminded to participate if they wish by their TEAM instructors/advisors. An additional complication of using a computer based survey system was the duplication of surveys. In the fall 2012 sample, 14 students submitted two survey sets that were not duplicates created by a flaw in the survey system. This did not affect the analyses since only the first submitted survey set was used. However, if students were given paper and pencil surveys they would not have the opportunity to complete the data twice.

Another complication of using a web-based survey is that the participants were given several weeks in which they could complete the survey sets. Survey sets were active for six weeks for the fall 2012 sample. It is possible that students who completed the survey sets in November are different than those who completed in December. Future research should attempt to narrow the time frame in which the survey sets are completed and one of the easiest ways to do this may be to use paper survey sets. It is possible that students who elected to participate in this research are different from those who did not. The demographic data suggest that in many ways the fall 2012 sample, which was the only one that yielded statistically significant and interpretable results, is comparable to the TEAM population. Perhaps there are differences that were not measured by the demographic questionnaire or surveys that differentiate these students from the non-responders regarding retention and persistence.

Also, the interpreted data were collected during the first semester for these students. Results may differ if collected at the end of the spring semester or during their second year of college. However, data collection at these times may be biased, as it would be on TEAM 
students who have been naturally separated between persisters and non-persisters since TEAM students can be suspended after the fall semester.

\section{Recommendations for future research}

The area of academic success and institutional persistence is relevant for students and postsecondary education institutions. The current research indicated that for the sampled at-risk students, institutional integration did not appear to be predictive of the success of at-risk firstyear college students during their first semester. It would be useful to conduct longitudinal research on this population to see if elements of institutional integration are increased during the second semester in the TEAM program or after students' progress into their second year of college. I suggest that a TEAM cohort be sampled once a year, perhaps at the end of each spring semester, to help determine if and when elements of institutional integration are predictive of academic success.

This research was not designed to determine if the TEAM program creates institutional integration. It would be helpful to know this information, which would require a comparison group. I suggest a study similar to the current one where at-risk, first-year students who are not part of the TEAM program would serve as a comparison group. Since TEAM students did not meet the admission criteria for WVU and the admission criteria for out-of-state students is higher than that for West Virginia residents, it is suggested that only non-resident TEAM students be sampled. This would make the two groups more comparable and the results more reliable.

An additional benefit to adding a comparison group is that the effects of stereotype threat could be studied. TEAM students are aware that they did not meet the admission criteria and that they are part of the TEAM program because of this; it is not a secret that they are at-risk 
students. This may induce stereotype threat that affects their performance or ability to successfully integrate into WVU. I suggest that this be measured in future research.

\section{Summary and Conclusions}

The current research suggests that there are factors of the TEAM program that provide academic integration for at-risk students, which can serve as protective factors regarding mental well-being and career decision self-efficacy. Students who report mental well-being tend to be able to cope with the stressors associated with college and successfully navigate through developmental tasks important for their personal and professional growth. Having the selfefficacy to choose a career is important for first-year students as it may prevent against foreclosing on a career choice or leaving the institution prematurely. This knowledge is important as postsecondary institutions continue to admit students who are not academically prepared for the rigors of college. While the TEAM program is not a panacea for this problem, the program appears to be useful in helping students integrate into West Virginia University, which positively affects career decision making and mental well-being. At-risk students who have the ability to cope with stressors and have the belief that they can complete one of the most fundamental tasks of college students, choosing a career, are more likely to persist and earn a degree. This benefits both the students and the institution. This research suggests that the TEAM program is a protective factor for at-risk first-year students by helping them integrate into the university community and more successfully navigate the challenges of college. 


\section{References}

Altbach, P. G. (1998). Comparative Higher Education: Knowledge, the University, and Development. Greenwich, CT: Ablex Publishing Corporation.

American College Health Association (2011). National College Health Assessment II. (Fall 2010). Retrieved from http://www.acha-ncha.org/docs/ACHA-NCHA-II_Reference Group_DataReport_Fall2010.pdf

American Psychological Association (2000). Diagnostic and statistical manual of mental disorders (4th ed., text rev.). Washington, D.C.

Anderson, E. (1985). Forces influencing student persistence and achievement. In L. Noel, R. Levitz, D. Saluri, \& Associates (Eds.), Increasing Student Retention: Effective programs and practices for reducing the dropout rate (pp. 44-61). San Francisco, CA: Jossey-Bass Inc.

Astin, A. W. (1993). What matters in college? San Francisco, CA: Jossey-Bass.

Aud, S., Hussar, W., Kena, G., Bianco, K., Frohlick. L, Kemp, J., \& Tahan, K., (2011). The Condition of Education 2011 (NCES 2011-033). U. S.Department of Education, National Center for Education Statistics. Washington, DC: U. S. Government Printing Office.

Baker, R. W. \& Siryk, B. (1984). Measuring adjustment to college. Journal of Counseling Psychology, 31(2), 179-189. doi: 10.1037/00220167.31.2.179

Bandura, A. (1977). Self-efficacy: Toward a unifying theory of behavioral change. Psychology Review, 84, 191-215.

Barbatis, P. (2010). Underprepared, ethnically diverse community college students: Factors contributing to persistence. Journal of Developmental Education, 33(3), 14-24. Retrieved 
from http://web.ebscohost.com.www libproxy.wvu.edu/ehost/ pdfviewer/pdfviewer? vid $=5 \&$ sid $=c 04448$ ee-02b8 $\quad 4 \mathrm{~b} 18-8 \mathrm{c} 8 \mathrm{~d}-\mathrm{e} 4 \mathrm{ae} 481$ fec29\%40sessionmgr4\&hid=123

Barefoot, B. O. (Jan/Feb 2000). The first-year experience: Are we making it any better? About Campus. Retrieved from http://www.earlycolleges.org/Downloads/FirstYear.pdf

Betz, N. \& Klein, K. (1996). Relationships among measures of career self-efficacy, generalized self-efficacy, and global self-esteem. Journal of Career Assessment, 4, 285-298.

Betz, N.E., Hammond, M., \& Multon, K . (2005). Reliability and validity of response for the Career Decision Self-efficacy Scale. Journal of Career Assessment, 13. 131-149.

Betz, N. E. \& Taylor, K. M. (2006). Manual for the Career Decision Self-Efficacy Scale and CDSE-Short Form. Retrieved from Nancy Betz, Department of Psychology, The Ohio State University, Columbus, $\mathrm{OH}$.

Bills, D. B. (2003). Credentials, signals, and screens: Explaining the relationship between schooling and job assignment. Review of Educational Research, 73(4), 441-469. doi $10.3102 / 00346543073004441$

Blickle, G., Schneider, P. B., Meurs, J. A., \& Perrewe, P. L. (2010). Antecedents and consequences of perceived barriers to obtaining mentoring: A longitudinal investigation. Journal of Applied Social Psychology, 40(8), 1897-1920. doi: 10.1111/j.15591816.2010.00644.x

Brittian, A. S., Sy, S. R., \& Stokes, J. E. (2009). Mentoring: Implications for African American college students. The Western Journal of Black Studies, 33(2), 87-97. Retrieved from http://web.ebscohost.com.www.libproxy.wvu.edu/ehost/pdfviewer/pdfviewer?vid=4\&hid $=11 \& \operatorname{sid}=6 \mathrm{a} 0 \mathrm{~d} 877 \mathrm{~b}-487 \mathrm{~d}-417 \mathrm{e}-\mathrm{ad} 11-\mathrm{dc} 2 \mathrm{f} 5 \mathrm{aa} 564 \mathrm{~cd} \% 40$ sessionmgr 14 
Bulger, S. \& Watson, D. (2006). Broadening the definition of at-risk students. The Community College Enterprise, 12(2), 23-32. Retrieved from http://www.schoolcraft.edu /pdfs/cce/12.2.23-32.pdf

Byrd, K. L. \& MacDonald, G. (2005). Defining college readiness from the inside out: Firstgeneration college student perspectives. Community College Review, 33(1), 22-30.

Caboni, T. C., Mundy, M. E., Deusterhaus, M. B. (2002). The implications of the norms of undergraduate college students for faculty enactment of principles of good practice in undergraduate education. Peabody Journal of Education, 77(3), 125-137. Retrieved from http://web.ebscohost.com/ehost/pdfviewer/pdfviewer?vid=4\&hid=106\&sid=90075accd0d2-4b21-a1a9-bf7cd8a54941\%40sessionmgr104

Carter, J. C. \& Daraviras, T. (2010). Cultivating college success among underprepared students. National Association for Developmental Education Digest, 5(1), 1-7. Retrieved from http://www.nade.net/2documents/publications/Digest/NADE\%20Digest\%20Fall\%20201 0.pdf

Chait, R. \& Venezia, A. (2009). Improving academic preparation for college: What we know and how state and federal policy can help. Center for American Progress. Retrieved from http://www.americanprogress.org/issues/2009/01/pdf/academic_prep.pdf

Chickering, A. W. (1980). Integrating adult development theory with higher education practice. Current Issues in Higher Education, 5, 6-17. ED194008.

Chickering, A. W. (2010). Our purposes: Personal reflections on character development and social responsibility in higher education. Liberal Education, 96(3), 54-59. Retrieved from http://web.ebscohost.com.www.libproxy.wvu.edu/ehost/pdfviewer/pdfviewer ?sid=ef9a8e94-0096-4c33-883f5c29d865fa60\%40session mgr4\&vid=1\&hid=14 
Chickering, A. W. \& Braskamp, L. A. (2009). Developing a global perspective for personal and social responsibility. Peer Review, 11(4), 27-30. Retrieved from http://findarticles.com/p /articles/mi_qa4115/is_200910/ai_n45880271/

Chickering, A. W. \& Gamson, Z. F. (1999). Development and adaptations of the seven principles for good practice in undergraduate education. New Directions for Teaching and Learning, 80, 75-81. Retrieved from http://web.ebscohost.com.www.libproxy.wvu.edu /ehost/pdfviewer/pdfviewer?sid=5c1e6ee2-fd0c-4e63-8815-09ce8b3dc58b $\% 40$ sessionmgr12\&vid=1\&hid=14

Chickering, A. W. \& Reisser, L. (1993). Education and Identity (2 ${ }^{\text {nd }}$ ed.). San Francisco, CA: Jossey-Bass.

Chickering, A. W. \& Stamm, L. (2002). Making our purposes clear: Getting beyond conflicting priorities and competing interests. About Campus, 7(2), 30-32. Retrieved from http://web.ebscohost.com.www.libproxy.wvu.edu/ehost/pdfviewer/pdfviewer?sid=e298e 19a-b3d8-4136-9553-fb7d12330712\%40sessionmgr115\&vid=1\&hid=122

Crisp, G. \& Cruz, I. (2009). Mentoring college students: A critical review of the literature between 1990 and 2007. Research in Higher Education, 50, 525-545. doi: 10.1007/s11162-009-9130-2.

Crissman Ishler, J. L. \& Upcraft, M. L. (2005). The keys to first-year student persistence. In M. L. Upcraft, J. N. Gardener, \& B. O. Barefoot (Eds.), Challenging and Supporting the First-Year Student: A Handbook for Improving the First Year of College (pp. 27-46). San Francisco, CA: Jossey-Bass.

Crites, J. O. (1969). Vocational Psychology. New York, NY: McGraw-Hill, Inc. 
Crites, J. O. (1981). Career Counseling: Models, Methods, and Materials. New York, NY: McGraw-Hill.

Dahmus, S., Bernardin, H.J., \& Bernardin, K. (1992). Student adaptation to college questionnaire. Measurement and Evaluation in Counseling and Development, 25(3),139142. Retrieved from http://web.ebscohost.com/ehost/delivery?sid=88d171eb-7938-4356 bc96-d4eb088e9acc\%40sessionmgr114\&vid=6\&hid=127

Diener, E., \& Lucas, R. E. (2000). Explaining differences in societal levels of happiness: Relative standards, need fulfillment, culture, and evaluation theory. Journal of Happiness Studies, 1, 41-78.

Entwistle, N., McCune, V., \& Walker, P. (2001). Conceptions, styles, and approaches within higher education: Analytic abstractions and everyday experiences. In R. J. Sternberg \& Zhang, L. F. (Eds.), Perspectives on Thinking, Learning, and Cognitive Styles (pp. 103-136). Mahwah, NJ: Lawrence Erlbaum Associates, Inc.

Erikson, E. H. (1959). Identity and the Life Cycle. New York, NY: W. W. Norton \& Company, Inc.

French, B. F. \& Oakes, W. (2004). Reliability and validity evidence for the institutional integration scale. Educational and Psychological Measurement, 64(1), 88-98. doi: $10.1177 / 0013164403258458$

Fox, M.A., Connolly, B.A., and Snyder, T.D., (2005). Youth indicators 2005: Trends in the well being of American youth. Washington, D.C.: Department of Education, National Center for Education Statistics. Retrieved from http://nces.ed.gov/pub2005/2005050.pdf. 
Furnham, A., Moutafi, J., \& Chamorro-Premuzic, T. (2005). Personality and intelligence: Gender, the Big Five, self-estimated and psychometric intelligence. International Journal of Selection and Assessment, 13(1), 11-24.

Gallagher, R. (2010). National survey of counseling center directors 2010. Retrieved from http://www.iacsinc.org/NSCCD\%202010.pdf

Hair, J. F., Anderson, R. E., Tatham, R. L., \& Black, W. C. (1998). Canonical Correlation Analysis. Multivariate Data Analysis ( $5^{\text {th }}$ ed.). Upper Saddle River, NJ: Prentice Hall.

Halpin, R.L. (1990). An application of the Tinto model to the analysis of freshmen persistence in a community college. Community College Review, 17(22), 22-32. DOI: 10.1177/009155219001700405.

Heppner, P. P., Wampold, B. E., \& Kivlighan, D. M. (2008). Research Design in Counseling (3 ${ }^{\text {rd }}$ ed.). Belmont, CA: The Thomson Corporation.

Hingson, R., Heeren, T., Winter, M., \& Wechsler, H. (2005). Magnitude of alcohol-related mortality and morbidity among U.S. college students ages 18-24: Changes from 1998 to 2001. Annual Review of Public Health, 26, 259-279. Retrieved from the National Institute of Alcohol Abuse and Alcoholism website: http://www.niaaa.nih.gov/AboutNIAAA/ NIAAA SponsoredPrograms/Pages/StatisticalSnapshotCollegeDrinking.aspx

Hodges, B. (2009). Factors that can influence mentorship relationships. Pediatric Nursing, 21(6), 32-35. Retrieved from http://web.ebscohost.com/ehost/pdfviewer/pdfviewer?vid=21\& hid=7\&sid=46207cf2-9e93-4c3a-b34d-d6a73a7e1122\%40sessionmgr13

Jacobi, M. (1991). Mentoring and undergraduate academic success: A literature review. Review of Educational Research, 61(4), 505-531. 
Johnston, L. D., O’Malley, P. M., Bachman, J. G., \& Schulenberg, J. E. (2008). Monitoring the Future National Survey Results on Drug Use, 1975-2007. Volume 1: Secondary School Students (NIH Publication No. 08-6418A) Bethesda, MD: National Institute on Drug Abuse. Retrieved from the National Institute of Alcohol Abuse and Alcoholism website: http://www.niaaa.nih.gov/AboutNIAAA/NIAAASponsoredPrograms/Pages/StatisticalSn apshotCollegeDrinking.aspx

Kadison, K. \& DiGeronimo, T. F. (2004). College of the Overwhelmed: The Campus Mental Health Crisis and What to Do About It. San Francisco, CA: Jossey-Bass.

Kerlinger, F. N. \& Pedhazur, E. J., (1973). Multiple Regression in Behavioral Research. New York, NY: Holt, Rinehart, \& Winston, Inc.

Kneipp, L. B., Kelly, K. E., \& Cyphers, B. (2009). Feeling at peace with college: Religiosity, spiritual well-being, and college adjustment. Individual Differences Research, 7(3), 188 196.

Larose, S., Bernier, A., \& Soucy, N. (2005). Attachment as a moderator of the effect of security in mentoring on subsequent perceptions of mentoring and relationship quality with college teachers. Journal of Social and Personal Relationships, 22(3), 399-415. doi: $10.1177 / 0265407505052443$

Laskey, M. L. \& Hetzel, C. J. (2011). Investigating factors related to retention of at-risk college students. The Learning Assessment Review, 16(1), 31-43.

Lotkowski, V. A., Robbins, S. B., \& Noeth, R. J. (2004). The role of academic and non-academic factors in improving college retention: ACT policy report. Retrieved from http://inpath ways.net/college_retention.pdf 
Marcia, J. E. (1966). Development and validation of the ego-identity status. Journal of Personality and Social Psychology, 3(5), 551-559. Retrieved from http://web. ebscohost.com.www. libproxy.wvu.edu/ehost/pdfviewer/pdfviewer?sid=16bf1460-5d774cb3-8e86-1306c720b83d\%40sessionmgr104\&vid=1\&hid=106

Markus, T. \& Zeitlin, A. (1992/1993). Remediation in American higher education: A new phenomenon? Community Review, 13(1/2), 13-23. Retrieved from http://web.ebscohost .com.www.libproxy.wvu.edu/ehost/detail?vid=7\&hid=112\&sid=b7f0394d-d8b3-4105acde6bafd3d19b32\%40sessionmgr113\&bdata=JnNpdGU9ZWhvc3QtbG12ZQ $\% 3 \mathrm{~d} \% 3 \mathrm{~d} \# \mathrm{db}=\mathrm{f} 5 \mathrm{~h} \& \mathrm{~A} N=9502270012$

Mason, M. G., Cohen, J. L., Lucas, T., \& Baltes, B. B. (2007). The relationship between self reported received and perceived social support: A meta-analytic review. American Journal of Community Psychology, 39, 133-144. doi: 10.1007/s10464-007-9100-9.

Meyer, M. D. E., Spencer, M., \& French, T. N. (2009). The identity of a "college student": Perceptions of college academics and academic rigor among first year students. College Student Journal, 43(4), 1070-1079. Retrieved from http://web.ebscohost.com. www.libproxy.wvu.edu/ehost/detail?vid=4\&hid=122\&sid=4c98e403-0231-40f5-8e241d52629ee116\%40sessionmgr115\&bdata=JnNpdGU9ZWhvc3QtbG12ZQ\%3d\%3d\#db=s $3 \mathrm{~h} \& \mathrm{~A} N=55492484$

Michael, A. E., Dickson, J., Ryan, B., \& Koefer, A. (2010). College prep blueprint for bridging and scaffolding incoming freshmen: Practices that work. College Student Journal, 44(4), 969-978. Retrieved from http://web.ebscohost.com/ehost/detail?vid=12\&hid=7\&sid= 46207cf2-9e93-4c3a-b34dd6a73a7e1122\%40sessionmgr13\&bdata= JnNpdGU9ZW hvc3QtbGl2ZQ\%3d\%3d\#db=a9h\&AN=58002464 
Mulvey, M. E. (2008). Under-prepared students: A continuing challenge for higher education. Research and Teaching in Developmental Education, 24(2), 77-87. Retrieved from http://www.docstoc.com/docs/40547497/Under-prepared-Students---A-Continuing Challenge-for-Higher-Education

Nunnally, J. C. \& Bernstein, I. H. (1994). Psychometric Theory, (3 ${ }^{\text {rd }}$ ed.). New York, NY: McGraw-Hill.

Pascarella, E. T. (1980). Student-faculty informal contact and college outcomes. Review of Educational Research, 50(4), 545-595. doi: 10.3102/00346543050004545

Pascarella, E. T., Pierson, C. T., Wolniak, G. C., \& Terenzini, P. T. (2004). First-generation college students: Additional evidence on college experiences and outcomes. The Journal of Higher Education, 75(3), 249-284. Retrieved from http://web.ebscohost.com.www. libproxy.wvu.edu/ehost/pdfviewer/pdfviewer?sid=2437995e-5d34-40a0-90b88c755a81ab6a\%40sessionmgr110\&vid=1\&hid=126

Pascarella, E. T. \& Terenzini, P. T. (1980). Predicting freshman persistence and voluntary dropout decisions from a theoretical model. Journal of Higher Education, 51(1), 60-75. doi: 0022-1546/80/0180

Pascarella, E. T. \& Terenzini, P. T. (1991). How College Affects Students: Findings and Insights from Twenty Years of Research. San Francisco, CA: Jossey-Bass Publishers. Pascarella, E. T. \& Terenzini, P. T. (1995). The impact of college on students: Myths, rational myths, and some other things that may not be true. NACADA Journal, 29(1), 90-97.

Peterson, S. L. (1993). Career decision-making self-efficacy and institutional integration of underprepared college students. Research in Higher Education, 34(6), 659-685. doi: 10.1007/BF00992155 
Roberts, A. (2000). Mentoring revisited: A phenomenological reading of the literature. Mentoring \& Tutoring, 8(2), 145-170. doi: 00/020145-26/1361-1267.

Russell, M., Goldberg, A., \& O’Connor, K. (2003). Computer-based testing and validity: A look back and into the future. Retrieved from http://www.bc.edu/research/intasc /PDF/ComputerBasedValidity.pdf

Ryan R. M., and Deci, E. L (2001). On happiness and human potential: a review of research on hedonic and eudaimonic well-being. Annual Review of Psychology, 52, 141-166.

Schultz, J. L. \& Higbee, J. L. (2007, Spring). Reasons for attending college: The student point of view. Research and Teaching in Developmental Education. Retrieved from http://findarticles.com/p/articles/mi_qa4116/is_200704/ai_n19430914/?tag=content;col1

Schmutte, P. S., \& Ryff, C. D. (1997). Personality and well-being: Reexamining methods and meanings. Journal of Personality and Social Psychology, 73, 540-559.

Schroeder, C. C. (2010). Retention consulting: Visit two. Centennial, CO: Noel-Levitz.

Seligman, M. E. P., \& Csikszentmihalyi, M. (2000). Positive psychology: An introduction. American Psychologist, 55, 5-14.

Sherry, A. \& Henson, R. K. (2005). Conducting and interpreting canonical correlation analysis in personality research: A user-friendly primer. Journal of Personality Assessment, 84(1), 37-48. Retrieved from http://digitalparadigm.net/Staging/alissa/download/PDFs/CCA.pdf

Stephens, D. (2001). Increasing access: Educating underprepared students in U.S. colleges and universities past, present, and future. Retrieved from http://faculty.etsu edu/stephen/increasingaccess.htm

Stevens, J. (1986). Applied multivariate statistics for the social sciences. Hillsdale, NJ: Erlbaum. 
Super, D. E. (1953). A theory of vocational development. American Psychologist, 8(5), 185-190. doi: $10.1037 / \mathrm{h} 0056046$

Super, D. E., (1980). A life-span, life-space approach to career development. Journal of Vocational Behavior, 16, 282-298. Retrieved from http://www.psy.lmu.de/peen/study/curriculum/current_courses/3d/8_super.pdf

Super, D. E. (1983). Assessment in career guidance: Toward truly developmental counseling. The Personnel and Guidance Journal, 61(9), 555-562.

Super, D. E., \& Douglas, T. H. (1978). Career development: Exploration and planning. Annual Review of Psychology, 29(1), 333-372. Retrieved from http://web.ebscohost.com.www. libproxy.wvu.edu/ehost/pdfviewer/pdfviewer?vid=5\&hid=13\&sid=e439636e-9fe0-452ab6f6-93ec2a023ef6\%40sessionmgr13

Tabachnik, B. G. \& Fidell, L. S. (2007). Canonical Correlation. Using Multivariate Statistics $\left(5^{\text {th }}\right.$ ed.). Boston, MA: Pearson.

Taras, H. (2009). Physical activity and student performance at school. Journal of School Health, 75(6), 214-218. doi: 10.1111/j.1746-1561.2005.tb06675x

Taylor, K. M. \& Betz, N. E. (1983). Applications of self-efficacy theory to the understanding and treatment of career indecision. Journal of Vocational Behavior, 22, 63-81. doi: 10.0001$8791 / 83 / 010063$

Tennant, R., Hiller, L., Fishwick, R., Platt, S., Joseph, S., Weich, S.,... Stewart-Brown, S. (2007). Health and Quality of Life Outcomes, 5(1), 63-75. doi: 10.1186/1477-75-5-63.

Thompson, B. (1984). Canonical Correlation Analysis: Uses and Interpretations. Beverly Hills, CA: Sage Publications, Inc. 
Thorndike, R. M. (1978). Correlational Procedures for Research. New York, NY: Gardner Press Inc.

Tinto, V. (1975). Dropout from higher education: A theoretical synthesis of recent research. Review of Educational Research, 45, 89-125.

Tinto, V. (1993). Leaving College: Rethinking the Causes and Cures of Student Attrition. $\left(^{\text {nd }}\right.$ ed.). Chicago, IL: The University of Chicago Press.

Uchino, B. N. (2004). Social Support and Physical Health: Understanding the Health Consequences of Physical Relationships. New Haven, CT: Yale University Press

Upcraft, M. L., Gardener, J. N., \& Barefoot, B. O. (2005). Introduction: The first year of college revisited. In M. L. Upcraft, J. N. Gardener, \& B. O. Barefoot (Eds.), Challenging and Supporting the First-Year Student: A Handbook for Improving the First Year of College (pp. 1-12).San Francisco, CA: Jossey-Bass.

U. S.Department of Education Institute of Education Sciences, National Center for Education Statistics (2001). Closer look 2001: Students whose parents did not go to college. Retrieved on June 272011 from http://nces.ed.gov/programs/coe/ analysis/2001index.asp

U. S.Department of Labor, Bureau of Labor Statistics (2010). BLS Spotlight on Statistics: Back to College. Retrieved on July 3, 2011 from http://www.bls.gov/spotlight/2010/college/ pdf/college.pdf

Valverde, L.A. (1985). Low-income students. In L. Noel, R. Levitz, D. Saluri, \& Associates (Eds.), Increasing Student Retention: Effective programs and practices for reducing the dropout rate (pp. 78-94). San Francisco, CA: Jossey-Bass Inc.

WVU enrollment rises as overall state enrollment decreases. (2011, November 10). WVUtoday. 
Retrieved from http://wvutoday.wvu.edu/n/2011/11/10/wvu-enrollment-rises-as-overall state-enrollment-decreases

WVU's largest freshman class joins the Mountaineer family on move-in weekend. (2012, August 19). WVUtoday. Retrieved from http://wvutoday.wvu.edu/n/2012/08/19/wvu-s-latest class-of-new-students-welcomed-to-campus

Williams, F. \& Monge, P. (2001). Reasoning with Statistics $\left(5^{\text {th }}\right.$ ed). Belmont, CA: Thomas Higher Education.

Zhang, L. F., \& Sternberg, R. J., (2001). Thinking styles across cultures: Their relationships with student learning. In R. J. Sternberg \& Zhang, L. F. (Eds.), Perspectives on Thinking, Learning, and Cognitive Styles (pp. 197-226). Mahwah, NJ: Lawrence Erlbaum Associates, Inc. 


\section{Appendix A}

\section{Demographics Questionnaire}

For the following questions, please provide an answer or circle the response that best fits for you.

1. Please provide your full name:

2. Age:

3. Gender:

1. Male

2. Female

4. Ethnicity:

1. Hispanic or Latino

2. American Indian or Alaska Native

3. Asian

4. Black or African American

5. Native Hawaiian or other Pacific Islander

6. White, not Hispanic or Latino

7. Other:

5. Did either of your parents graduate from a 4-year college or university?

1. Yes, at least one of my parents has a degree from a 4-year college or university.

2. No, neither of my parents have a degree from a 4-year college or university.

6. Please name the City and State from which you graduated high school.

7. Residence location:

1. On campus in a residence hall

2. Off campus in an apartment or house by self or with friends

3. Off campus with family members 
8. Regarding employment during this semester:

\section{Employed}

2. Not employed

8A. If employed, the number of hours worked:

hours on average during a 7 day week.

8B. If employed:

1. Employed through the school like work-study or student work

2. Employment off campus in a job that is not affiliated with WVU

9. Right now, the highest level of education intended is:

1. Some college but not finishing

2. Two-year college degree (Associate's degree)

3. Four-year college degree (Bachelor's degree)

4. Graduate or Professional degree (Master's degree, R.N., M.B.A., etc)

5. Advanced Graduate degree (Medical degree, Doctorate degree, J. D.)

10. Please indicate which is correct for you:

1. I am a first-semester college student at West Virginia University

2. I am a NOT a first-semester college student at West Virginia University. I have attended at least one semester as a full-time (12 credit hours or more) student at this or another university or college. 
Appendix B

\section{Career Decision Self-Efficacy Scale-Short Form}

INSTRUCTIONS: For each statement below, please read carefully and indicate how much confidence you have that you could accomplish each of these tasks by marking your answer according to the key. Mark your answer by checking your answer below each question.

Example: $\quad$ How much confidence do you have that you could:

a. NO CONFIDENCE AT ALL 1

Summarize the skills you have developed in the jobs you have held?
VERY LITTLE CONFIDENCE 2

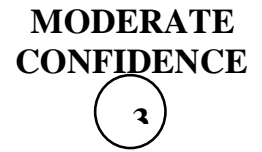

MODERATE
MUCH CONFIDENCE

4
COMPLETE

CONFIDENCE

5

If your response was "Moderate Confidence," you would mark the number 3 below the question.

HOW MUCH CONFIDENCE DO YOU HAVE THAT YOU COULD:

1. Use the internet to find information about occupations that interest you.

$\begin{array}{ccccc}\text { NO CONFIDENCE } & \text { VERY LITTLE } & \text { MODERATE } & \text { MUCH } & \text { COMPLETE } \\ \text { AT ALL } & \text { CONFIDENCE } & \text { CONFIDENCE } & \text { CONFIDENCE } & \text { CONFIDENCE } \\ 1 & 2 & 3 & 4 & 5\end{array}$

2. Select one major from a list of potential majors you are considering.

NO CONFIDENCE

AT ALL

1

\begin{abstract}
VERY LITTLE
CONFIDENCE
\end{abstract}

2

\begin{abstract}
MODERATE
CONFIDENCE

3
\end{abstract}

MUCH

CONFIDENCE

4
COMPLETE

CONFIDENCE

5

3. Make a plan of your goals for the next five years.

NO CONFIDENCE

AT ALL

1
VERY LITTLE

2
MODERATE

CONFIDENCE

3
MUCH
CONFIDENCE

4
COMPLETE

CONFIDENCE

5

4.Determine the steps to take if you are having academic trouble with an aspect of your chosen major.

NO CONFIDENC

AT ALL

1

\section{VERY LITTLE CONFIDENCE}

2
MODERATE CONFIDENCE

3
MUCH
CONFIDENCE

4

COMPLETE CONFIDENCE

5

5. Accurately assess your abilities.

NO CONFIDENCE

AT ALL

1
VERY LITTLE
CONFIDENCE

2

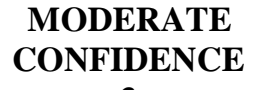

3

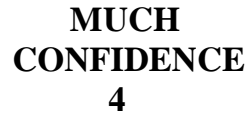

4
COMPLETE

CONFIDENCE

5 
6. Select one occupation from a list of potential occupations you are considering.

$\begin{array}{ccccc}\text { NO CONFIDENCE } & \text { VERY LITTLE } & \text { MODERATE } & \text { MUCH } & \text { COMPLETE } \\ \text { AT ALL } & \text { CONFIDENCE } & \text { CONFIDENCE } & \text { CONFIDENCE } & \text { CONFIDENCE } \\ 1 & 2 & 3 & 4 & 5\end{array}$

7. Determine the steps you need to take to successfully complete your chosen major.

$\begin{array}{ccccc}\text { NO CONFIDENCE } & \text { VERY LITTLE } & \text { MODERATE } & \text { MUCH } & \text { COMPLETE } \\ \text { AT ALL } & \text { CONFIDENCE } & \text { CONFIDENCE } & \text { CONFIDENCE } & \text { CONFIDENCE } \\ 1 & 2 & 3 & 4 & 5\end{array}$

8. Persistently work at your major or career goal even when you get frustrated.

$\begin{array}{ccccc}\text { NO CONFIDENCE } & \text { VERY LITTLE } & \text { MODERATE } & \text { MUCH } & \text { COMPLETE } \\ \text { AT ALL } & \text { CONFIDENCE } & \text { CONFIDENCE } & \text { CONFIDENCE } & \text { CONFIDENCE } \\ 1 & 2 & 3 & 4 & 5\end{array}$

9. Determine what your ideal job would be.

$\begin{array}{ccccc}\text { NO CONFIDENCE } & \text { VERY LITTLE } & \text { MODERATE } & \text { MUCH } & \text { COMPLETE } \\ \text { AT ALL } & \text { CONFIDENCE } & \text { CONFIDENCE } & \text { CONFIDENCE } & \text { CONFIDENCE } \\ 1 & 2 & 3 & 4 & 5\end{array}$

10. Find out the employment trends for an occupation over the next ten years.

$\begin{array}{ccccc}\text { NO CONFIDENCE } & \text { VERY LITTLE } & \text { MODERATE } & \text { MUCH } & \text { COMPLETE } \\ \text { AT ALL } & \text { CONFIDENCE } & \text { CONFIDENCE } & \text { CONFIDENCE } & \text { CONFIDENCE } \\ 1 & 2 & 3 & 4 & 5\end{array}$

11. Choose a career that will fit your preferred lifestyle.

$\begin{array}{ccccc}\text { NO CONFIDENCE } & \text { VERY LITTLE } & \text { MODERATE } & \text { MUCH } & \text { COMPLETE } \\ \text { AT ALL } & \text { CONFIDENCE } & \text { CONFIDENCE } & \text { CONFIDENCE } & \text { CONFIDENCE } \\ 1 & 2 & 3 & 4 & 5\end{array}$

12. Prepare a good resume.

$\begin{array}{ccccc}\text { NO CONFIDENCE } & \text { VERY LITTLE } & \text { MODERATE } & \text { MUCH } & \text { COMPLETE } \\ \text { AT ALL } & \text { CONFIDENCE } & \text { CONFIDENCE } & \text { CONFIDENCE } & \text { CONFIDENCE } \\ 1 & 2 & 3 & 4 & 5\end{array}$

13. Change majors if you did not like your first choice.

$\begin{array}{ccccc}\text { NO CONFIDENCE } & \text { VERY LITTLE } & \text { MODERATE } & \text { MUCH } & \text { COMPLETE } \\ \text { AT ALL } & \text { CONFIDENCE } & \text { CONFIDENCE } & \text { CONFIDENCE } & \text { CONFIDENCE } \\ 1 & 2 & 3 & 4 & 5\end{array}$

14. Decide what you value most in an occupation.

$\begin{array}{ccccc}\text { NO CONFIDENCE } & \text { VERY LITTLE } & \text { MODERATE } & \text { MUCH } & \text { COMPLETE } \\ \text { AT ALL } & \text { CONFIDENCE } & \text { CONFIDENCE } & \text { CONFIDENCE } & \text { CONFIDENCE } \\ 1 & 2 & 3 & 4 & 5\end{array}$

15. Find out about the average yearly earnings of people in an occupation.

$\begin{array}{ccccc}\text { NO CONFIDENCE } & \text { VERY LITTLE } & \text { MODERATE } & \text { MUCH } & \text { COMPLETE } \\ \text { AT ALL } & \text { CONFIDENCE } & \text { CONFIDENCE } & \text { CONFIDENCE } & \text { CONFIDENCE } \\ 1 & 2 & 3 & 4 & 5\end{array}$


16. Make a career decision and then not worry whether it was right or wrong.

NO CONFIDENCE

AT ALL

1
VERY LITTLE

CONFIDENCE

2
MODERATE

CONFIDENCE

3
MUCH

CONFIDENCE

4
COMPLETE

CONFIDENCE

5

17. Change occupations if you are not satisfied with the one you enter.

NO CONFIDENCE

AT ALL

1
VERY LITTLE

CONFIDENCE

2
MODERATE

CONFIDENCE

3
MUCH

CONFIDENCE

4
COMPLETE

CONFIDENCE

5

18. Figure out what you are and are not ready to sacrifice to achieve your career goals.

NO CONFIDENCE
AT ALL

1
VERY LITTLE

CONFIDENCE

2

\section{MODERATE}

CONFIDENCE

3
MUCH

CONFIDENCE

4
COMPLETE

CONFIDENCE

5

19. Talk with a person already employed in a field you are interested in.

NO CONFIDENCE

AT ALL

1
VERY LITTLE

CONFIDENCE

2
MODERATE

CONFIDENCE

3
MUCH

CONFIDENCE

4

COMPLETE

CONFIDENCE

5

20. Choose a major or career that will fit your interests.

NO CONFIDENCE
AT ALL

1
VERY LITTLE

2

\section{MODERATE}

CONFIDENCE

3

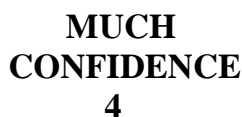

4
COMPLETE

CONFIDENCE

5

21. Identify employers, firms, and institutions relevant to your career possibilities.

$\begin{array}{ccccc}\text { NO CONFIDENCE } & \text { VERY LITTLE } & \text { MODERATE } & \text { MUCH } & \text { COMPLETE } \\ \text { AT ALL } & \text { CONFIDENCE } & \text { CONFIDENCE } & \text { CONFIDENCE } & \text { CONFIDENCE } \\ 1 & 2 & 3 & 4 & 5\end{array}$

22. Define the type of lifestyle you would like to live.

$\begin{array}{ccccc}\text { NO CONFIDENCE } & \text { VERY LITTLE } & \text { MODERATE } & \text { MUCH } & \text { COMPLETE } \\ \text { AT ALL } & \text { CONFIDENCE } & \text { CONFIDENCE } & \text { CONFIDENCE } & \text { CONFIDENCE } \\ 1 & 2 & 3 & 4 & 5\end{array}$

23. Find information about graduate or professional schools.

$\begin{array}{ccccc}\text { NO CONFIDENCE } & \text { VERY LITTLE } & \text { MODERATE } & \text { MUCH } & \text { COMPLETE } \\ \text { AT ALL } & \text { CONFIDENCE } & \text { CONFIDENCE } & \text { CONFIDENCE } & \text { CONFIDENCE } \\ 1 & 2 & 3 & 4 & 5\end{array}$

24. Successfully manage the job interview process.

$\begin{array}{ccccc}\text { NO CONFIDENCE } & \text { VERY LITTLE } & \text { MODERATE } & \text { MUCH } & \text { COMPLETE } \\ \text { AT ALL } & \text { CONFIDENCE } & \text { CONFIDENCE } & \text { CONFIDENCE } & \text { CONFIDENCE } \\ 1 & 2 & 3 & 4 & 5\end{array}$

25. Identify some reasonable major or career alternatives if you are unable to get your first choice.

NO CONFIDENCE

AT ALL

1
VERY LITTLE
CONFIDENCE

2

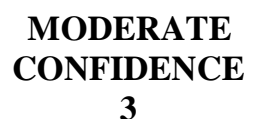

3

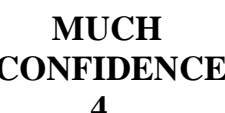

4
COMPLETE

CONFIDENCE

5 


\section{Appendix C}

\section{Institutional Integration Scale}

INSTRUCTIONS: For each statement below, please read carefully and indicate how much confidence you have that you could accomplish each of these tasks by marking your answer according to the key. Mark your answer by circling your answer below each question.

1. Since coming to West Virginia Univesity I have developed close personal relationships with other students.

$\begin{array}{ccccc}\text { STRONGLY } & \text { AGREE } & \text { NEITHER AGREE } & \text { DISAGREE } & \text { STRONGLY } \\ \text { AGREE TO } & \text { TO } & \text { NOR DISAGREE TO } & \text { TO } & \text { DISAGREE TO } \\ 5 & 4 & 3 & 2 & 1\end{array}$

2. The student friendships I have developed at West Virginia University have been personally satisfying.

$\begin{array}{ccccc}\text { STRONGLY } & \text { AGREE } & \text { NEITHER AGREE } & \text { DISAGREE } & \text { STRONGLY } \\ \text { AGREE TO } & \text { TO } & \text { NOR DISAGREE TO } & \text { TO } & \text { DISAGREE TO } \\ 5 & 4 & 3 & 2 & 1\end{array}$

3. My interpersonal relationships with other students have had a positive influence on my personal growth, attitudes, and values.

$\begin{array}{ccccc}\text { STRONGLY } & \text { AGREE } & \text { NEITHER AGREE } & \text { DISAGREE } & \text { STRONGLY } \\ \text { AGREE TO } & \text { TO } & \text { NOR DISAGREE TO } & \text { TO } & \text { DISAGREE TO } \\ 5 & 4 & 3 & 2 & 1\end{array}$

4. My interpersonal relationships with other students have had a positive influence on my intellectual growth and interest in ideas.

$\begin{array}{ccccc}\text { STRONGLY } & \text { AGREE } & \text { NEITHER AGREE } & \text { DISAGREE } & \text { STRONGLY } \\ \text { AGREE TO } & \text { TO } & \text { NOR DISAGREE TO } & \text { TO } & \text { DISAGREE TO } \\ \mathbf{5} & \mathbf{4} & \mathbf{3} & \mathbf{2} & \mathbf{1}\end{array}$

5. It has been difficult for me to meet and make friends with other students.

$\begin{array}{ccccc}\text { STRONGLY } & \text { AGREE } & \text { NEITHER AGREE } & \text { DISAGREE } & \text { STRONGLY } \\ \text { AGREE TO } & \text { TO } & \text { NOR DISAGREE TO } & \text { TO } & \text { DISAGREE TO } \\ 5 & 4 & 3 & 2 & 1\end{array}$

6. Few of the students I know would be willing to listen to me and help me if I had a personal problem.

$\begin{array}{ccccc}\text { STRONGLY } & \text { AGREE } & \text { NEITHER AGREE } & \text { DISAGREE } & \text { STRONGLY } \\ \text { AGREE TO } & \text { TO } & \text { NOR DISAGREE TO } & \text { TO } & \text { DISAGREE TO } \\ 5 & 4 & 3 & 2 & 1\end{array}$

7. Most students at West Virginia University have values and attitudes different from my own.

$\begin{array}{ccc}\text { STRONGLY } & \text { AGREE } & \text { NEITHER AGREE } \\ \text { AGREE TO } & \text { TO } & \text { NOR DISAGREE TO } \\ \mathbf{5} & 4 & 3\end{array}$
DISAGREE STRONGLY
TO
2
DISAGREE TO
1


8. My nonclassroom interactions with faculty have had a positive influence on my personal growth, values, and attitudes.

$\begin{array}{ccccc}\text { STRONGLY } & \text { AGREE } & \text { NEITHER AGREE } & \text { DISAGREE } & \text { STRONGLY } \\ \text { AGREE TO } & \text { TO } & \text { NOR DISAGREE TO } & \text { TO } & \text { DISAGREE TO } \\ 5 & 4 & 3 & 2 & 1\end{array}$

9. My nonclassroom interactions with faculty have had a positive influence on my intellectual growth and interest in ideas.

$\begin{array}{ccccc}\text { STRONGLY } & \text { AGREE } & \text { NEITHER AGREE } & \text { DISAGREE } & \text { STRONGLY } \\ \text { AGREE TO } & \text { TO } & \text { NOR DISAGREE TO } & \text { TO } & \text { DISAGREE TO } \\ 5 & 4 & 3 & 2 & 1\end{array}$

10. My nonclassroom interactions with faculty have had a positive influence on my career goals and aspirations.

$\begin{array}{cc}\text { STRONGLY } & \text { AGREE } \\ \text { AGREE TO } & \text { TO } \\ 5 & 4\end{array}$

NEITHER AGREE
NOR DISAGREE TO
\[ \begin{array}{l}3 \\ \end{array} \]
DISAGREE STRONGLY TO DISAGREE TO 21

11. Since coming to West Virginia University I have developed a close, personal relationship with at least one faculty member.

$\begin{array}{ccccc}\text { STRONGLY } & \text { AGREE } & \text { NEITHER AGREE } & \text { DISAGREE } & \text { STRONGLY } \\ \text { AGREE TO } & \text { TO } & \text { NOR DISAGREE TO } & \text { TO } & \text { DISAGREE TO } \\ 5 & 4 & 3 & 2 & 1\end{array}$

12. I am satisfied with the opportunities to meet and interact informally with faculty members.

$\begin{array}{ccccc}\text { STRONGLY } & \text { AGREE } & \text { NEITHER AGREE } & \text { DISAGREE } & \text { STRONGLY } \\ \text { AGREE TO } & \text { TO } & \text { NOR DISAGREE TO } & \text { TO } & \text { DISAGREE TO } \\ 5 & 4 & 3 & 2 & 1\end{array}$

13. Few of the faculty members I have had contact with are generally interested in students.

$\begin{array}{ccccc}\text { STRONGLY } & \text { AGREE } & \text { NEITHER AGREE } & \text { DISAGREE } & \text { STRONGLY } \\ \text { AGREE TO } & \text { TO } & \text { NOR DISAGREE TO } & \text { TO } & \text { DISAGREE TO } \\ 5 & 4 & 3 & 2 & 1\end{array}$

14. Few of the faculty members I have had contact with are generally outstanding or superior teachers.

$\begin{array}{ccccc}\text { STRONGLY } & \text { AGREE } & \text { NEITHER AGREE } & \text { DISAGREE } & \text { STRONGLY } \\ \text { AGREE TO } & \text { TO } & \text { NOR DISAGREE TO } & \text { TO } & \text { DISAGREE TO } \\ 5 & 4 & 3 & 2 & 1\end{array}$

15. Few of the faculty members I have had contact with are willing to spend time outside of class to discuss issues of interest and importance to students.

$\begin{array}{ccccc}\text { STRONGLY } & \text { AGREE } & \text { NEITHER AGREE } & \text { DISAGREE } & \text { STRONGLY } \\ \text { AGREE TO } & \text { TO } & \text { NOR DISAGREE TO } & \text { TO } & \text { DISAGREE TO } \\ \mathbf{5} & \mathbf{4} & \mathbf{3} & \mathbf{2} & \mathbf{1}\end{array}$


16. Most of the faculty members I have had contact with are interested in helping students grow in more than just academic areas.

$\begin{array}{ccccc}\text { STRONGLY } & \text { AGREE } & \text { NEITHER AGREE } & \text { DISAGREE } & \text { STRONGLY } \\ \text { AGREE TO } & \text { TO } & \text { NOR DISAGREE TO } & \text { TO } & \text { DISAGREE TO } \\ \mathbf{5} & \mathbf{4} & \mathbf{3} & \mathbf{2} & \mathbf{1}\end{array}$

17. Most of the faculty members I have had contact with are genuinely interested in teaching.

$\begin{array}{ccccc}\text { STRONGLY } & \text { AGREE } & \text { NEITHER AGREE } & \text { DISAGREE } & \text { STRONGLY } \\ \text { AGREE TO } & \text { TO } & \text { NOR DISAGREE TO } & \text { TO } & \text { DISAGREE TO } \\ 5 & 4 & 3 & 2 & 1\end{array}$

18. I am satisfied with the extent of my intellectual development since enrolling in this university.

$\begin{array}{ccc}\text { STRONGLY } & \text { AGREE } & \text { NEITHER AGREE } \\ \text { AGREE TO } & \text { TO } & \text { NOR DISAGREE TO } \\ 5 & 4 & 3\end{array}$
DISAGREE STRONGLY TO DISAGREE TO 21

19. My academic experience has had a positive influence on my intellectual growth and interest in ideas.

$\begin{array}{ccccc}\text { STRONGLY } & \text { AGREE } & \text { NEITHER AGREE } & \text { DISAGREE } & \text { STRONGLY } \\ \text { AGREE TO } & \text { TO } & \text { NOR DISAGREE TO } & \text { TO } & \text { DISAGREE TO } \\ 5 & 4 & 3 & 2 & 1\end{array}$

20. I am satisfied with my academic experience at West Virginia University.

$\begin{array}{ccccc}\text { STRONGLY } & \text { AGREE } & \text { NEITHER AGREE } & \text { DISAGREE } & \text { STRONGLY } \\ \text { AGREE TO } & \text { TO } & \text { NOR DISAGREE TO } & \text { TO } & \text { DISAGREE TO } \\ 5 & 4 & 3 & 2 & 1\end{array}$

21. Few of my courses this year have been intellectually stimulating.

$\begin{array}{ccccc}\text { STRONGLY } & \text { AGREE } & \text { NEITHER AGREE } & \text { DISAGREE } & \text { STRONGLY } \\ \text { AGREE TO } & \text { TO } & \text { NOR DISAGREE TO } & \text { TO } & \text { DISAGREE TO } \\ 5 & 4 & 3 & 2 & 1\end{array}$

22. My interest in ideas and intellectual matters has increased since coming to West Virginia University.

$\begin{array}{ccccc}\text { STRONGLY } & \text { AGREE } & \text { NEITHER AGREE } & \text { DISAGREE } & \text { STRONGLY } \\ \text { AGREE TO } & \text { TO } & \text { NOR DISAGREE TO } & \text { TO } & \text { DISAGREE TO } \\ \mathbf{5} & \mathbf{4} & \mathbf{3} & \mathbf{2} & \mathbf{1}\end{array}$

23. I am more likely to attend a cultural event (for example, a concert, lecture, or art show) now than I was before coming to West Virginia University.

$\begin{array}{ccccc}\text { STRONGLY } & \text { AGREE } & \text { NEITHER AGREE } & \text { DISAGREE } & \text { STRONGLY } \\ \text { AGREE TO } & \text { TO } & \text { NOR DISAGREE TO } & \text { TO } & \text { DISAGREE TO } \\ \mathbf{5} & 4 & 3 & 2 & 1\end{array}$

24. I have performed academically as well as I anticipated I would.

$\begin{array}{ccccc}\text { STRONGLY } & \text { AGREE } & \text { NEITHER AGREE } & \text { DISAGREE } & \text { STRONGLY } \\ \text { AGREE TO } & \text { TO } & \text { NOR DISAGREE TO } & \text { TO } & \text { DISAGREE TO } \\ 5 & \mathbf{5} & \mathbf{3} & \mathbf{2} & \mathbf{1}\end{array}$


25. It is important for me to graduate from college.

$\begin{array}{ccccc}\text { STRONGLY } & \text { AGREE } & \text { NEITHER AGREE } & \text { DISAGREE } & \text { STRONGLY } \\ \text { AGREE TO } & \text { TO } & \text { NOR DISAGREE TO } & \text { TO } & \text { DISAGREE TO } \\ 5 & 4 & 3 & 2 & 1\end{array}$

26. I am confident that I made the right decision in choosing to attend West Virginia University.

$\begin{array}{ccccc}\text { STRONGLY } & \text { AGREE } & \text { NEITHER AGREE } & \text { DISAGREE } & \text { STRONGLY } \\ \text { AGREE TO } & \text { TO } & \text { NOR DISAGREE TO } & \text { TO } & \text { DISAGREE TO } \\ 5 & 4 & 3 & 2 & 1\end{array}$

27. It is likely that I will register at West Virginia University next fall.

$\begin{array}{ccccc}\text { STRONGLY } & \text { AGREE } & \text { NEITHER AGREE } & \text { DISAGREE } & \text { STRONGLY } \\ \text { AGREE TO } & \text { TO } & \text { NOR DISAGREE TO } & \text { TO } & \text { DISAGREE TO } \\ 5 & 4 & 3 & 2 & 1\end{array}$

28. It is not important to me to graduate from West Virginia University.

$\begin{array}{ccccc}\text { STRONGLY } & \text { AGREE } & \text { NEITHER AGREE } & \text { DISAGREE } & \text { STRONGLY } \\ \text { AGREE TO } & \text { TO } & \text { NOR DISAGREE TO } & \text { TO } & \text { DISAGREE TO } \\ \mathbf{5} & \mathbf{4} & \mathbf{3} & \mathbf{2} & \mathbf{1}\end{array}$

29. I have no idea at all what I want to major in.

$\begin{array}{ccccc}\text { STRONGLY } & \text { AGREE } & \text { NEITHER AGREE } & \text { DISAGREE } & \text { STRONGLY } \\ \text { AGREE TO } & \text { TO } & \text { NOR DISAGREE TO } & \text { TO } & \text { DISAGREE TO } \\ 5 & 4 & 3 & 2 & 1\end{array}$

30. Getting good grades is not important to me.

$\begin{array}{ccccc}\text { STRONGLY } & \text { AGREE } & \text { NEITHER AGREE } & \text { DISAGREE } & \text { STRONGLY } \\ \text { AGREE TO } & \text { TO } & \text { NOR DISAGREE TO } & \text { TO } & \text { DISAGREE TO } \\ 5 & 4 & 3 & 2 & 1\end{array}$




\section{Appendix D}

The Warwick-Edinburgh Mental Well-being Scale

Instructions: Below are some statements about feelings and thoughts. Please tick the box that best describes your experience of each over the last 2 weeks.

\begin{tabular}{|c|c|c|c|c|c|}
\hline Statements & $\begin{array}{l}\text { None of } \\
\text { the time }\end{array}$ & Rarely & $\begin{array}{l}\text { Some of } \\
\text { the time }\end{array}$ & Often & $\begin{array}{l}\text { All of } \\
\text { the time }\end{array}$ \\
\hline \multicolumn{6}{|l|}{$\begin{array}{l}\text { I've been feeling optimistic about } \\
\text { the future. }\end{array}$} \\
\hline \multicolumn{6}{|l|}{ I've been feeling useful. } \\
\hline \multicolumn{6}{|l|}{ I've been feeling relaxed. } \\
\hline \multicolumn{6}{|l|}{$\begin{array}{l}\text { I've been feeling interested in } \\
\text { other people. }\end{array}$} \\
\hline \multicolumn{6}{|l|}{ I've had energy to spare. } \\
\hline \multicolumn{6}{|l|}{$\begin{array}{l}\text { I've been dealing with problems } \\
\text { well. }\end{array}$} \\
\hline \multicolumn{6}{|l|}{ I've been thinking clearly. } \\
\hline \multicolumn{6}{|l|}{$\begin{array}{l}\text { I've been feeling good about } \\
\text { myself. }\end{array}$} \\
\hline \multicolumn{6}{|l|}{$\begin{array}{l}\text { I've been feeling close to other } \\
\text { people. }\end{array}$} \\
\hline \multicolumn{6}{|l|}{ I've been feeling confident. } \\
\hline \multicolumn{6}{|l|}{$\begin{array}{l}\text { I've been able to make up my own } \\
\text { mind about things. }\end{array}$} \\
\hline \multicolumn{6}{|l|}{ I've been feeling loved. } \\
\hline \multicolumn{6}{|l|}{ I've been interested in new things. } \\
\hline I've been feeling cheerful. & & & & & \\
\hline
\end{tabular}

Warwick-Edinburgh Mental Well-Being Scale (WEMWBS)

(C) NHS Health Scotland, University of Warwick and University of Edinburgh, 2006, all rights reserved. 


\author{
Appendix E \\ Recruitment Emails for Spring 2012 Sample
}

1. Initial email:

TEAM students,

My name is Jan Miller and I am a TEAM advisor and instructor. I am sending you this email to invite you to participate in research that is part of my dissertation and could help provide valuable feedback regarding the effectiveness of the TEAM program. Any information you provide as part of this research is private and will be part of an aggregate. Neither your identity nor identifying information will ever be revealed. You do not have to participate in this research and your participation or lack of has no effect on your standing in the TEAM program. You may withdraw your participation at any time without fear of penalty. If you choose to participate, simply click on the Survey Monkey link below and complete the surveys. This process should take 20-30 minutes total. At the end of April I will randomly select four participants to receive $\$ 25$ Visa gift cards. I appreciate your consideration of this research. If you have any questions or concerns you may contact either the primary investigator, Jeff Daniels, Ph.D.

(Jeffrey.Daniels@mail.wvu.edu) or myself (Jan-Erin.Miller@mail.wvu.edu). IRB Approval of the Research Study is on File. For your convenience and records, a copy of the consent form is attached to this email.

Survey Monkey link:

Thank you,

Jan Miller

Counseling Psychology

2. Follow up emails:

TEAM students,

I am sending this reminder out for those who have not had a chance to complete the research surveys attached to the link below. As I mentioned previously, this research that is part of my dissertation and could help provide valuable feedback regarding the effectiveness of the TEAM program. Any information you provide as part of this research is private and will be part of an aggregate. Neither your identity nor identifying information will ever be revealed. You do not have to participate in this research and your participation or lack of has no effect on your standing in the TEAM program. You may withdraw your participation at any time without fear of penalty. If you choose to participate, simply click on the Survey Monkey link below and complete the surveys. This process should take 20-30 minutes total. At the end of April I will randomly select four participants to receive $\$ 25$ Visa gift cards. I appreciate your consideration of this research. If you have any questions or concerns you may contact either the primary 
investigator, Jeff Daniels, Ph.D. (Jeffrey.Daniels@ mail.wvu.edu) or myself (JanErin.Miller@mail.wvu.edu). IRB Approval of the Research Study is on File. For your convenience and records, a copy of the consent form is attached to this email.

Survey Monkey link:

Thank you,

Jan Miller

Counseling Psychology 


\section{Appendix F}

Informed Consent Attached to Recruitment Emails

For Spring 2012 Sample

CONSENT AND INFORMATION FORM

OMR ICF

Principal Investigator: Daniels, Jeffrey Department: HUMAN RESOURCES \& EDUCATION

- Counseling, Tracking Number: Rehabilitation Counseling, \& Counseling Psychology (CRP)

H-23628

Study Title:

Institutional Integration as a Predictor for Success in At-Risk First-Year College Students

Co-Investigator(s):

,Miller, Jan-Erin,

Sponsor

Contact Persons

In the event you experience any side effects or injury related to this research, you should contact Jan Miller at 706.631.0674 or Dr. Jeffrey Daniels at 304.293.2235. (After hours contact Carruth Center for Psychological and Psychiatric Services at 304.293.4431.)

If you have any questions, concerns, or complaints about this research, you can contact Jan Miller at 706.631.0674 or Dr. Jeffrey Daniels at 304.293.2235.

For information regarding your rights as a research subject, you may contact the Office of Research Compliance at 304/293-7073.

Introduction

In addition if you would like to discuss problems, concerns, have

Tracking \#: H-23628 Page 1 of 5 Approved On: 03/02/2012 Valid Through: 03/01/2013 Last Amended: N/A

Initials Date 
In addition if you would like to discuss problems, concerns, have suggestions related to research, or would like to offer input about the research, contact the Office of Research Integrity and Compliance at 304- 293-7073.

You have been asked to participate in this research study, which has been explained to you by Jan Miller in the email where the link to this survey was found. This study is being conducted by Jan Miller, M.S., doctoral candidate and Jeffrey Daniels, Ph.D in the Department of Counseling, Rehabilitation Counseling, and Counseling Psychology at West Virginia University. This research is being conducted to fulfill the requirements for a doctoral dissertation in Counseling Psychology in the Department of Counseling, Rehabilitation Counseling, and Counseling Psychology at West Virginia University, under the supervision of Dr. Jeffrey Daniels, Ph.D.

\section{Purposes of the Study}

The purpose of this study is to learn more about the role of institutional integration in the success of first-year TEAM students at WVU. A total of approximately 300 subjects at all sites are expected to participate in this study.

\section{Description of Procedures}

This study is available through a Survey Monkey link. Your participation in this research will involve you providing an electronic signature on the consent form, completion of a demographics questionnaire, and completion of three surveys. This process will take approximately 20-30 minutes for you to complete. You will be asked to fill out a questionnaire regarding your background characteristics and you will be asked to type your name so that your Fall 2011 GPA can be connected with the information you provide in the surveys. Once your GPA has been connected with the data from the surveys, your name will be removed from all data so that your information remains unidentifiable. The remaining surveys you will be asked to complete are about your integration into WVU, your ability to choose a major or career, and about your mental well-being. As previously stated, you do not have to answer all the questions or choose to provide your name on the demographics form. You may discontinue at any time. Please keep in mind that incomplete data cannot be used so if you choose to not provide your name or any information this will withdraw you from

Tracking \#: H-23628

Tracking \#: H-23628 Page 2 of 5 Approved On: 03/02/2012 Valid Through: 03/01/2013 Last Amended: N/A

Initials Date

$\overline{\text { Tracking }} \overline{\#: ~ H-23628}$ 
the study. This action will in no way affect your status in the TEAM program. However, only fully completed surveys are eligible for the gift card drawings.

Risks and Discomforts

There are no known or expected risks from participating in this study, except for the mild frustration associated with answering the questions.

Alternatives

You do not have to participate in this study.

Benefits

You may not receive any direct benefit from this study. The knowledge gained from this study may eventually benefit others.

Financial Considerations

[Participation in this study makes you eligible to win one of four \$25 Visa gift cards. Only fully completed surveys will be eligible for this drawing. The drawing for the gift cards will be on May 1, 2012 and the winners will be notified via their MIX email account that they have won. Winners will have 14 days to respond and claim their prize. After this time a second batch of winners will be notified and given 14 days to claim their prize.]

Confidentiality

Any information about you that is obtained as a result of your participation in this research will be kept as confidential as legally possible. Your research records and test results, just like hospital records, may be subpoenaed by court order or may be inspected by federal regulatory authorities without your additional consent.

Data will be kept locked up and will be destroyed as soon as possible after the research is finished.

Tracking \#: H-23628 Approved On: 03/02/2012 Valid Through: 03/01/2013 Last Amended: N/A Page 3 of 5

Initials Date

Tracking \#: H-23628

In any publications that result from this research, neither your name nor any information from 
which you might be identified will be published without your consent.

We know that information about you and your health is private. We are dedicated to protecting the privacy of that information. Because of this promise, we must get your written authorization (permission) before we may use or disclose your protected health information or share it with others for research purposes.

If you cancel this authorization, any information that was collected already for this study cannot be withdrawn. Once information is disclosed, according to this authorization the recipient may redisclose it and then the information may no longer be protected by federal privacy regulations.

\section{Voluntary Participation}

Participation in this study is voluntary. You are free to withdraw your consent to participate in this study at any time. Refusal to participate or withdrawal will not affect your future care, [or your employee status at West Virginia University or your class standing or grades, as appropriate] and will involve no penalty to you. In the event new information becomes available that may affect your willingness to participate in this study, this information will be given to you so that you can make an informed decision about whether or not to continue your participation. You have been given the opportunity to ask questions about the research, and you have received answers concerning areas you did not understand.

Tracking \#: H-23628 Page 4 of 5 Approved On: 03/02/2012 Valid Through: 03/01/2013 Last Amended: N/A

Initials Date

\section{$\overline{\text { Tracking }} \overline{\#: \mathrm{H}-23628}$}

Upon signing this form, you will receive a copy. I willingly consent to participate in this research.

Signature of Subject or Printed Name Date Time Subjects Legal Representative

The participant has had the opportunity to have questions addressed. The participant willingly agrees to be in the study.

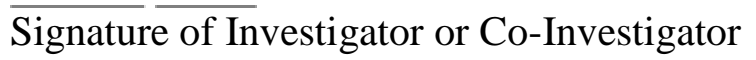

Printed Name 
Date Time

Tracking \#: Approved On: Valid Through: Last Amended:

H-23628 03/02/2012 03/01/2013 N/A

Page 5 of 5 


\author{
Appendix G \\ Recruitment Emails for Fall 2012 Sample
}

1. Initial email:

Dear Participant,

This email is to request for you to take part in a research project to assess how your participation in the 2012-2013 TEAM program has affected your success as a first-year college student at WVU. This project is being conducted by Jan Miller, M.S., doctoral candidate and Jeffrey Daniels, Ph.D. in the Department of Counseling, Rehabilitation Counseling, and Counseling at West Virginia University. This research is being conducted to fulfill the requirements for a doctoral dissertation in Counseling Psychology, under the supervision of Dr. Jeffrey Daniels. Your participation in the project is greatly appreciated and will take approximately 15-20 minutes to complete the four questionnaires in the attached email link. West Virginia University's Institutional Review Board acknowledgement of this project is on file. If you would like to discuss problems, concerns, have suggestions related to research, or would like to offer input about the research, contact the Office of Research Integrity and Compliance at 304.293.7073. Your involvement in this project will be kept as confidential as legally possible. All date will be reported in the aggregate. You must be 18 years of age or older to participate. I will ask for your first and last names in order to later gather your fall 2012 GPA, which will be part of the data. Once your fall 2012 GPA has been linked to your questionnaire data, all identifying information will be removed. Your participation is completely voluntary. You may discontinue at any time. Your TEAM standing will not be affected if you decide either not to participate or to withdraw. There are no known or expected risks from participating in this study, except for the mild frustration associated with answering the questions. In the event you experience any side effects or injury related to this research, you should contact Jan Miller at 706.631.0674 or Dr. Jeffrey Daniels at 304.293.2235. (After hours contact Carruth Center for Psychological and Psychiatric Services at 304.293.4431.) If you have any questions, concerns, or complaints about this research, you can contact Jan Miller at 706.631.0674 or Dr. Jeffrey Daniels at 304.293.2235.

\title{
The survey link is:
}

I hope that you will participate in this research project, as it could be beneficial in understanding the impact of the TEAM program on success for first-year college students. Thank you for your time. Should you have any questions about this letter or the research project, please feel free to contact Jan Miller at (706) 631.0674 or by email at janerin@gmail.com Thank you for your time and help with this project.

Sincerely, 
Jan Miller, M.S.

Doctoral Candidate in Counseling Psychology

West Virginia University

PO Box 6122, Morgantown, WV 26506-6122

Phone: (304) 293-3807 Fax: (304) 293-4082

http://counseling.wvu.edu

2. Follow up emails:

Dear Participant,

This email is a follow up request for you to take part in a research project to assess how your participation in the 2012-2013 TEAM program has affected your success as a first-year college student at WVU. If you have already completed the survey, please ignore this email. This project is being conducted by Jan Miller, M.S., doctoral candidate and Jeffrey Daniels, Ph.D. in the Department of Counseling, Rehabilitation Counseling, and Counseling at West Virginia University. This research is being conducted to fulfill the requirements for a doctoral dissertation in Counseling Psychology, under the supervision of Dr. Jeffrey Daniels. Your participation in the project is greatly appreciated and will take approximately 15-20 minutes to complete the four questionnaires in the attached email link. West Virginia University's Institutional Review Board acknowledgement of this project is on file. If you would like to discuss problems, concerns, have suggestions related to research, or would like to offer input about the research, contact the Office of Research Integrity and Compliance at 304.293.7073. Your involvement in this project will be kept as confidential as legally possible. All date will be reported in the aggregate. You must be 18 years of age or older to participate. I will ask for your first and last names in order to later gather your fall 2012 GPA, which will be part of the data. Once your fall 2012 GPA has been linked to your questionnaire data, all identifying information will be removed. Your participation is completely voluntary. You may discontinue at any time. Your TEAM standing will not be affected if you decide either not to participate or to withdraw. There are no known or expected risks from participating in this study, except for the mild frustration associated with answering the questions. In the event you experience any side effects or injury related to this research, you should contact Jan Miller at 706.631.0674 or Dr. Jeffrey Daniels at 304.293.2235. (After hours contact Carruth Center for Psychological and Psychiatric Services at 304.293.4431.) If you have any questions, concerns, or complaints about this research, you can contact Jan Miller at 706.631.0674 or Dr. Jeffrey Daniels at 304.293.2235.

\section{The survey link is:}

I hope that you will participate in this research project, as it could be beneficial in understanding the impact of the TEAM program on success for first-year college students. Thank you for your time. Should you have any questions about this letter or the research project, please feel free to contact Jan Miller at (706) 631.0674 or by email at janerin@gmail.com Thank you for your time and help with this project. 
Sincerely,

Jan Miller, M.S.

Doctoral Candidate in Counseling Psychology

West Virginia University

PO Box 6122, Morgantown, WV 26506-6122

Phone: (304) 293-3807 Fax: (304) 293-4082

http://counseling.wvu.edu 